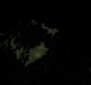




$61.0 \mathrm{ct}$

$13 / 5$ 


THE

\section{TOWER MENAGERIE.}



THE

\section{TOWER MENAGERIE:}

COMPRISING

THE NATURAL HISTORY

OF THE

ANIMALS CONTAINED IN THAT ESTABLISHMENT;

WITH

Anecidotes of their Characters and I

ILLUSTRATED BY

PORTRAITS OF EACH, TAKEN FROM LIFE, BY WILLIAM HARVEY;

AND ENGRAVED ON WOOD BY BRANSTON AND WRIGHT.

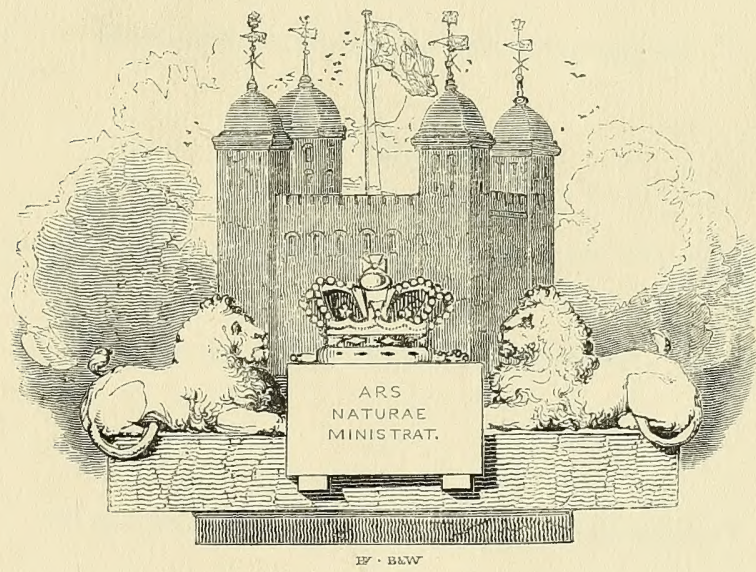

LONDON :

PRINTED FOR ROBERT JENNINGS, POULTRY;

AND SOLD BY W. F. WAKEMAN, DUBLIN.

M DCCCXXIX. 




\section{CONTENTS.}

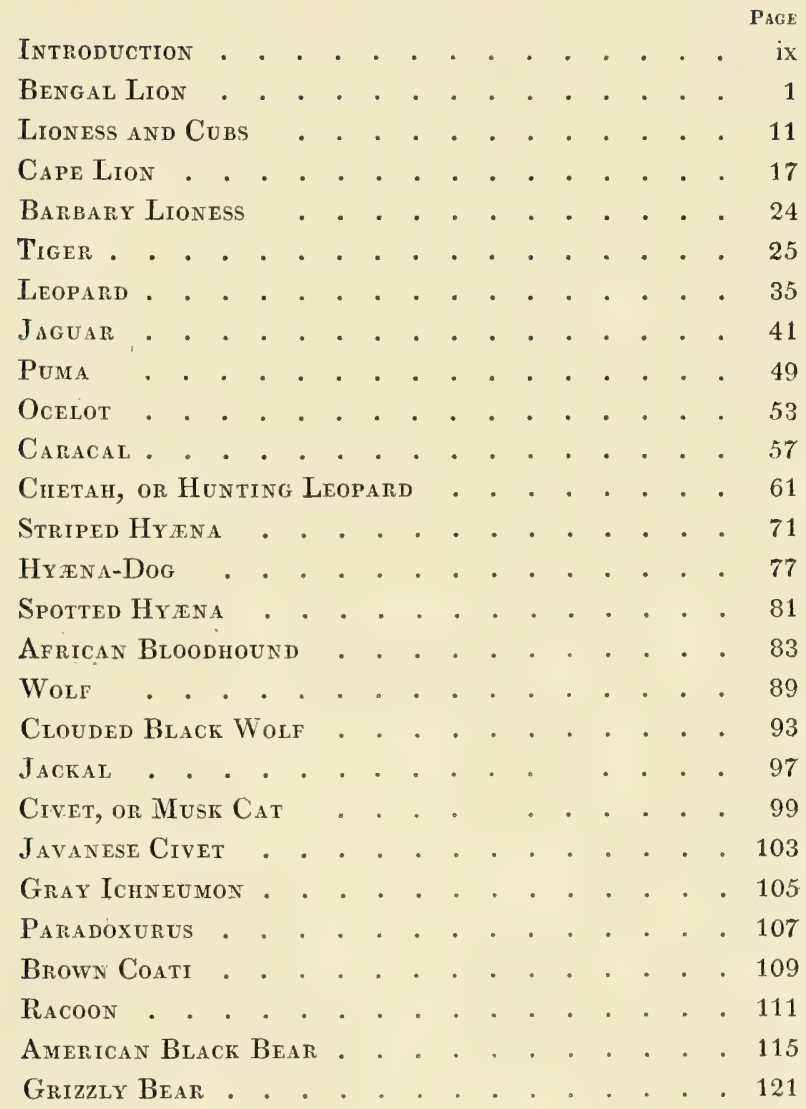


viii

CONTENTS.

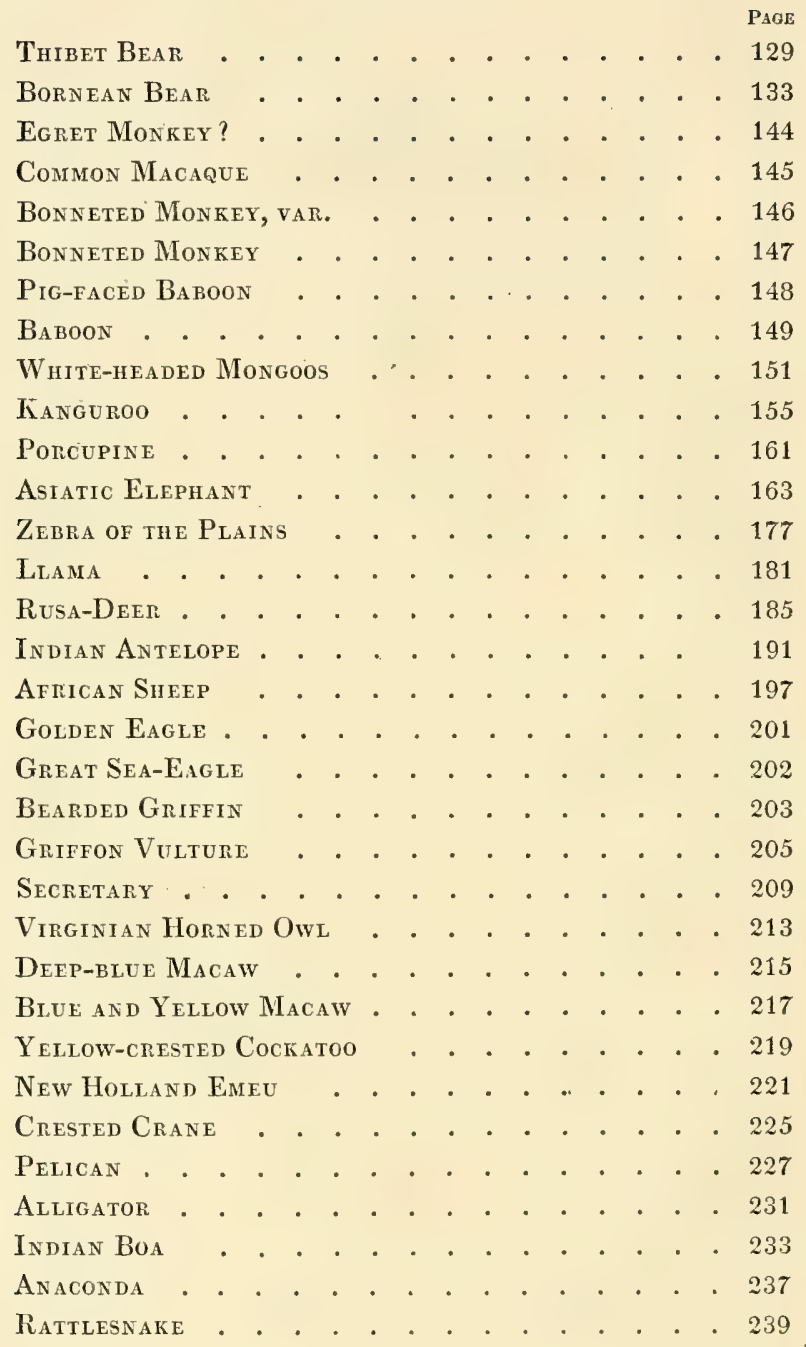




\section{INTRODUCTION.}

THE origin of Menageries dates from the most remote antiquity. Their existence may be traced even in the obscure traditions of the fabulous ages, when the contests of the barbarian leader with his fellow-men were relieved by exploits in the chase scarcely less adventurous, and when the monster-queller was held in equal estimation with the warrior-chief. The spoils of the chase were treasured up in common with the trophies of the fight; and the captive brute occupied his station by the side of the vanquished hero. It was soon discovered that the den and the dungeon were not the only places in which this link of connexion might be advantageously preserved, and the strength and ferocity of the forest beast were found to be available as useful auxiliaries even in the battle-field. The only difficulty to be surmounted in the application of this new species of brute force to the rude conflicts of the times consisted in giving to it the wished-for direction; and for this purpose it was necessary that the animals to be so employed should be confined in what may be considered as a kind of Menagerie, there to be rendered subservient to the control, and obedient to the commands, of their masters.

In the theology too of these dark ages many animals occupied a distinguished place, and were not only venerated in their own proper persons, on account of their size, their power, their uncouth figure, their resemblance 
to man, or their supposed qualities and influence, but were also looked upon as sacred to one or other of the interminable catalogue of divinities, to whose service they were devoted, and on whose altars they were sacrificed. For these also Menageries must have been constructed, in which not only their physical peculiarities but even their moral qualities must have been to a certain extent studied; although the passions and prejudices of the multitude would naturally corrupt the sources of information thus opened to them, by the intermixture of exaggerated perversions of ill observed facts and by the addition of altogether imaginary fables.

If to these two kinds of Menageries we add that which has every where and under all circumstances accompanied the first dawn of civilization, and which constitutes the distinguishing characteristic of man emerging from a state of barbarism and entering upon a new and social state of existence, the possession of flocks and herds, of animals useful in his domestic economy, serviceable in the chase, and capable of sharing in his daily toils, a tolerable idea may be formed of the collections which were brought together in the earliest ages, and were more or less the subjects of study to a race of men who were careless of every thing that had no immediate bearing upon their feelings, their passions, or their interests.

But as civilization advanced, and the progress of society favoured the developement of mind, when those who were no longer compelled by necessity to labour for their daily bread found leisure to look abroad with expanded views upon the wonders of the creation, the animal kingdom presented new attractions and awakened ideas which had before lain dormant. What was at first 
a mere sentiment of curiosity became speedily a love of science; known objects were examined with more minute attention; and whatever was rare or novel was no longer regarded with a stupid stare of astonishment and an exaggerated expression of wonder, but became the object of careful investigation and philosophic meditation. Such was the state of things in civilized Greece when the Macedonian conqueror carried his victorious arms to the banks of the Indus, and penetrated into countries, not altogether unknown to Europeans, but the natural productions of which were almost entirely new to the philosophers of the West. With the true spirit of a man of genius, whose sagacity nothing could escape, and whose views of policy were as profound as the success of his arms was splendid, Alexander omitted no opportunity of proving his devotion to the cause of science; and the extensive collections of rare and unknown animals which he transmitted to his old tutor and friend, in other words the Menagerie which he formed, laid the foundation of the greatest, the most extensive, and the most original work on zoology that has ever been given to the world. The first of moral philosophers did not disdain to become the historian of the brute creation, and Aristotle's History of Animals remains a splendid and imperishable record of his qualifications for the task.

Very different were the feelings by which the Roman generals and people. were swayed even in their most civilized times and at the height of their unequalled power. Through all the gloss which history has thrown over the character of these masters of the universe there appears a spirit of unreclaimed barbarity which was never entirely shaken off. From the scenes of their distant conquests their prætors sent to the metropolis 
of the world bears and lions and leopards and tigers; but a love of science had no share in the motives for the gratification of which they were transmitted, and the chief curiosity manifested on such occasions by the people of Rome was to ascertain how speedily hundreds or thousands, as the case might happen, of these ferocious beasts would destroy each other when turned out halffamished into the public amphitheatre, or how long a band of African slaves, of condemned criminals, or of hired gladiators, would be able to maintain the unequal contest against them. The consul or emperor who exhibited at one time the greatest number of animals to be thus tortured before the eyes of equally brutal spectators was held in the highest esteem among a people who regarded themselves as civilized, and whose chief delight was in witnessing these wanton effusions of blood. It was only under the later Cæsars that a few private individuals brought together in their vivaria a considerable number of rare and curious animals; and the Natural History of Pliny derives most of its zoological value from the opportunities which he had of consulting these collections. But the monstrous fables and the innumerable errors, which the most superficial examination would have taught him to correct, with which every page of this vast compilation absolutely teems, speak volumes with regard to the wretched state of natural science in the most splendid days of Roman greatness.

From the unsuspecting credulity with which this textbook of the naturalists of the middle ages continued to be received, it is evident that the science remained stationary, if it did not actually retrograde, during the lapse of fourteen or fifteen centuries. The want of 
opportunities of investigation may be regarded as the principal cause of this lamentable deficiency. Some of the rarer animals, it is true, were occasionally to be seen in Europe; but Menageries constructed upon a broad and comprehensive plan were as yet unknown. The first establishment of modern days, in which such a plan can fairly be said to have been realised, was the Menagerie founded at Versailles by Louis the Fourteenth. It is to this institution that we owe the Natural History of Buffon and his coadjutor Daubenton; the one as eloquent as Pliny, with little of his credulity, but with a greater share of imagination; and the other a worthy follower of Aristotle in his habits of minute research and patient investigation, but making no pretensions to the powerful and comprehensive mind and the admirable facility of generalising his ideas which so preeminently distinguished that great philosopher.

Of the characters of most of the institutions which we have noticed the Tower Menagerie has at various times partaken in a greater or less degree. Originally intended merely for the safe-keeping of those ferocious beasts, which were until within the last century considered as appertaining exclusively to the royal prerogative, it has occasionally been converted into a theatre for their contests, and has terminated by adapting itself to the present condition of society as a source of rational amusement and a school of zoological science.

The first notice of a Royal Menagerie in England places this establishment at Woodstock, where King Henry the First had a collection of lions, leopards, and other strange beasts. Three leopards were presented to Henry the Third by the Emperor Frederic the Second, himself a zoologist of no mean rank. From Woodstock 
they were transferred to the Tower; and numerous orders issued in this and the succeeding reigns to the sheriffs of London and of the counties of Bedford and Buckingham to provide for the maintenance of the animals and their keepers are' extant among the Records. Thus in the year 1252 the sheriffs of London were commanded to pay four pence a day for the maintenance of a white bear; and in the following year to provide a muzzle and chain to hold the said bear while fishing, or washing himself, in the river Thames. In 1255 they were directed to build a house in the Tower for an elephant which had been presented to the king by Louis king of France; and a second writ occurs in which they were ordered to provide necessaries for him and his keepers.

From various orders during the reigns of Edward the First, Second, and Third, we learn that the allowance for each lion or leopard was six pence a day, and the wages of their keeper three halfpence. At later periods the office of keeper of the lions was held by some person of quality about the king, with a fee of six pence a day for himself, and the same for every lion or leopard under his charge. On these terms it was granted by King Henry the Sixth, first to Robert Mansfield, Esq. marshal of his hall, and afterwards to Thomas Rookes, his dapifer. It was not unfrequently held by the lieutenant or constable of the Tower himself, on the condition of his providing a sufficient deputy. There was also another office in the royal household somewhat resembling this in name, that of master, guider, and ruler of the king's bears and apes; but the latter animals appear to have been kept solely for the royal " game and pleasure."

During all this period, and even almost down to our 
own times, the common phrase of "seeing the lions" in the Tower appears to have been almost literally correct, for we seldom hear of any other animals confined there than lions or leopards. Howel tells us in his Londinopolis, published in 1657, that there were then six lions in the Tower, and makes no allusion to any other animals as being at that time contained in it. In 1708 some improvement had taken place; for there were then, according to Strype, no fewer than eleven lions, two leopards or tigers (the worthy historian, it seems, knew not which), three eagles, two owls, two cats of the mountain, and a jackal. Maitland gives a much longer catalogue as existing there in 1754; and this is still further extended in a little pamphlet entitled "An Historical Description of the Tower of London and its Curiosities," published in 1774. After this time, however, the collection had been so greatly diminished both in value and extent, that in the year 1822 , when $\mathrm{Mr}$. Alfred Cops, the present keeper, succeeded to the office, the whole stock of the Menagerie consisted of the grizzly bear, an elephant, and one or two birds. How rapidly and how extensively the collection has increased under his superintendence will best be seen by a reference to the numerous and interesting animals whose natural history forms the subject of the present work. By his spirited and judicious exertions the empty dens have been filled, and new ones have been constructed; and the whole of them being now kept constantly tenanted, the Menagerie affords a really interesting and attractive spectacle to the numerous visiters who are drawn thither either from motives of curiosity or by a love of science.

Such is a brief outline of the history up to the present period of the establishment known as the Tower Mena- 
gerie. Of the animals contained in it during the summer of 1828, and of two others which had then recently died, the succeeding pages offer delineations, descriptions, and anecdotes. Among so numerous a collection of inhabitants, of such dissimilar habits, and brought together into one spot from such distant and various climes, some changes have almost necessarily taken place even while our work has been passing through the press; yet so excellent is the management of Mr. Cops, especially as regards cleanliness, that essential security of animal health, that not a single death has occurred from disease, and one only from an accidental cause: the secretary bird, having incautiously introduced its long neck into the den of the hyæna, was deprived of it and of its head at one bite. Other removals are owing to the spirit of commerce. The Cape lion, the chetahs, the Thibet bear, and the deep-blue macaw, have passed into foreign hands, and are now on the continent of Europe. Two of the wolves and one of the Javanese civets have been transferred to the Zoological Society; and the white antelope has also exchanged its habitation in the Tower for the delightful Garden created by that Society in the Regent's Park.

With the exceptions which have just been enumerated the whole of the animals which are here figured and described are actually living in the Tower Menagerie. Their continuance there affords a test of the fidelity of our work which could not be applied to any production on zoology that has yet appeared in this country, nor, to an equal extent, in any other. As a visit to the Menagerie will enable the reader at once to compare our representations and descriptions with their living prototypes, the imperative necessity of scrupulous accu- 
racy has been deeply impressed throughout the whole undertaking on the minds of those who have been engaged in its completion. In this, it is trusted, they have fully succeeded. To explain the share which each has taken in the work, and to record a debt of gratitude to those kind friends who have assisted in it, is the pleasing duty which it now remains to fulfil.

The whole of the drawings are from the pencil of Mr. William Harvey, who, in seizing faithful and characteristic portraits of animals in restless and almost incessant motion, has succeeded in overcoming difficulties which can only be appreciated by those who have attempted similar delineations. In the portraits he has strictly confined himself to the chastity of truth; but in the vignettes, which have always some reference to the subject of the article which they conclude, he has occasionally held himself at liberty to give full scope to his imagination.

The engravings have been executed throughout by Messrs. Branston and Wright. Determined on securing the accuracy of the representations, they have in every instance compared the proofs with the animals, and have made corrections where necessary until the resemblance has been rendered perfect. In one case alone has a deviation from the original been indulged in: the tail of the ocelot has been figured of the length usual in the species, instead of the truncated state in which it exists in the specimen; the markings of the animal are, however, as noticed in its article, accurately represented.

The literary department has been superintended by E. T. Bennetr, Esq. F.L.S., an active member of the Zoological Society, who has arranged for the press the 
whole of the materials collected from various and authentic sources. To John Bayley, Esq. F.R. and A.S. M.R.I.A. \&c. he is indebted for several suggestions in addition to the information contained in that gentleman's valuable work, "The History and Antiquities of the Tower of London." To.Mr. Alfred Cops, the present Keeper of the Lions, whose meritorious exertions for the increase and improvement of the Menagerie have been already adverted to, he has also to tender. his thanks and those of his coadjutors for the facilities constantly afforded to them in the most ready and obliging manner, and for much valuable information relative to the history and habits of the animals.

But especially are his best thanks due for numerous suggestions and much valuable assistance to his friend N. A. Vigors, Esq. A.M. F.R. and L.S., the zealous and talented Secretary of the Zoological Society. To that distinguished zoologist, whose extensive and intimate acquaintance with the animal kingdom at large, and particularly with its feathered tribes, is universally acknowledged, and to other leading Members of the Society to which he devotes his talents and his time, a work like the present appeared not ill adapted to advance the good cause in which they are engaged, the diffusion of knowledge. Under their auspices it was commenced, by their countenance it has been fostered, and it is with the sanction of their approval that it is now submitted to the public eye. 


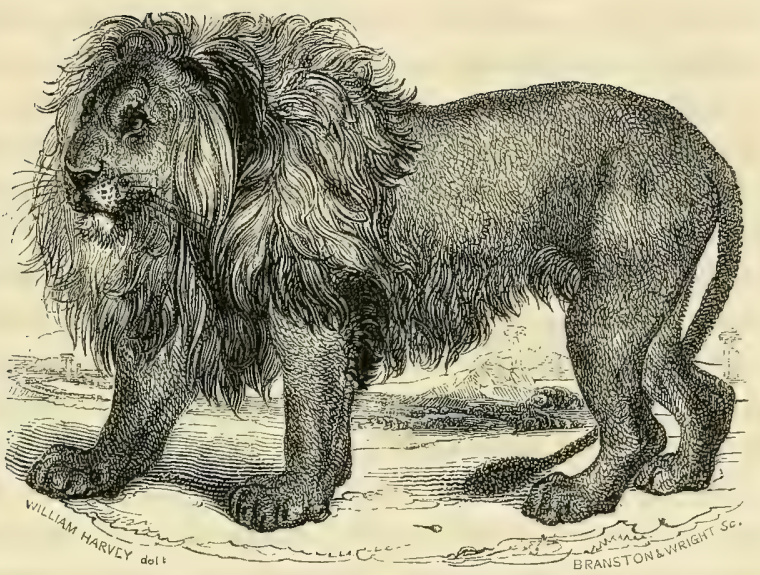

THE BENGAL LION.

Felis Leo. Linn.—Var. Bengalensis.

First in majesty as in might, the monarch of the brute creation asserts an undisputed claim to occupy the foremost place in our delineation of the inhabitants of this Royal Menagerie. Who is there to whom his stately mien, his unequalled strength, his tremendous powers of destruction, combined with the ideas generally entertained of his dauntless courage, his grateful affection, and his merciful forbearance, are not familiar " as household words?"' When we speak of a Lion, we call up to our imaginations the splendid picture of might unmingled with ferocity, of courage undebased by guile, of dignity tempered with grace and ennobled by generosity; 
in a word, of all that combination of brilliant qualities, the imputation of which, by writers of all ages, has placed him by universal consent above other beasts, and invested him with regal attributes.

Such, indeed, is the outline which we have been taught to frame to ourselves of this noble animal ; and beautifully has this imaginary sketch, for such in a great measure it will be found on closer examination, been filled up by the magic pencil of Buffon, who, in this, as in too many other instances, suffered himself to be borne along by the strong tide of popular opinion. Yielding to the current, instead of boldly stemming it, he has added the weighty sanction of his authority to those erroneous notions which were already consecrated by their antiquity, and has produced a history of the Lion, which, however true in its main facts, and however eloquent in its details, is, to say the least, highly exaggerated and delusive in its colouring. The Lion of Buffon is, in fact, the Lion of popular prejudice; it is not the Lion, such as he appears to the calm observer, nor such as he is delineated in the authentic accounts of those naturalists and travellers who have had the best means of observing his habits, and recording the facts of which they have been themselves eye witnesses.

The Lion, like all the other cats (the genus to which, in a natural arrangement, he obviously belongs) is armed in each jaw with six strong and exceedingly sharp cutting-teeth, with two formidable canine, and with six others, three on each side, occupying the places of the molar or grinding-teeth, but terminating in sharp protuberances to assist in the laceration of the animal food, which is the proper nutriment of his tribe. Besides 
these, he has, on each side of the upper jaw, a small tooth, or rather tubercle, placed immediately behind the rest. His tongue is covered with innumerable rough and elevated papillæ, the points of which are directed backwards: these also assist in comminuting his food, and not unfrequently leave their traces on the hand which has been offered him to lick. His claws, five in number on the fore feet, and four on the hind, are of great length, extremely hard, and much curved; they are retractile within a sheath enclosed in the skin which covers the extremity of his paws; and as they are only exposed when he has occasion to make use of them, they thus preserve the sharpness of their edge and the acuteness of their point unimpaired. In all these particulars the Lion essentially agrees with the rest of the cats; and it is these which constitute what naturalists have termed their generic character; in other words, they are the points of agreement which are common to the whole group or genus, and form the most prominent and striking characteristics, by which they may be at once connected together and separated from all other animals.

The Lion is distinguished from other cats by the uniformity of his colour, which is pale tawny above, becoming somewhat lighter beneath, and never, except in his young state, exhibiting the least appearance of spots or stripes: by the long and flowing mane of the adult male, which, originating nearly as far forward as the root of his nose, extends backwards over his shoulders, and descends in graceful undulations on each side of his neck and face; and by the tuft of long and blackish hairs which terminates his powerful tail. These constitute what is termed his specific character, or that which 
is peculiar to the species or race; connecting the individuals together by marks common to them all, and at the same time separating them from the other animals of the same group or genus.

In his moral and intellectual faculties, as well as in his external and physical characters, the Lion exhibits a close agreement with the strikingly distinct and well marked group to which he belongs, and of which he is unquestionably the first in rank and importance: and perhaps the most effectual means of guarding against the general prejudice, which has delighted in exalting him at the expense of his fellow beasts, will be found in the recollection that, both physically and morally, he is neither more nor less than a cat, of immense size and corresponding power it is true, but not on that account the less endowed with all the guileful and vindictive passions of that faithless tribe. His courage is proverbial : this, however, is not derived from any peculiar nobility of soul, but arises from the blind confidence inspired by a consciousness of his own superior powers, with which he is well aware that none of the inferior animals can successfully compete. Placed in the midst of arid deserts, where the fleet but timid antelope, and the cunning but powerless monkey fall his easy and unresisting prey; or roaming through the dense forests and scarcely penetrable jungles, where the elephant and the buffalo find in their unwieldy bulk and massive strength no adequate protection against the impetuous agility and fierce determination of his attacks, he sways an almost undisputed sceptre, and stalks boldly forth in fearless majesty. But change the scene, and view him in the neighbourhood of populous towns, or even 
near the habitations of uncultivated savages, and it will then be seen that he recognises his master, and crouches to the power of a superior being. Here he no longer shows himself openly in the proud consciousness of his native dignity, but skulks in the deepest recesses of the forest, cautiously watches his opportunities, and lies in treacherous ambush for the approach of his unwary prey. It is this innate feeling of his incapacity openly to resist the power of man, that renders him so docile in captivity, and gives him that air of mild tranquillity, which, together with the dignified majesty of his deportment, has unquestionably contributed not a little towards the general impression of his amiable qualities.

His forbearance and generosity, if the facts be carefully investigated, will be found to resolve themselves into no more than this: that in his wild state he destroys only to satiate his hunger or revenge, and never, like the " gaunt wolves," and " sullen tigers," of whom the poet has composed his train, in the wantonness of his power and the malignity of his disposition; and that, when tamed, his hunger being satisfied and his feelings being free from irritation, he suffers smaller animals to remain in his den uninjured, is familiar with, and sometimes fond of, the keeper by whom he is attended and fed, and will even, when under complete control, submit to the caresses of strangers.

But even this limited degree of amiability, which, in an animal of less formidable powers, would be considered as indicating no peculiar mildness of temper, is modified by the calls of hunger, by the feelings of revenge, which he frequently cherishes for a considerable length of time, and by various other circumstances which render it dan- 
gerous to approach him unguardedly, even in his tamest and most domesticated state, without previously ascertaining his immediate state of mind. On such occasions no keeper possessed of common prudence would be rash enough to venture upon confronting him: he knows too well that it is no boy's play to

And fright him there, and make him tremble there;

for in this state of irritation, from whatever cause it may have arisen, he gives free scope to his natural ferocity, unrestrained by that control to which at other times he submits with meek and unresisting patience.

Happily for mankind the range of this tremendous animal is limited to the warmer climates of the earth; and even in these the extent of that range is constantly becoming more and more confined by the spread of human civilization, which, at the same time that it drives him to take refuge at a distance from the haunts of men, contributes greatly to thin his numbers and to diminish his power of annoyance. His true country is Africa, in the vast and untrodden wilds of which, from the immense deserts of the north to the trackless forests of the south, he reigns supreme and uncontrolled. In the sandy deserts of Arabia, in some of the wilder districts of Persia, and in the vast jungles of Hindostan, he still maintains a precarious footing: but from the classic soil of Greece, as well as from the whole of Asia Minor, both of which were once exposed to his ravages, he has been utterly dislodged and extirpated.

There is some variation in the different races of Lions from these distant localities; but this is by no means of 
sufficient importance to establish a distinction between them. The Asiatic Lion, of which we are now treating, seldom attains a size equal to that of the full-grown Southern African; its colour is a more uniform and paler yellow throughout; and its mane is, in general, fuller and more complete, being furnished moreover with a peculiar appendage in the long hairs, which, commencing beneath the neck, occupy the whole of the middle line of the body below. All these distinctions are, however, modified by age, and vary in different individuals. Their habits are in essential particulars the same: we shall therefore defer what we have farther to say on this head until we come to speak of the Cape Lion, and proceed to the history of the Asiatic individual now exhibiting in this Menagerie, a striking likeness of which is given in the engraving at the head of the present article.

This fine animal, although called by the keepers " the Old Lion," is, in reality, little more than five years old; and that designation was adopted only for the purpose of distinguishing him from the Cape Lion, a comparatively modern resident of the Menagerie. His proper name, or rather that by which he has been known ever since his arrival at the Tower, is George. The following anecdotes relative to the mode of his capture, and to his habits and demeanour in his captivity, are given on the authority of Mr. Cops, who derived his information on the first point from General Watson himself, and speaks to the rest from his personal observation.

It was in the commencement of the year 1823, when the General was on service in Bengal, that being out one morning on horseback, armed with a double-barrelled 
rifle, he was suddenly surprised by a large male Lion; which bounded out upon him from the thick jungle at the distance of only a few yards. He instantly fired, and, the shot taking complete effect, the animal fell dead almost at his feet. No sooner was this formidable foe thus disposed of than a second, equally terrible, made her appearance in the person of the Lioness, whom the General also shot at and wounded so dangerously that she retreated into the thicket. As her following so immediately in the footsteps of her mate afforded strong grounds for suspecting that their den could not be far distant, he determined upon pursuing the adventure to the end, and traced her to her retreat, where he completed the work of her destruction, by again discharging the contents of one of the barrels of his rifle; which he had reloaded for the purpose. In the den were found a beautiful pair of cubs, male and female, supposed to be then not more than three days old. These the General brought away with him, and succeeded by the assistance of a goat, who was prevailed upon to act in the capacity of foster-mother to the royal pair, in rearing them until they attained sufficient age and strength to enable them to bear the voyage to England. On their arrival in this country, in September, 1823, he presented them to his Majesty, who commanded them to be placed in the Tower. The male of this pair is the subject of the present, the female that of the succeeding article.

The extreme youth of these Lions at the time of their capture, and the constant control to which they had been accustomed from that early period of their existence, rendered them peculiarly tame and docile, insomuch that, for twelve months after their arrival, they were fre- 
quently suffered to walk in the open yard among the visitors, who caressed them and played with them with impunity. The Duke of Sussex, in particular, was highly delighted with the unusual spectacle of a Lion and a Lioness bounding about him at perfect liberty, and with all their natural grace and agility. It must, however, be observed that they were not then fully grown, and that it was afterwards thought necessary to place them under greater restraint; but more with the view of guarding against possible mischief, than in consequence of any positive symptoms of rebellion. Of the change which has taken place in the character of the female, we shall have occasion to speak hereafter : the male still continues perfectly docile, and suffers himself to be treated with the greatest familiarity by his keepers and those to whom he is accustomed.

Like all the other carnivorous animals in the Menagerie, he is fed but once in the twenty-four hours; and his meal usually consists of a piece of beef, of eight or nine pounds weight, exclusive of bone. This he seizes with avidity, tears it to pieces instantly with his claws, and ravenously devours it; contrary to the usual custom of his fellow lions in a state of nature, who are said generally to remain for a considerable time after they have struck the fatal blow, before proceeding to glut their appetite with the flesh and blood of their victim. This awful pause of suspense may, however, under such circumstances, be attributable to an instinctive desire completely to finish their work, or at least to preclude the possibility of resistance, prior to removing from the body of their prostrate prey the weapon with which his destruction has been inflicted. 
It has been generally remarked, that lions in captivity have certain constant and stated times for roaring: this observation is not, however, strictly true with regard to those now in the Tower. It may nevertheless be observed that in the summer time, especially when the atmospheric temperature is considerable, they uniformly commence roaring about dawn, one of them taking the lead, and the others joining in the concert in succession; and Mr. Cops has frequently had occasion to remark that whenever any one of them fails in accompanying the rest in their by no means harmonious performance, the cessation from the customary roar is an infullible symptom of actual or approaching illness. At no other time is there that regularity in their roaring which has been so frequently stated; although the chorus which has just been described is sometimes repeated after feeding, and also when they have been left alone for any length of time; hence it occurs particularly on Sundays, a day on which they have no company except from the occasional visits of the keepers.

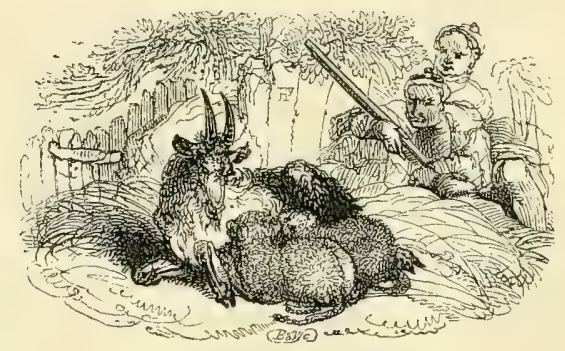




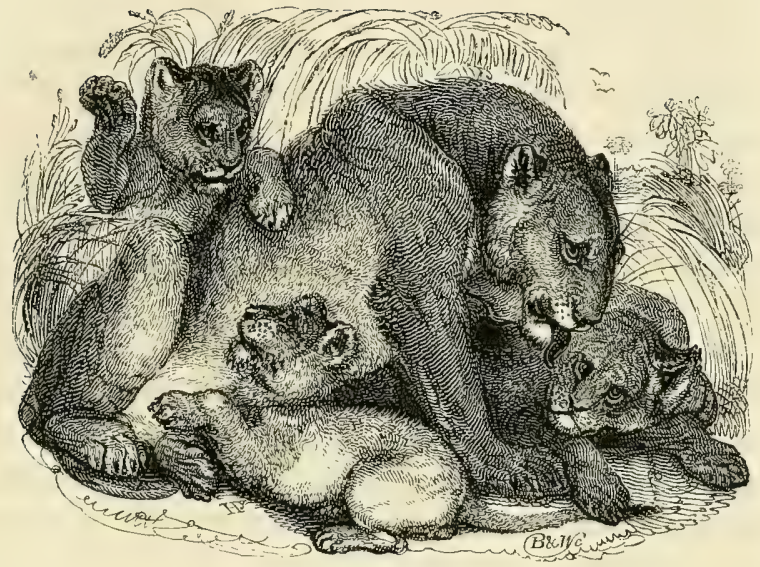

THE LIONESS AND HER CUBS.

Strikingly distinguished at the first glance from her royal mate by the absence of the flowing honours of the mane, which invest him with an air of superior dignity and gravity, the Lioness is also remarkable for her smaller size, her more slender and delicate make, and the superior grace and agility of her movements. Her inferiority in muscular strength to the Lion, and to him alone, is, however, fully compensated by the greater liveliness of her disposition, the unrestrained ardour of her passions, and the vigorous impetuosity of her motions, which all contribute to render her an equally formidable opponent with her more powerful, but less irritable, lord. They differ also in another obvious cha- 
racteristic, the habitual position and direction of their heads, that of the Lion being almost uniformly elevated and thrown upwards with an air of mingled frankness and hauteur, agreeing well with the popular notions of his tranquil dignity of temper and deportment; while the Lioness as constantly carries her head on a level with the line of her back, thus giving to her otherwise expressive countenance a sullen and downcast look, and evincing a nearer approach to the inferior races of the feline tribe. This singular distinction appears to be in a great measure dependent on the absence of the mane; for it is observed that the young male cubs, until the period at which this badge of dignity begins to make its appearance, that is to say until they are about twelve months old, carry their heads in the same level position with the female.

It cannot be doubted that the lighter and slenderer shape of the Lioness, and her consequently greater activity, tend in an especial manner to the formation of that more lively and sensitive character by which all her actions are so strongly marked: but there is another cause, no less powerful than these, which operates with peculiar force, in the vivid excitability of her maternal feelings, which she cherishes with an ardour almost unparalleled in the history of any other animal. From the moment that she becomes a mother, the native ferocity of her disposition is renovated as it were with 'tenfold vigour; she watches over her young with that undefined dread of danger to their weak and defenceless state, and that suspicious eagerness of alarm, which keep her in a constant state of feverish excitation: and woe be to the wretched intruder, whether man or beast, who 
should unwarily at such a time approach the precincts of her sanctuary. Even in a state of captivity, and however completely she may have been previously subjected to the control of her keeper, she loses all respect for his commands, and abandons herself occasionally to the most violent paroxysms of rage.

Of this the individual Lioness now in the Tower affords a striking example. We have already observed in our account of the Lion that, for a considerable time after her arrival in England, she was so tame as to be allowed frequently to roam at large about the open yard; and even long after it had been judged expedient that this degree of liberty should no longer be granted, her disposition was far from exciting any particular fear in the minds of her keepers. As an instance of this, we may mention that when, on one occasion about a year and a half ago, she had been suffered through inadvertence to leave her den, and when she was by no means in good temper, George Willoughway, the under keeper, had the boldness, alone and armed only with a stick, to venture upon the task of driving her back into her place of confinement; which he finally accomplished, not however without strong symptoms of resistance on her part, as she actually made three springs upon him, all of which he was fortunate enough to avoid.

But from the period when she gave birth to her Cubs a total alteration has taken place in her temper and demeanour. She no longer suffers the least familiarity even on the part of her keepers, but gives full scope to the violence of her passions. Intent solely on providing for the security of her young, she imagines that the object of every person who approaches her den is to rob 
her of her treasures, over which she watches with almost sleepless anxiety, exhibiting the truly beautiful but appalling picture of maternal tenderness combined with savage ferocity, each in their utmost intensity of force and colouring.

The Cubs, which are three in number, two male and one female, were whelped on the 20th of October, 1827, the day of the battle of Navarino; and it is remarked by $\mathrm{Mr}$. Cops, as a curious coincidence, that they are the only Lions which have been whelped in the Tower since the year 1794, rendered memorable by the great naval victory gained by Lord Howe over the French fleet: They are universally considered to be the finest ever bred in England, and are now in a most thriving condition. They have not, however, yet reached the period when the shedding of the milk-teeth takes place, a process which is perhaps more perilous to the brute creation than that of dentition to the offspring of the human race, and appears indeed to be attended with greater risks in proportion to the carnivorous propensities of the respective species. To the Lion it has always proved, at least in his state of captivity, a period of the greatest danger, very few individuals of the numerous whelps which have been produced either here or on the continent surviving its effects. Still there is good reason to hope, from the peculiarly healthy appearance of the present litter, that, by means of skilful management, the danger may be averted, and that a pair at least of these noble animals, " born and bred in England," may in a few years rival their parents in size, in beauty, and in majesty.

The mother and her whelps are admirably represented in the spirited group of portraits which heads the present article. The latter have all the playfulness of kittens, 
and are fondled by their dam in a similar manner to that in which the domestic cat caresses her young. While they were small enough she carried them from place to place in her mouth, and showed the greatest solicitude to keep them from the view of strangers; and even now that they are grown too large for this mode of treatment, she continues to pay the strictest attention to the cleanliness of their persons, and licks their fur, as they tumble about her, with all the matronly dignity and gravity of an accomplished nurse.

The Cubs have hitherto exhibited very faint traces of the striped livery which is generally characteristic of the Lion's whelp; but it is highly probable that when they lose their winter coat, this marking may become more obvious, although, on account of their advancing age, it will never show itself with that distinctness which has been observed in other instances. It consists of a blackish band, extending along the centre of the back, from the head almost to the extremity of the tail, and branching off into numerous other bands of the same colour, which are parallel to each other, and pass across the upper parts of the sides and tail. The very young lion consequently bears no small resemblance to the tiger; a circumstance which it is interesting to remark as one which furnishes additional evidence of the close affinity of these formidable animals. The colouring of its bands is, however, much less intense; and in addition to these it possesses on the head and on the limbs numerous irregular spots of a darker hue than the rest of the fur, which are never found in the neighbouring species. On the limbs of the present Cubs these spots and blotches are distinctly visible amidst the rough and half shaggy coat which covers them, and which is not exchanged for 
the smooth and sleek fur, with which they are subsequently invested, until they approach their full growth. As they advance towards the adult age, which takes place in the fifth or sixth year, the livery gradually disappears, and is then usually entirely lost. The Lioness herself, however, still retains some trifling vestiges of it. The Cubs are, as usual, destitute of the longer hairs which form the tuft at the extremity of the tail of the adult, which in them tapers to a black tip. Their voice is at present perfectly similar to the mewing of a cat; and it is not until they reach the age of eighteen months that it changes into that peculiar roar which afterwards becomes so tremendous. At that age the mane has already attained considerable developement. This appendage begins to make its appearance in the males when they are ten or twelve months old, having at first the shape of a slight frill or ruff, but gradually becoming more and more extensive, and at length assuming that striking form which gives to the full grown animal a graceful and dignified, and to the more aged a reverend and majestic, air.

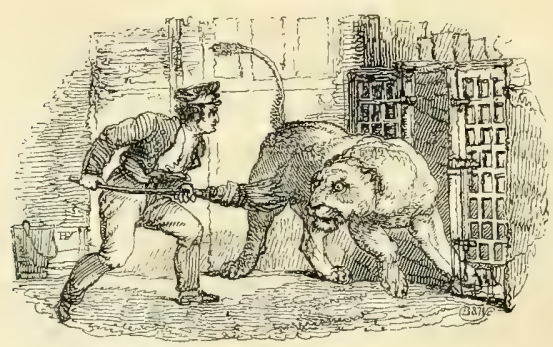




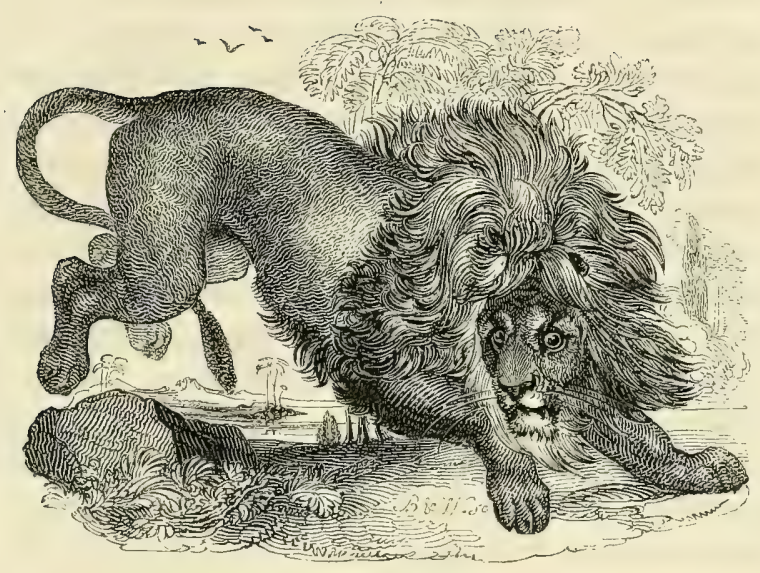

THE CAPE LION.

FELIS LEO._Var. CaPensis.

Africa, as we have already observed, is truly the native country of the Lion; and in no part of that vast continent, we may add; does he attain greater size, or exhibit all his characteristic features in fuller and more complete developement, than in the immediate vicinity of the settlements which have been formed in the interior of its southern extremity by the Dutch and English colonists of the Cape. In speaking of the Bengal Lion, we have also pointed out the more striking characteristics by which the Asiatic race is distinguished from that of Southern Africa; consisting principally in the larger size, the more regular and graceful form, the generally 
darker colour, and the less extensive mane of the African. It remains, however, to be mentioned that, even in this latter race, there are two varieties, which have been long known to the settlers under the names of the Pale and the Black Lion, distinguished, as their appellations imply, by the lighter or darker colour of their coats, and more particularly of their manes. This variation, there can be little doubt, is entirely produced by the different character of the districts which they inhabit, and of the food which they are enabled to procure. The black Lion, as he is termed, is the larger and the more ferocious of the two, more frequently attacking man himself, if less noble prey should fail him; and sometimes measuring the enormous distance of eight feet from the tip of the nose to the origin of the tail, which is generally about half the length of the body. He is, however, of less frequent occurrence than the pale variety.

It is in the night-time more particularly that the Lion prowls abroad in search of his prey, the conformation of his eyes not only, like those of the cat, allowing him to see with a very moderate degree of light, but even rendering the full glare of day distressing and intolerable to him. It is for this reason that travellers, who are compelled to sleep in the open air in countries infested by these animals, are careful to keep up a blazing fire, which the tenderness of their eyes deters them from approaching, unless when they are extremely hard pressed by the calls of hunger. These, it would appear, sometimes become paramount to every other consideration, and urge the Lion, as they do many more ignoble beasts, into the exhibition of a degree of courage, which, 
in despite of all that has been said on the subject, is by no means his natural characteristic.

"At the time," says Mr. Burchell, in his admirable Travels in Southern Africa, "when men first adopted the Lion as the emblem of courage, it would seem that they regarded great size and strength as indicating it; but they were greatly mistaken in the character they had given of this indolent skulking animal." That an animal which seldom attacks by open force, but, stealing along with cautious and noiseless tread, silently approaches his victim, conceals himself in treacherous ambush, and at length, when he imagines his prey to be fairly within his reach, bounds forth upon him with an overwhelming leap, crushes him beneath the tremendous weight of his irresistible paw, tears him piece-meal with his talons, and, after having surfeited on his horrid meal, returns into the depths of his solitary concealment to sleep away the hours until his satiated appetite shall be again renewed, and his craving maw stimulate him to fresh exertion,--that such an animal should ever have been regarded as the type of courage and the emblem of magnanimity would indeed be most astonishing, were it not that men have in all ages been too prone to flatter superior power, and to offer at the shrine of greatness that homage which is due only to the good.

True it is that on some occasions the Lion has been known, in the capriciousness of his disposition, to suffer his prostrate prey to escape but little injured from his clutch; but these instances are of rare occurrence, and may, safely be referred either to his natural indolence, when excited neither by hunger nor by provocation, or to that intellectual debasement which among brutes is c 2 
the usual concomitant of increased bulk and formidable strength. But to conclude from such whims and freaks; unaccountable as they may sometimes appear, that he is actuated by feelings of mercy, or by the natural impulse of a generous mind, would be about as reasonable as it would be to assume from the instances which are recorded of the justice and generosity of a Tamerlane or a Tippoo, that those monsters of sanguinary cruelty were in reality the mildest and most merciful of despots.

We have said that the Lion generally chooses the night for his excursions; and this is in fact the only time at which he ventures to approach the habitations of man, from which he will frequently carry off horses or oxen, apparently with the greatest ease, and almost without seeming to be incumbered by his burthen. Beyond the precincts of European civilization, and out of the reach of the dreaded rifle, he will sometimes penetrate into the very hut of the Bushman, and prey upon its human inhabitants. It is even stated, and on very respectable authority, that in some of the most distant kraals, or villages, those wretched people purposely expose the old and the infirm among them in such situations as they consider most open to attack, as the Lion's share, in the expectation that he will instinctively seize upon those who are first thrown in his way. When, however, the Lion finds his appetite thus easily satiated, it is said that he is sure to return night after night to the kraal for a fresh victim; until the miserable remnant of its inhabitants at length find it absolutely necessary to quit the ground, and to seek a precarious safety in flight.

In the day-time, when pressed by hunger, the Lion 
takes his secret stand among the reeds and long grass in the neighbourhood of springs and rivers, and watches with unwearied patience for such animals as may, for the purpose of quenching their thirst, pass sufficiently near him to ensure the success of his attack. This is generally made in one enormous bound of fifteen, twenty, or even, it is said, thirty feet, and with a force capable of bearing to the ground and completely disabling the most formidable opponent. At times, however, he will pursue his prey somewhat more openly, and by quickly repeated springs; but this is an exertion which he is unable to continue for any considerable length of time, and which, consequently, any animal of moderate fleetness, that has fairly got the start of him, is certain to outstrip. Of this the Lion appears to be fully aware; for, if not successful in the commencement of the chase, he generally relinquishes it at once, and retires gradually, and step by step, to his place of ambush, to watch for a better opportunity and a more certain prey.

It is rarely that the Lion of the Cape district ventures to attack a man, unless provoked, or impelled by urgent hunger. The colonists, however, who are very great sufferers (especially in their horses, for whose flesh he seems to have a peculiar taste) by his frequent visits, are his most determined and deadly foes, and omit no opportunity of wreaking their vengeance upon him for the injuries which he has inflicted upon their property. The frontier boors in particular, who are more exposed to his ravages, and who, being well trained to hunting, are most of them excellent marksmen, appear to take a peculiar pleasure in attacking the Lion, even when they 
meet him almost singly. They, however, more frequently make up parties for the chase, which is unquestionably attended with no little danger, even when the huntsmen are numerous and experienced; for although the Lion on such occasions almost always takes to his heels, and endeavours to make his escape without confronting his pursuers; yet, when he finds that flight is in vain, he turns upon them with a fierceness and determination that nothing could withstand, were it not for the well proved superiority possessed by them in the formidable rifle, which, on such an emergency, they know how to direct with a steady and almost unerring aim.

The Cape Lion is seldom taken alive; his utter destruction and extermination forming the primary object of his pursuers. Occasionally, however, when a Lioness has been shot, and the hunters have been fortunate enough to trace out her den, the cubs are brought away, and in some measure domesticated, at least for a season, and until they acquire sufficient force to become dangerous. Up to this period some of the colonists will even suffer them to remain almost at large in their dwellings; but they have frequently occasion to rue the mercy they have shown, and are at length compelled, by the unequivocal manifestations of that ferocity which never fails to make its appearance when the animals have attained a certain age, to destroy the creatures whom they have nourished and caressed.

Two male individuals of this breed are now exhibiting at the Tower: the one whose portrait illustrates the present article, and who, although scarcely more than two years and a half old, already rivals his adult Asiatic 
neighbour in size and majesty, while he exceeds him in grace and agility; and a second, of about ten months old, apparently belonging to the pale variety, and who is just beginning to exhibit the first faint outline of the mane. The former of these is remarkably beautiful and docile: he became an inmate of the Tower in May, 1827; and was, during his voyage from the Cape, being then very young, so tame and domesticated as to be allowed to run about the deck like a dog.

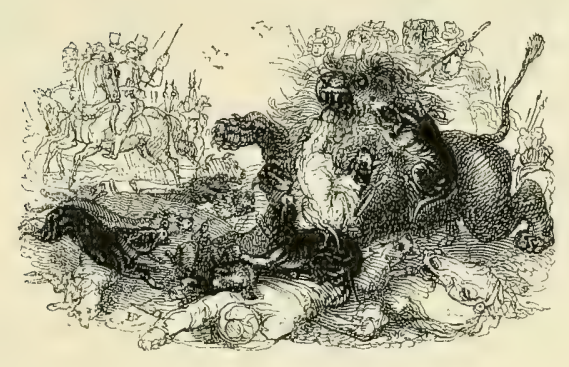




\section{THE BARBARY LIONESS.}

FELIS LEO.—Var. NuMidA.

In the male of this variety, which has been more frequently brought to Europe than any other, the mane attains as much developement and covers the under parts of the body as extensively as in the Lion of Eastern Asia, whom, however, at the adult age, he exceeds considerably in size. The Lioness has little to distinguish her from the other breeds.

The specimen now in the Menagerie is a young female about three years and a half old. She was a present to his Majesty from the Emperor of Morocco. During some tempestuous weather, which occurred on her passage, the male who accompanied her was killed, and she herself met with an accident, from the falling of a spar, by which she was curtailed of her fair proportions, and deprived of the greater part of her tail. The disfigurement thus caused is, however, trifling, and she is still a very fine animal. 


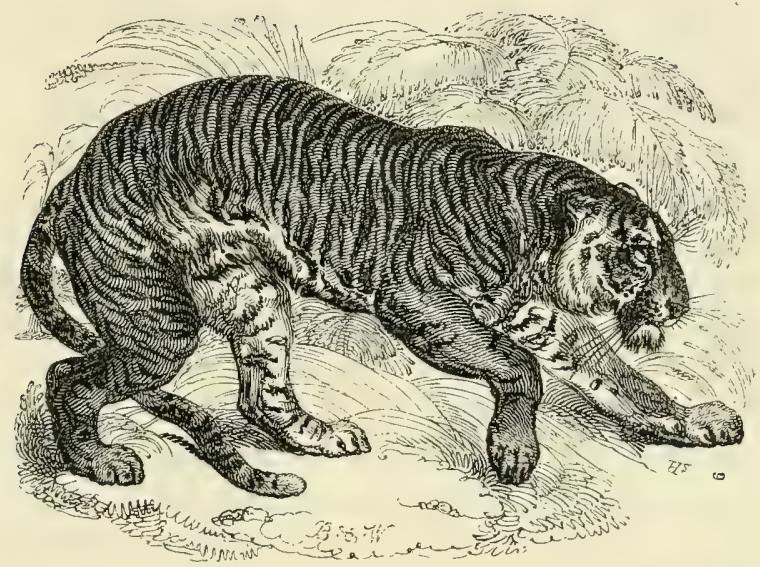

THE TIGER.

FELIS TIGRIS. LINN.

Crosely allied to the Lion, whom he resembles in size, in power, in external form, in internal structure, in zoological characters, in his prowling habits, and in his sanguinary propensities, the Tiger is at once distinguished from that king of beasts, and from every other of their common genus, by the peculiar marking of his coat. On a ground which exhibits in different individuals various shades of yellow, he is elegantly striped by a series of transverse black bands or bars, which occupy the sides of his head, neck, and body, and are continued upon his tail in the form of rings, the last of the series uniformly occupying the extremity of that 
organ, and giving to it a black tip of greater or less extent. The under parts of his body and the inner sides of his legs are almost entirely white; he has no mane; and his whole frame, though less elevated than that of the Lion, is of a slenderer and more graceful make. His head is also shorter and more rounded.

Almost in the same degree that the Lion has been exalted and magnified, at the expense of his fellow brutes, has the Tiger been degraded and depressed below his just and natural level. While the one has been held up to admiration, as the type and standard of heroic perfection, the other has, with equal capriciousness of judgment and disregard of the close and intimate relationship subsisting between them, been looked upon by mankind in general with those feelings of unmingled horror and detestation which his character for untameable ferocity and insatiable thirst of blood was so well calculated to inspire. It requires, however, but little consideration to teach us that the broad distinction, which has thus been drawn, cannot by possibility exist; and the recorded observations of naturalists and travellers, both at home and abroad, will be found amply sufficient to prove that the difference in their characters and habits, on which so much stress has been laid, is in reality as slight and unessential as that which exists in their corporeal structure.

Unquestionably the Tiger has not the majesty of the Lion; for he is destitute of the mane, in which that majesty chiefly resides. Neither has he the same calm and dignified air of imperturbable gravity which is at once so striking and so prepossessing in the aspect of the Lion. But, on the other hand, it will readily be 
granted, that in the superior lightness of his frame, which allows his natural agility its free and unrestricted scope, and in the graceful ease and spirited activity of his motions, to say nothing of the beauty, the regularity, and the vividness of his colouring, he far excels his competitor, whose giant bulk and comparative heaviness of person, added to the dull uniformity of his colour, detract in no small degree from the impression produced by his noble and majestic bearing.

In comparing the moral qualities of these two formidable animals, we shall also find that the shades of difference, for at most they are but shades, which distinguish them, are, like their external characteristics, pretty equally balanced in favour of each. In all the leading features of their character, the habits of both are essentially the same. The Tiger, equally with the Lion, and in common indeed with the whole of the group to which he belongs, reposes indolently in the security of his den, until the calls of appetite stimulate him to look abroad for food. He then chooses a convenient ambush, in which to lie concealed from observation, generally amid the underwood of the forest, but sometimes even on the branches of a tree, which he climbs with all the agility of a cat. In this secret covert he awaits with patient watchfulness the approach of his prey, upon which he darts forth with an irresistible bound, and bears it off in triumph to his den. Unlike the Lion, however, if his first attack proves unsuccessful, and he misses his aim, he does not usually slink sullenly back into his retreat, but pursues his victim with a speed and activity which is seldom baffled even by the fleetest animals.

It is only when this close and covert mode of attack 
has failed in procuring him the necessary supply, that; urged by those inward cravings, which are the ruling impulse of all his actions, he prowls abroad under the veil of night, and ventures to approach the dwellings of man, of whom he does not appear to feel that instinctive awe which the Lion has been known so frequently to evince. But even on such occasions, and although impelled by the strong stimulus of famine, he is in general far from unmindful of his own security; but creeps slowly along his silent path with all the stealthy caution so characteristic of the feline tribe. Occasionally, however, when the pangs of hunger have become intolerable, and can no longer be controlled even by the overpowering sway of instinct, he will boldly'advance upon man himself in the open face of day, and brave every danger in the pursuit of that object which, to the exclusion of every other sentiment, appears under such circumstances wholly to engross his faculties.

It is evident then that in the general outline of his habits, and even in most of the separate traits by which his character is marked, he differs but little from the Lion. His courage, if brute force stimulated by sensual appetite can deserve that honourable name, is at least equal; and as for magnanimity and generosity, the idea of attributing such noble qualities to either is in itself so absurd, and is so fully refuted by every particular of their authentic history, that it would be perfectly. ridiculous to attempt a comparison where no materials for comparison exist. It may, however, be observed that in one point the disposition of the Tiger appears to be more cruel than that of the Lion; inasmuch as it is related, that he is not at all times satisfied with a single 
victim, but deals forth wholesale destruction, without mercy and without distinction, upon whatever may chance to be within the reach of his murderous talons. This, however, is by no means his constant or usual practice; his instinct being in general sufficient to teach him that his purpose is as effectually answered by one fatal bound as by the most extensive devastation; for neither he, nor any of the more powerful of his tribe, return to their prey after the first meal, but leave its mangled relics for the ignoble beasts which follow in their train.

To what cause then, if the similarity between these two animals be so great, and the points of distinction between them so trifling, can we attribute the very different impressions which we have all received, and in all probability continue to cherish, with regard to their respective characters? Perhaps something like a plausible answer to this question may be found in the fact, that our notions of the Lion have been formed on the striking and exaggerated pictures of his noble qualities, for which we are indebted to the poets of antiquity, who contemplated him only in his captive and almost domesticated state; while our early ideas of the Tiger were derived in a great measure from the equally exaggerated statements of miserable and pusillanimous Hindoos, the spiritless and unresisting victims of every species of oppression, who regarded him with almost unspeakable horror as the merciless tyrant of their forests, - a tyrant whose ferocious temper and sanguinary ravages were equalled only by those of the human despots, to whom, as well as to their brute oppressors, they paid the base 
tribute of servile minds, in the fearful dread and crouching awe with which they prostrated themselves at the feet of both.

Nothing in fact can exceed the terror which this formidable animal inspires in those countries which are liable to his devastations. More restricted, however, in this respect than the Lion, he is entirely unkhown in Africa, and is rarely, if ever, to be met with in Asia on this side the Indus. In the south of China, and in the larger Asiatic Islands, such as Sumatra and Java, he is unhappily but too common; but it is said, we know not with what degree of truth, that in the last mentioned locality he is less ferocious than in the Peninsula of Hindostan. This is truly the cradle of his existence and the seat of his empire, in which he disputes dominion even with the Lion himself, who is comparatively rare in the Indian jungles, and with whom the Tiger has been sometimes known to join in deadly and successful struggle for the mastery. Endowed with a degree of force, which the Lion and the Elephant alone can equal, he carries off a buffalo in his tremendous jaws, almost without relaxing from his usual speed. With a single stroke of his claws he rips open the body of the largest animals; and is said to suck their blood with insatiable avidity. Of the correctness of this latter statement, at least in its full extent, there is however strong reason to doubt. The Tiger does not, according to the most credible accounts, exhibit this propensity to drinking the blood of his victims in any greater degree than the rest of his carnivorous and blood-thirsty companions. In this, as in other instances, fear has drawn largely on credulity, and 
the simple and sufficiently disgusting fact has been amplified and exaggerated with all the refinements upon horror which the terrified imagination could suggest.

In making these observations it is far from our intention to become the apologists of this ferocious beast: our object is simply to place him in the rank which he deserves to hold, on a level with those animals with whom Nature has decreed that he should be associated no less in character than in form. In his wild and unrestricted state, he is unquestionably one of the most terrible of the living scourges, to whose fatal ravages the lower animals, and even man himself, are exposed. But in captivity, and especially if domesticated while young, his temper is equally pliant, his disposition equally docile, and his manners and character equally susceptible of amelioration, with those of any other animal of his class. All the stories that have been so frequently reiterated, until they have at length passed current without examination as accredited truths, of his intractable disposition and insensibility to the kind treatment of his keepers, towards whom it is alleged that he never exhibits the slightest feelings of gratitude, have been proved by repeated experience to be utterly false and groundless. He is tamed with as much facility, and as completely, as the Lion; and soon becomes familiarised with those who feed him, whom he learns to distinguish from others, and by whom he is fond of being noticed and caressed. Like the cat, which he resembles so closely in all his actions, he arches his broad and powerful back beneath the hand that caresses him; he licks his fur and smooths himself with his paws; and purrs in the same mild and expressive manner when he is particularly pleased. He 
remains perfectly quiet and undisturbed, unless when hungry or irritated, and passes the greater part of his time in listless repose. His roar is nearly similar to that of the Lion, and, like his, is by no means to be regarded as a symptom of anger, which he announces by a short and shrill cry, approaching to a scream.

Two of these noble animals, the one male and the other female, are among the most striking and attractive ornaments of the Menagerie. The beautiful male, of which our figure offers a characteristic likeness, is a very recent importation, having arrived in England in the month of April of the present year, in the East India Company's ship Buckinghamshire, to the commander of which, Captain Glasspool, we are indebted for the following particulars relative to his birthplace, capture, early life, and education. He was taken prisoner in company with two other cubs, supposed to be not more than three weeks old, on that part of the coast of the peninsula of Malacca which is opposite to the island of Penang, and is commonly known by the name of the Queda Coast. In our present imperfect acquaintance. with this part of the farther peninsula of Hindoostan, it affords perhaps but little ground for surprise that none of these terrible animals should have previously reached this quarter of the globe from a locality so seldom visited by European vessels. Their existence in its extensive jungles and marshy plains has long, however, been notorious; and to judge from the specimen now before us, which, although barely two years old, already exceeds in size the full-grown Asiatic Lion which occupies the neighbouring den, they must in that situation be at. least as formidable as their fellows of the hither peninsula. The 
dam of this individual had, it appears, made a nocturnal incursion into one of the towns of the district, from which she had carried off a large quantity of provisions. She was pursued and killed, and her three cubs were taken possession of by the conquerors in token of their victory and brought home in triumph. One of them, a female, died shortly after; the second, a male, is still living in the possession of a resident at Penang; and the third, the subject of the present article, also fell into the hands of a gentleman of that settlement, in whose paddock he was confined, in company with a pony and a dog, for upwards of twelve months, without evincing the least inclination to injure his companions or any one who approached him. By this gentleman he was presented to Captain Glasspool, who brought him to England: on the voyage he was remarkably tame, allowing the sailors to play with him, and appearing to take much pleasure in their caresses. On being placed in his present den he was rather sulky for a few days; but seems now to have recovered his good temper, and to be perfectly reconciled to his situation. The mildness of his temper may probably be in a great measure due to his having from a very early age been accustomed to boiled food; raw flesh never having been offered to him until after his arrival in the Menagerie. This change of food he seems particularly to enjoy, although he has by no means lost his appetite for soup, which he devours with much eagerness. Notwithstanding his immature age, Mr. Cops considers him the largest Tiger that he ever saw.

The other individual at present in the Tower is a Tigress of great beauty from Bengal, scarcely a twelve- 
month old, who also promises to become an exceedingly fine animal. During her passage from Calcutta she was allowed to range about the ressel unrestricted, became perfectly familiar with the sailors, and showed not the slightest symptom of ferocity. On her arrival, however, in the Thames, the irritation produced by the sight of strangers completely and instantly changed her temper, rendering her irascible and dangerous. Her deportment was so sulky and savage that Mr. Cops could scarcely be prevailed on by her former keeper, who saw her shortly afterwards, to allow him to enter her den: but no sooner did she recognise her old friend, than she fawned upon him, licked him, and caressed him, exhibiting the most extravagant signs of pleasure; and when he left her she cried and whined for the remainder of the day. To her new residence and her new keeper she is now perfectly reconciled.

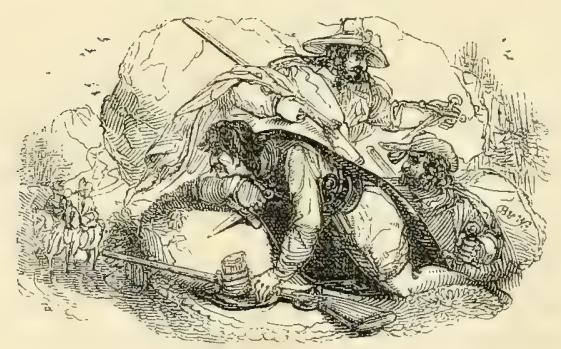




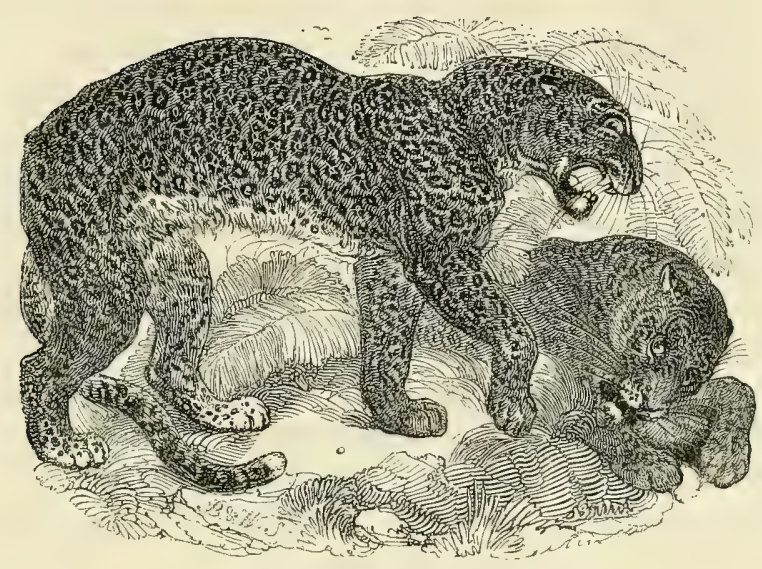

THE LEOPARD.

FELIS LEOPARDUS. LINN.

THE race of this wily and sanguinary animal, which is unsurpassed in all the terrible characteristics of its tribe, and yields to the tremendous and ferocious beasts, to the illustration of whose habits and manners our previous pages have been devoted, in none of their dreaded attributes, excepting only in size and strength, is spread almost as extensively over the surface of the Old World as that of the Lion himself. From the shores of the Mediterranean to the immediate neighbourhood of the Cape he is familiar to every part of the monster-bearing continent of Africa; while in the east of Asia his fatal spring and murderous talons are equally known and

$$
\text { D } 2
$$


dreaded by the mild and timid Hindoos, the polite but still barbarous Chinese, and the fierce and savage Islanders of the great Sumatran chain. Throughout this immense tract of country he varies but in a trifling degree, and that merely in his comparative magnitude, in the size, shape, and disposition of his markings, and in the greater or less intensity of his colouring: in the more essential particulars of form and structure, as well as in character and disposition, he is every where the same.

It has already been mentioned that the Leopard is smaller than the Tiger; indeed he seldom exceeds from three to four feet from the tip of the nose to the root of the tail, which latter is somewhat shorter than the body. Perhaps the largest authentic measurement is that of an animal, spoken of under the designation of Panther, but in all probability truly a Leopard, which was killed by Colonel Denham's party in the course of that zealous and successful traveller's late expedition, and which is stated at eight feet two inches from the muzzle to the extremity of the tail. This savage creature, although twice impaled by the lances of his pursuers which he had snapped asunder in his rage, was still on the point of making a spring upon the foremost of the party, when a musket ball through the head completely deprived him of that vitality which his previous wounds, dangerous and fatal as they undoubtedly were, had not even appeared to diminish in any sensible degree.

The ground colour of the fur of the Leopard, which is eminently and beautifully sleek, is a yellowish fawn above, which becomes paler on the sides, and is entirely lost in the pure white of the under part of the body. The top of the back, the head, neck, limbs, and under: 
surface of the body, are irregularly covered with larger or smaller, roundish or oval, perfectly black spots; while the whole of the sides of the animal and a portion of his tail are occupied by numerous distinct roses, formed by the near approach of three or four elongated small black spots, which surround a central area, about an inch or an inch and a quarter in breadth, of a somewhat deeper colour than the ground on which it is placed. There are some black lines on the lips, and bands of the same colour on the inside of the legs; two or three imperfect black circles, alternating with white, also occur towards the extremity of the tail, which is entirely white beneath.

It would be superfluous to enter into any detail of his habits, which correspond but too well with those of his fellow cats already described, and are only modified by his want of equal power. This deficiency is, however, in a great measure supplied by the extreme pliability of his spine, which gives to his motions a degree of velocity, agility, and precision combined, that is altogether unequalled by any other quadruped, and to which the greater lateral compression of his body, the increased length and more slender proportions of his limbs, and the suppleness of all his joints must of necessity materially contribute. Equally savage, equally dastardly, and equally cruel, he closely imitates the manners of the Lion and the Tiger, on a somewhat reduced, but still formidable, scale. Antilopes, monkeys, and the smaller quadrupeds constitute his usual prey, upon which he darts forth from his secret stand, and which he pertinaciously pursues even upon the trees where they may have taken refuge, climbing after them with surprising agility. Man he generally endeavours, if possible, to 
avoid; but, when hard pressed, he fears not to make head against the hunter; and it frequently requires the exertion of no common sliare of skill and intrepidity in the latter to save himself from the deadly fangs of the infuriated object of his pursuit. Occasionally, indeed, the cravings of hunger stimulate the treacherous animal to attack the unwary woodcutter, or the lone traveller whose path has led to his secret haunts; but in this case he rarely, if ever, shows himself openly in the face of day, but watches with insidious glare for the fatal opportunity of springing upon his wretched victim from behind, and of annihilating his power of resistance before it could possibly be exerted in his defence.

In captivity, however, especially if taken while yet young, his character frequently undergoes a change as favourable as that which takes place under the same circumstances in the generality of his tribe. The pair at present in the Tower are male and female; they are both Asiatic, and are confined in the same den, but they differ very materially in temper and disposition. The female, which is the olcier of the two, and has been a resident in the Menagerie for upwards of four years, is exceedingly tame, suffering herself to be patted and caressed by the keeper, and licking his hands. Strangers, however, especially ladies, should be cautious of approaching her too familiarly, as she has always evinced a particular predilection for the destruction of umbrellas, parasols, muffs, hats, and such other articles of dress as may happen to come within her reach, seizing them with the greatest quickness and tearing them into pieces almost before the astonished visiter has become aware of the loss. To so great an extent has she carried this peculiar 
taste that Mr. Cops declares that he has no doubt that during her residence in the Tower she has made prey of at least as many of these articles as there are days in the year. The agility with which she bounds round her cell, which is of considerable size, touching at one leap, and almost with the velocity of thought, each of its four walls, and skimming along the ceiling with the same rapidity of action, which is scarcely to be followed by the eye, is truly wonderful, and speaks more forcibly of the muscular power and flexibility of limb by which such extraordinary motions are executed than language can express.

The male, on the contrary, although he has been more than twelve months an inmate of the Tower, is still as sullen and as savage as on the day of his arrival. Notwithstanding the lind treatment which has been lavished upon him by the keepers, he yet refuses to become familiarised with them, and receives all their overtures at a nearer acquaintance with such sulky and even angry symptoms as plainly evince that it would be dangerous to tamper with his unreclaimed and unmanageable disposition. He is, as is usual in all these animals, larger than the female, and much richer and more beautiful in the style of his marking and depth of his colouring. The two animals, however, although differing so greatly in temper, agree together tolerably well, excepting only at meal times, when their usual harmony is in some measure broken in upon by the jealousy with which they regard each other's share of the repast.

Their food consists of about five pounds of beef per day for each: this the keeper generally tosses up in front of their den, at the distance of nearly two feet from 
the bais, and to the height of six or eight feet from the floor. The animals, who are on the alert for their dinner, immediately leap towards the bars, and, darting out their paws with incredible swiftness, almost uniformly succeed in seizing it before it falls to the ground. If, as it sometimes happens, the meat is thrown up at too great a distance, so as not to be fairly within reach, they remain perfectly stationary and make no attempt to spring upon it, but watch it with anxious avidity, apparently calculating and comparing the distance of the object and the extent of their own grasp. When they have, in this way, secured their meal, instead of ravenously falling to, like the other carnivorous animals in the collection, they stand growling over it for some minutes, leering upon each other with the most frightful contortions. This growling attitude of mistrust in feeding was constantly maintained by the female, even before she had a companion in her captivity, and when consequently there existed no immediate object for the excitement of her selfish or envious feelings.

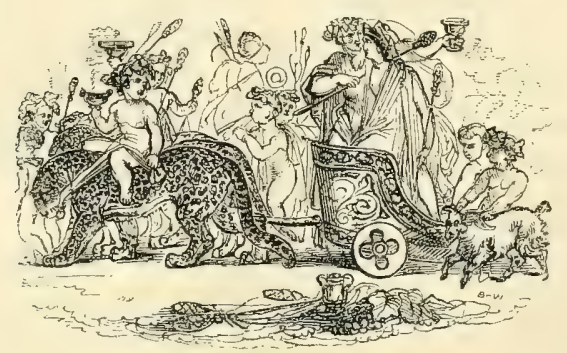




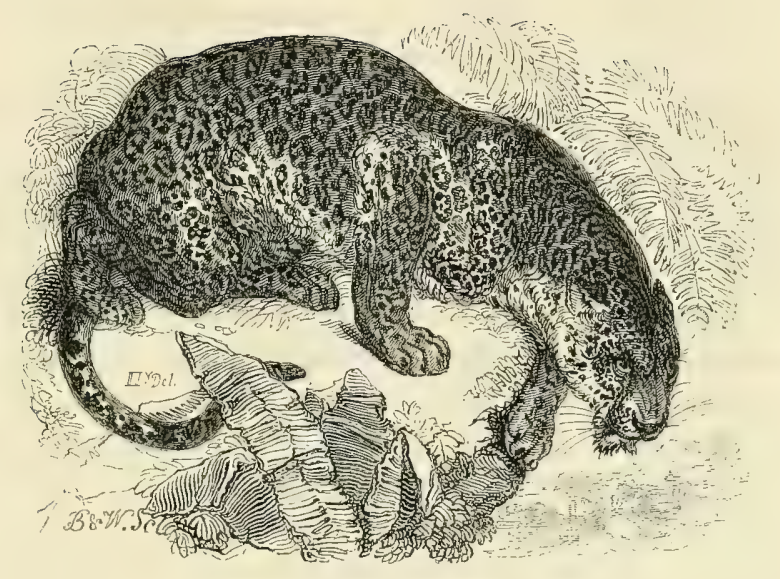

THE JAGUAR.

FELIS ONCA. LINN.

IT can scarcely fail to have been remarked by those who have perused the preceding pages with moderate attention that the species of cats described in them, including the largest and most formidable of the whole genus, are exclusively natives of the Old World, and confined to the hot and burning climates of Southern Asia and of Africa. A second and more numerous class, of which, however, no example exists at present in the Tower Menagerie, and which, consequently, it does not fall within our province to illustrate, occupy the colder and northern regions of both hemispheres. These belong principally to the same subdivision with the Lynx 
(being, like him, distinguished by the pencils of long hairs which surmount their ears), and to that which comprehends the domestic eat; and are all of diminutive size and trifling power when compared with those monstrous productions of the torrid zone, the Lion, the Tiger, and the Leopard. The reader is not, however, to imagine that the smaller species exist only in the vicinity of the pole and in the temperate regions of the earth: he will find, on the contrary, that many of them are natives of more southern climes, and commit their petty ravages under as fierce a sun as that which fires their more dreaded competitors in the career of rapine and of blood. Of one of these, the true Lynx of antiquity, we shall have occasion to treat in a subsequent article.

But there is also a third class which springs into existence in the warmer climates of America, some of whose representatives almost equal the Tiger in magnitude, in vigour, and in ferocity, while others rival the Leopard in the beauty and sleekness of their fur, and in the agility and gracefulness of their motions. Foremost of these, and holding the highest rank among the most formidable animals of the New World, stands the Jaguar, or, as he is sometimes called, the American Tiger. Superior to the Leopard in size as well as in strength, he approaches very nearly in both respects to the Lionesses of the smaller breeds: he is, however, less elevated on his legs, and heavier and more clumsy in all his proportions. His head is larger and rounder than that of the Leopard; and his tail is considerably shorter in proportion, being only of sufficient length to allow of its touching the ground when the animal is standing, while that of the Leopard, as we have before observed, is very 
nearly as long as his whole body. This disproportion between the length of their tails affords perhaps the most striking distinction between the two animals, offering, as it does, a constant and never-failing criterion; whereas the difference in the marking of their furs, although sufficiently obvious on a close examination, depends almost entirely on such minute particularities as would probably escape the notice of a superficial observer, and were in fact for a long time so completely neglected, even by zoologists, that it is only within a few years that we have been again taught accurately to distinguish between them. These particularities we shall now proceed to point out.

On the whole upper surface of the body of the Jaguar the fur, which is short, close, and smooth, is of a bright yellowish fawn; passing on the throat, belly, and inside of the legs, into a pure white. On this ground the head, limbs, and under surface are covered with full black spots of various sizes; and the rest of the body with roses, either entirely bordered by a black ring or surrounded by several of the smaller black spots arranged in a circular form. The full spots are generally continued upon the greater part of the tail, the tip of which is black, and which is also encircled near its extremity by three or four black rings. So far there is little to distinguish the marking of the Jaguar from that of the Leopard; we come now to the differences observable between them. The spots which occupy the central line of the back in the former are full, narrow, and elongated; and the roses of the sides and haunches, which are considerably larger and proportionally less numerous than in the Leopard, are all or nearly all marked with one or 
sometimes two black dots or spots of smaller size towards their centre: an apparently trifling, but constant and very remarkable distinction, which exists in no other species. By this peculiarity alone the Jaguar may at once be recognised; and this external characteristic, together with the extreme shortness of his tail, his much greater size, his comparatively clumsy form, and the heaviness of all his motions, not to speak of the peculiarity of his voice, which has the sharp and harsh sound of an imperfect bark, are unquestionably fully sufficient to sanction his separation from a race of animals, from which, however much he may resemble them in general characters, he differs in so many and such essential particulars. That this separation has been made more complete by the hand of Nature herself, who has interposed the wide ocean between him and those of his fellows with whom alone there is any probability of his being confounded, is an additional proof, if any confirmation were wanting, of the soundness of the distinction which has been drawn between them.

It is in the swampy forests of South America that the Jaguar commits his destructive ravages, which are spread over nearly the whole of that continent from Paraguay almost to the Isthmus of Darien. It has frequently been said that he is also to be found in Mexico; but this appears to be a mistake, originating probably in Buffon's having confounded the Jaguar with the Ocelot, describing and figuring the latter under the name of the former, and intermingling with his description many of the peculiar traits of the real Jaguar derived from the relations of travellers. On the other hand he has erroneously figured the latter animal under the name of the Panther; a 
mistake in which he has been followed by Pennant and others, and with which the writings of zoologists are more or less infected even up to the present day. What the Panther of the ancients actually was, or whether there exists any real difference between it and the Leopard, is a much disputed question, into which we have neither space nor inclination to enter: certain it is that it could not possibly have been the present animal, which has never been found out of the limits of America; and that Buffon himself had no idea, while he was figuring the latter, that the specimen before him was not a native of Africa or the East. The name of Jaguar is corruptedly derived from the Brazilian appellation of the animal, to which the Portuguese have given the name of Onça; another blunder, for the Ounce of the Old World is now universally allowed to be identical with the Leopard, and with the latter we have already shown that it is impossible that the American species can be conjoined.

Like the Cats already described, to whom, however, he is much inferior in the suppleness and elasticity of his motions, the Jaguar makes his solitary haunt in the recesses of the forest, especially in the neighbourhood of large rivers, which he swims with the greatest dexterity. Of the extent of this faculty, as well as of his extraordinary strength, some judgment may be formed from a circumstance related by D'Azara, which fell partly under that traveller's personal observation; namely, that a Jaguar, after having attacked and destroyed a horse, carried the body of his victim for about sixty paces to the bank of a broad and deep river, over which he swam with his prey, and then dragged it into the adjoining wood. According to M. Sonnini he is as expert at 
climbing as at swimming. "I have seen," he says, "in the forests of Guiana, the prints left by the claws of the Jaguar on the smooth bark of a tree from forty to fifty feet in height, measuring about a foot and a half in circumference, and clothed with branches near its summit alone. It was easy to follow with the eye the efforts which the animal had made to reach the branches: although his talons had been thrust deeply into the body of the tree, he had met with several slips, but he had always recovered his ground, and, attracted no doubt by some favourite object of prey, had at length succeeded in gaining the vely top."

Endowed with such tremendous powers it is no wonder that this formidable animal is regarded with terror by the inhabitants of the countries which he infests. He seldom, however, attacks the human race; although he does not appear to shun it with any peculiar dread. His onset is always made from behind, and in the same treacherous manner as that of all his tribe; of a herd of animals or of a band of men passing within his reach, he uniformly singles out the last as the object of his fatal bound. When he has made choice of his victim he springs upon its neck, and, placing one of his paws upon the back of its head while he seizes its muzzle with the other, twists its head round with a sudden jerk, which dislocates its spine and deprives it instantaneously of life and motion. His favourite game appears to be the larger quadrupeds, such as oxen, horses, sheep, and dogs, whom he attacks indiscriminately and almost always successfully, when urged by the powerful crayings of his maw. At other times he is indolent and cowardly, secretes himself in caverns, skulks in the 
depths of the forest, and is scared by the most trifling causes.

The Spaniards and even the native Indians appear to take a pleasure in hunting the Jaguar, whom they attack in various ways. One of the most common is to chase him with a numerous pack of dogs, who, although they dare not attack so formidable an opponent, frequently succeed in driving him to seek refuge on a tree or in a thick copse. Should he trust himself to the former, he is usually destroyed by the musket or the lance; but if he has taken covert among the bushes, it is sometimes difficult to aim at him with precision. In this latter case some of the Indians are hardy enough to attack him single-handed; a perilous exploit, which, according to D'Azara, they perform in the following manner. Armed only with a lance, of five feet in length, they envelope their left arm in a sheep-skin, by means of which they evade the first onset of the furious animal, and gain sufficient time to plunge their weapon into his body before he can turn upon them for a second attack. Another mode of destroying him is by means of the lasso ; but this method can of course be employed only when the animal roams abroad upon the plains, or can be driven by the dogs into an open space fit for the purpose. Riding at full gallop with the lasso coiled up in their hands, these excellent horsemen will throw the noose with such certainty and precision as infallibly to secure their formidable enemy at the distance of a hundred paces, and to place him completely at their mercy.

The Jaguar is generally said to be quite untameable, and to maintain his savage ferocity even in a state of captivity, showing no symptoms of attachment to those 
who have the care of him. This assertion is amply contradicted by the fact that an individual confined in the Paris Menagerie, was exceedingly mild in his temper, and particularly fond of licking the hands of those with whom he was familiar; as was also remarkably the case with the specimen lately in the Tower, whose portrait ornaments the present article. This animal was obtained by Lord Exmouth while on the American station, and accompanied the expedition to Algiers at the memorable bombardment of that nest of pirates. On his return to England, his Lordship gave it to the Marchioness of Londonderry, who soon afterwards presented it to his Majesty, by whose order it was placed in the Tower; where it continued until a short time since, when it unfortunately died. Mr. Cops is, however, in expectation of being soon enabled to replace it. It was exhibited under the name of the Panther, an appellation which we have before stated that the Jaguar had erroneously obtained, not only among the furriers, by whom it is universally so called, but even among scientific zoologists.

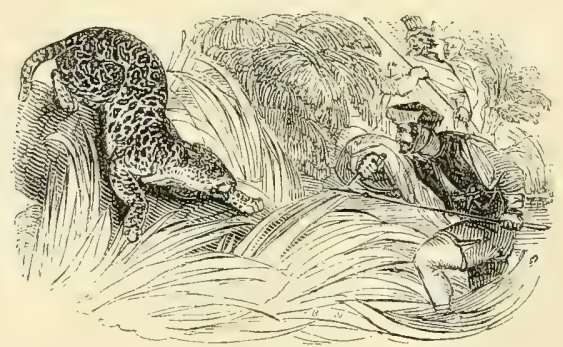




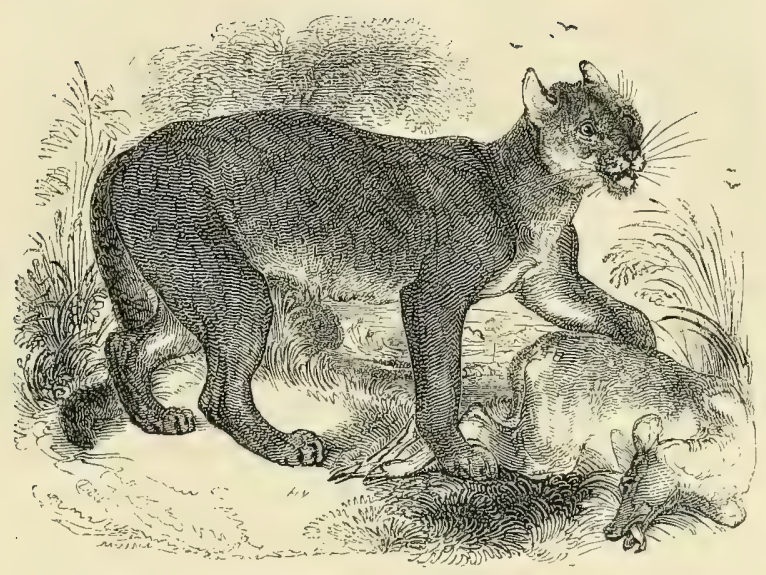

THE PUMA.

Felis Concolor. Linn.

NeArLy approaching to the Jaguar in size and form, but obviously distinguished from him at the first glance, by the total absence of spots, the Puma, Couguar, or, as he was once called, the American Lion, occupies the second place among the cats of the New World, over nearly the whole of which he was formerly spread, from Canada and the United States in the North, to the very extremity of Patagonia in the South. From a large portion of this immense expanse of country he appears, however, to have been of late years in a great measure, if not entirely, rooted out; and it is seldom that he is now heard of in the vicinity of that civilization, which 
involves, as a necessary consequence, either the complete extinction, or, at least, the gradual diminution and dispersion to more secure and sheltered habitations, of all the more savage and obnoxious beasts. For his title of the American Lion he was, in a great degree, indebted to an absurd notion on the part of the early colonists, which was even shared by many naturalists, that he was, in reality, neither more nor less than a degenerate variety of that far more noble animal. This opinion has, however, long since given way before the prevalence of sounder views; and he is now universally recognised as forming a species clearly distinguishable from every other, by a combination of characters which it is impossible to mistake.

Almost the only striking point of resemblance between him and the Lion consists in the uniform sameness of his colour, which on the upper parts of his body is of a bright silvery fawn, the tawny hairs being terminated by whitish tips: beneath and on the inside of the limbs he is nearly white, and more completely so on the throat, chin, and upper lip. The head has an irregular mixture of black and gray; the outside of the ears, especially at the base, the sides of the muzzle from which the whiskers take their origin, and the extremity of the tail, are black. The latter is not terminated, as in the Lion, by a brush of hair; neither has the Puma any vestige of a mane. His length from the tip of the nose to the root of the tail is commonly about four feet, and his tail measures above half as much more, being just sufficiently long to suffer its extremity to trail upon the ground. His head is remarkably small and rounded, with a broad and somewhat obtuse muzzle; and his body is proportionably more slender and less elevated than that of the 
Lion. His young, like those of the latter animal, have a peculiar livery, consisting in spots of a darker shade than the rest of their fur, scattered over every part of the body, but only visible in a particular light, and disappearing entirely at the adult age. There is no difference whatever in colour between the sexes, the fur of the female being in every respect similar to that of the male: in size the latter is superior to his mate; and his head, a part which in the female is disproportionately small, corresponds better with the general form of his body.

More circumspect, or rather more cowardly, than any of the larger species of his cautious tribe, he is, notwithstanding his much greater magnitude, scarcely more dangerous than the common wild cat, preying only upon the smaller species of animals, seldom venturing to attack any living creature of greater size or courage than a sheep, and flying from the face of man with more than usual terror. But this cowardice is also, in a state of nature, connected with a degree of ferocity, fully equal to that which is developed in the most savage and blood-thirsty of his fellow cats. Unlike the Jaguar, which generally contents itself with a single victim, the Puma, if he should happen to find himself undisturbed in the midst of a flock of sheep, deserted by their guardians and left entirely at his mercy, is said never to spare, but to destroy every individual that he can reach, for the purpose of sucking its blood. He differs also from the Jaguar in his habit of frequenting the open plain rather than the forest and the river, in and near which the latter usually takes his secret and destructive stand. Hence he is more exposed to the pursuit of the skilful thrower of the lasso, from whom, as his swiftness 
is by no means great and his timidity excessive, he rarely escapes.

In captivity the Puma readily becomes tame, and may even be rendered docile and obedient. His manners closely resemble those of the domestic cat; like it he is extremely fond of being noticed, raises his back and stretches his limbs beneath the hand that caresses him, and expresses his pleasure by the same quiet and complacent purring. They soon become attached to those with whom they are familiar; and numerous instances might be mentioned in which they have been suffered to roam almost at large about the house without any injurious results. One of these is no doubt familiar to many of our readers, occurring as it did under the roof of Mr. Kean, the tragedian, who possessed an animal of this species so tame as to follow him about almost like a dog, and to be frequently introduced into his drawing-room, when filled with company, at perfect liberty.

The Puma figured above is a female, about three years old, exceedingly sleek in her fur and lively in her colours, and equally mild and good-tempered with any of her: ruce.

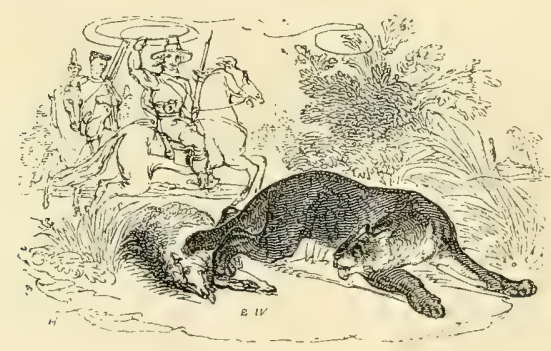




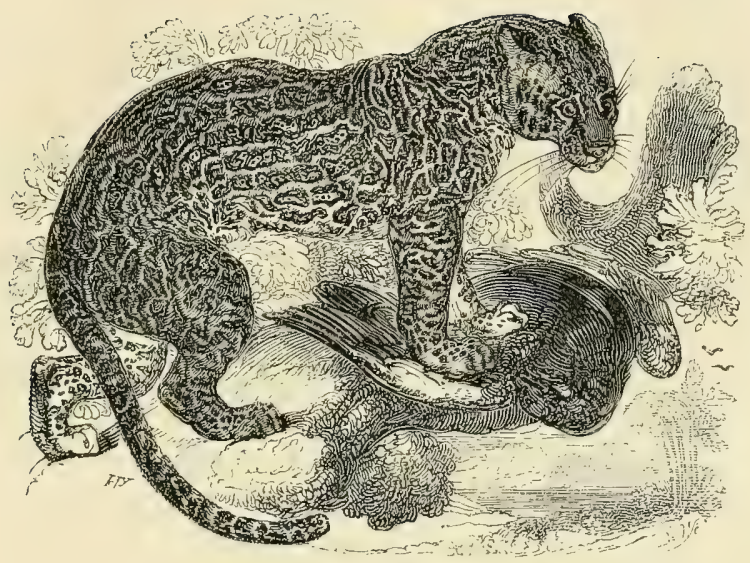

THE OCELOT.

FELIS PARDALIS. LINN.

"OF all the animals with tigrine skins," says Buffon, " the male Ocelot has unquestionably the most beautiful and at the same time the most elegantly variegated robe; that of the Leopard himself does not approach it in liveliness of colour or regularity of design." That this estimate is by no means exaggerated will readily be allowed by all who have had an opportunity of seeing this truly beautiful creature, which may unquestionably be regarded as the beau ideal of a cat. Nearly equal in size to the Lynx of Europe, but shorter in its proportions and more graceful in its form, it holds, as it were, a middle station between the Leopard and the domestic cat. 
Its body, when full grown, is nearly three feet in length, and its tail rather more than one; while its medium height may be reckoned at about eighteen inches. The ground colour of its fur is gray mingled with a slight tinge of fawn; and on this it is elegantly marked with numerous longitudinal bands, the dorsal one being continuous and entirely black, and the lateral, to the number of six or seven on each side, consisting for the most part of a series of elongated spots with black margins, sometimes completely distinct, and sometimes running together. The centre of each of these spots offers a deeper tinge of fawn than the ground colour external to them; and this deeper tinge is also conspicuous on the upper part of the head and neck, and on the outside of the limbs, all of which parts are irregularly marked with full black lines and spots of various sizes. From the top of the head, between the ears, there pass backwards, towards the shoulders, two, or more frequently four, uninterrupted diverging bands, which are full black anteriorly, but generally bifurcate posteriorly and enclose a narrow farw-coloured space within a black margin; between these there is a single longitudinal somewhat interrupted narrow black line, occupying the centre of the neck above. The ears are short and rounded, and externally margined with black, surrounding a large central whitish spot. The under parts of the body are whitish, spotted with black, and the tail, which is of the same ground colour with the body, is also covered with blackish spots.

The description above given is chiefly derived from the comparison of two living specimens, the one existing in the Menagerie of the Tower, the other in that of the 
Zoological Society, at their gardens in the Regent's Park. There is one circumstance, however, of which it may be necessary to offer some explanation. We have stated the length of the tail at more than a foot; and in all the known Ocelots, as well as in all the species (of which there are several) that approach it in form and colouring, the proportionate length of the tail is at least equal to that which we have given as its average measurement. That of the Tower specimen, however, does not exceed six or seven inches; its extremity is completely overgrown with hair, and there is no appearance of a cicatrix. Still its equality throughout, and its abrupt stumpiness, if we may so express ourselves, induce the belief that this abbreviation of the tail is purely accidental; and we feel by no means inclined to regard the specimen before us as belonging to a new species, to be distinguished by the excessive shortness of that appendage, by the unusually pale colour of its markings, and by some slight peculiarities in the mode of their arrangement, which varies indeed in every individual that we have seen.

The animal in question, accurately represented in the portrait which is prefixed to the present article, was presented by the late Sir Ralph Woodford, governor of Trinidad, about six months since, under the name of the Peruvian Tiger; from which denomination we may presume that it was originally brought from that part of the continent of America. The species, however, is very widely spread, being found as well in Mexico, from the language of which country it derives its name, as in Paraguay. Its habits are similar to those of the other cats, keeping itself close in the depths of the forests 
during the day, and prowling abroad at night in search of victims, which it finds in the smaller quadrupeds and birds. In the chase of the latter it is particularly successful, pursuing them even to their nests amid the trees; which it climbs with the greatest agility. It is easily tamed, but seldom loses all trace of its natural ferocity. D'Azara, however, speaks of one which was so completely domiciliated as to be left at perfect liberty; it was strongly attached to its master, and never attempted to make its escape. The specimen in the Tower, which is a male, is perfectly good tempered, exceedingly fond of play, and has, in fact, much of the character and manners of the domestic cat. Its food consists principally of rabbits and of birds, the latter of which it plucks with the greatest dexterity, and always commences its meal with their heads, of which it appears to be particularly fond: It does not eat with the same ravenous avidity which characterizes nearly all the animals of his tribe.

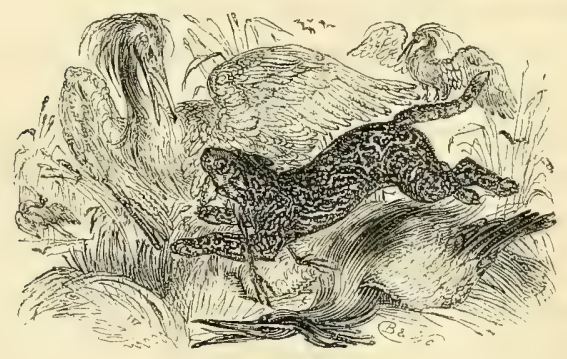




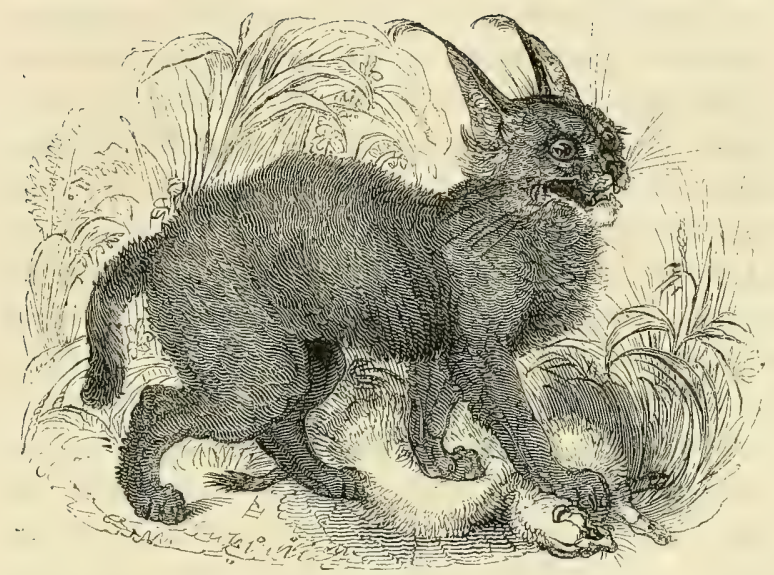

THE CARA C A L.

FELIS CARACAL. LinN.

THE Caracal, which is unquestionably identical with the Lynx of the Ancients, but whose original name has been; in modern times, usurped by an animal of northern origin, utterly unknown to the Greeks, and distinguished by the Romans by a totally different appellation, is a native of most of the warmer climates of the Old World, infesting probably as large an extent of the surface of the earth as the Lion or the Leopard themselves. Throughout the whole of Africa, from Egypt and Barbary to the extremity of Caffraria, and in the southern half of Asia, at least as far eastwards as the Ganges, he follows, as it were, in the footsteps of those larger and 
more formidable beasts. So uniformly indeed has he been met with in the train of the Lion, that many early writers, determined to find a reason for every thing, laid it down as a settled fact that the Caracal, equally with the Jackal, although in a different manner, was the Lion's purveyor; that he accompanied that terrible animal in the pursuit of his prey; pointed it out to him by means of his more delicate nostril and piercing sight; and, when his royal master had finished his meal, received a portion of the flesh in reward for his good and loyal service. But the greater part of this fanciful tale is now known to have had its origin only in the imagination of men who had caught a glimpse of the real truth, and made up for the want of accurate observation by the invention of a theory almost as fabulous as the stories of the ancients, which attributed to the same animal such wonderful powers of sight as to pierce even through stone walls. He follows, it is true, in the traces of the Lion; but, far from associating with him in the pursuit of game, he ventures not, any more than the other beasts of the forest, to trust himself within reach of his paw. His object is solely to satiate his appetite upon the remains of the mangled carcases which the Lion may leave; consequently the latter might with much greater truth and propriety be regarded as the purveyor of the Caracal, who depends perhaps more for his subsistence upon the food thus provided for him, than upon that which he can procure by the exercise of his own powers or sagacity. He frequently, however, indulges his native ferocity in petty ravages on the smaller and more timid quadrupeds, such as hares and rabbits: birds also form a favourite object of his attacks, and in pursuit of them 
he mounts the tallest trees with surprising swiftness and agility. It is even said that his qualifications for the chase are capable of cultivation ; and it has been repeated by travellers, from the days of the celebrated Marco Polo downwards, that the princes of the East occasionally make use of his services in taking small game in nearly the same manner as they employ the subject of the succeeding article for the larger: but from all that we know of his disposition in a state of captivity, this statement appears, to say the least, extremely questionable.

In size the Caracal is somewhat larger than the Fox. The whole of the upper surface of his body is of a deep and uniform brown, the hairs being for the most part slightly tipped with gray; the under and inner parts are nearly white; and the chin and lower lip, and two spots, one on the inner side of and above the eye, and the other beneath its outer angle, completely so. The neck and throat are of a lighter and brighter brown than the rest of the fur. The ears, which are long and upright, taper gradually to a fine tip, which is surmounted by a pencil of long black hairs; they are black externally and whitish within. It is to the striking character afforded by these organs that the animal is indebted for his modern name of Caracal, corrupted from his Turkish appellation, which, equally with that by which he is known in Persia, signifies "black ear." His whiskers are short, and take their origin from a series of black lines which occupy the sides of the muzzle; at some distance behind them, in front of the neck on each side, is a short and thick tuft of lighter coloured hairs. The tail, which is eight or nine inches 
in length, is of the same uniform colour with the body from its base to its tip.

The specimen in the Tower, from which our engraving was made and our description taken, is a native of Bengal, a locality from which these animals have been so rarely brought to Europe, that it has been a question among naturalists whether the Caracal of India and that of Africa really belonged to the same species. There is, however, no difference of any importance observable between the present animal and those which have been brought from the latter continent. It is extremely sulky, keeping constantly retired in one of the backward corners of its cage, and swearing, as we express it in the common cat, almost incessantly when conscious of being noticed. The Lynxes indeed appear, at least when in captivity, to exercise this peculiar faculty of voice to a much greater extent than any other species of the group. They are remarkably irascible and mistrustful, and are seldom completely tamed.

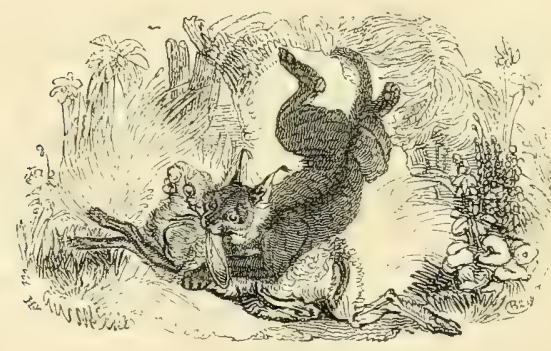




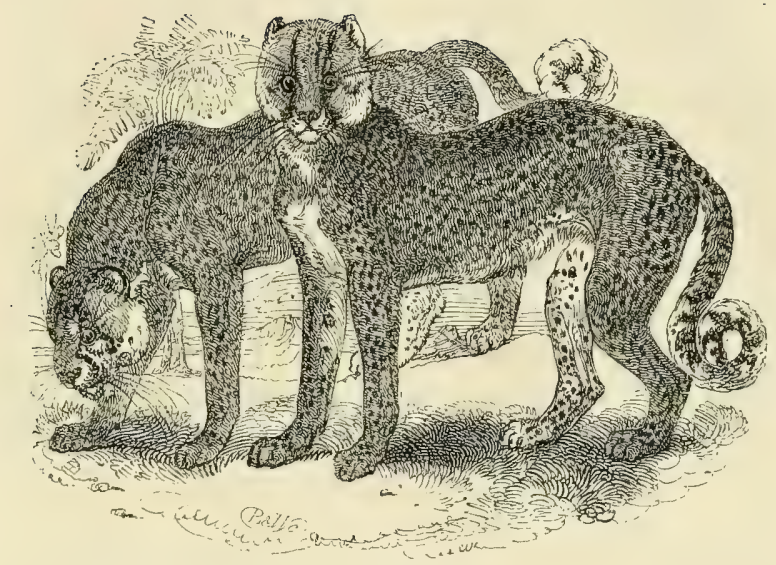

\section{THE CHETAH, OR HUNTING LEOPARD.}

Felis JUbata. SChreb.

Uniting to the system of dentition, the general habit and many of the most striking peculiarities of the cats; some of the distinguishing features and much of the intelligence, the teachableness, and the fidelity of the dog, the Hunting Leopard forms a sort of connecting link between two groups of animals, otherwise completely separated, and exhibiting scarcely any other character in common than the carnivorous propensities by which both are; in a greater or less degree, actuated and inspired. Intermediate in size and shape between the leopard and the hound, he is slenderer in his body, more elevated on his legs, and less flattened on the fore 
part of his head than the former, while he is deficient in the peculiarly graceful and lengthened form, both of head and body, which-characterize the latter. His tail is entirely that of a cat; and his limbs, although more elongated than in any other species of that group, seem better fitted for strong muscular exertion than for active and long-continued speed. From these indications it may be gathered that he approaches much more nearly to the feline than to the canine group: we shall therefore follow the example of zoologists in general, by referring him for the present and provisionally to the genus Felis, and proceed to point out more particularly the characters by which he is connected with, as well as those by which he is distinguished from, the rest of that formidable and extensive tribe.

In the number and form of his teeth, in the asperity of his tongue, in the conformation of his organs of sense, and in the number of his claws, he accurately corresponds with the legitimate species of the genus Felis. The principal character in which he differs from them consists in the slight degree of retractility of these latter organs. Instead of being withdrawn within sheaths appropriated for the purpose, as in the whole of the cats properly so called, the claws of the Hunting Leopard are capable of only a very limited retraction within the skin, and are consequently exposed to the action of the ground on which they tread, their points and edges being thus rendered liable to be blunted by the constant pressure to which they are subjected, almost to the same extent as in the dogs. The slightest consideration of the uses to which the claws are applied by the whole of the feline tribe, in whom they are, in fact, in consequence 
of their extreme power and sharpness, organs of offence if possible more deadly and more destructive than the teeth, will teach us that the modification which has just been described in so important a part of their organization, must of necessity be accompanied by a corresponding change in manners and habits; and that convenience alone, and the want of analogous structure in any other animal, could justify us in continuing to class the Chetah among the cats, from whom he differs in so essential a particular.

In outward form, however, notwithstanding his more slender make, the difference between them is by no means great. His head, although more elevated and prominent in front, exhibits the same broad lateral expansion, caused by the thick mass of muscle which acts so powerfully upon the short and dilated jaws of the cats, and imparts to them that tremendous force and effect for which they are so remarkable. His legs, notwithstanding their increased length and slender proportions, retain all the elastic springiness, by means of which the Leopard or the Tiger are enabled to bound with so much vigour and velocity upon their unsuspecting prey. His air and manners, too, are unquestionably those of the cats; and his mode of colouring, which we shall next proceed to describe, although exhibiting very peculiar and marked distinctions, offers so close an analogy to that of the Jaguar and the Leopard, that, were we to regard this character alone, it would be impossible to arrange him in a different group from that which comprehends those beautifully spotted, but ferocious, beasts. His fur, however, it must be remarked, has little of the sleekness which characterizes those 
animals, but exhibits, on the contrary, a peculiar crispness which is not to be found in any other of the tribe.

His ground-colour is a bright yellowish fawn above, and nearly pure white beneath, covered above and on the sides by innumerable closely approximating spots, from half an inch to an inch in diameter, which are intensely black, and do not, as in the Leopard and others of the spotted cats, form roses with a lighter centre, but are full and complete. These spots, which are wanting on the chest and under part of the body, are larger on the back than on the head, sides, and limbs, where they are more closely set: they are also spread along the tail, forming on the greater part of its extent interrupted rings, which, however, become continuous as they approach its extremity, the three or four last rings surrounding it completely. The tip of the tail is white, as is also the whole of its under surface, with the exception of the rings just mentioned; it is equally covered with long hair throughout its entire length, which is more than half that of the body. The outside of the ears, which are short and rounded, is marked by a broad black spot at the base, the tip, as also the inside, being whitish. The upper part of his head is of a deeper tinge; and he has a strongly marked flexuous black line, of about half an inch in breadth, extending from the inner angle of the eye to the angle of the mouth. The extremity of the nose is black, like that of the dog. The mane, from which he derives his scientific name, is not very remarkable: it consists of a series of longer, crisper, and more upright hairs, which extend along the back of the neck and the anterior portion of the spine. 
Such are the outward and physical characteristics of this beautiful animal; in his moral and intellectual qualities he differs still more widely from that compound of unteachableness, malice, and mistrust, which is the necessary result of the low degree of intelligence possessed by the remainder of the group of animals with which he is at present associated. Of his habits in a state of nature we have no certain information; but in his tamed and domesticated condition he has been rendered, in some countries at least, auxiliary to man, by the successful cultivation of his mental faculties, which have been trained into a degree of subservience to the commands of his master, that can only be surpassed by the superior sagacity of the hound. Chardin, Bernier, Tavernier, and others of the older travellers had related that in several parts of Asia it was customary to make use of a large spotted cat in the pursuit of game, and that this animal was called Youze in Persia, and Chetah in India; but the statements of these writers were so imperfect, and the descriptions given by them so incomplete, that it was next to impossible to recognise the particular species intended. We now, however, know with certainty that the animal thus employed is the Felis jubata of naturalists, which inhabits the greater part both of Asix and of Africa. It is common in India and Sumatra, as well as in Persia; and is well known both in Senegal and at the Cape of Good Hope; but the ingenuity of the savage natives of the latter countries has not, so far as we know, been exerted in rendering its services available in the chase in the manner so successfully practised by the more refined and civilized inhabitants of Persia and of: Hindostan. In Senegal it 
is valued only on account of its skin, which forms an important article in the commerce of that colony; while at the Cape, where it is known to the Dutch settlers by the misapplied name of Luipard (Leopard), it seems to be entirely neglected even in a commercial point of view. In the neighbourhood of the latter colony, it should be added, the animal appears from the testimony of travellers to be of rare occurrence; and Professor Iichtenstein, in particular, mentions an instance in which the skin of one was worn by the chief of a horde of Caffres as a badge of peculiar dignity and distinction.

But even in the East, where the qualities of the Chetah appear to be best appreciated, and his faculties to be turned to most account, it would seem that he is not employed in hunting by all classes of the people indiscriminately; but, on the contrary, that he is reserved for the especial amusement and gratification of the nobles and princes of the land, rather than used for purposes of real and general advantage. In this respect, and indeed in many others, as will be seen by the following brief account of the mode in which the chase with the Hunting Leopard is conducted, it bears a close resemblance to the ancient sport of hawking, so prevalent throughout Europe in the days of feudal tyranny, but scarcely practised at the present day except by the more splendid slaves of Asiatic despotism. The animal or animals, for occasionally several of them are employed at the same time, are carried to the field in low chariots, on which they are kept chained and hooded, in order to deprive them of the power and temptation to anticipate the word of command by leaping forth before the appointed time. When they are thus brought within view 
of a herd of antelopes, which generally consists of five or six females and a male, they are unchained and their hoods are removed, their keepers directing their attention to the prey, which, as they do not hunt by smell, it is necessary that they should have constantly in sight. When this is done, the wily animal does not at once start forwards towards the object of his pursuit, but, seemingly aware that he would have no chance of overtaking an antelope in the fleetness of the race, in which the latter is beyond measure his superior, winds cautiously along the ground, concealing himself as much as possible from sight, and, when he has in this covert manner nearly reached the unsuspecting herd, breaks forth upon them unawares, and after five or six tremendous bounds, which he executes with almost incredible velocity, darts at once upon his terrified victim, strangles him in an instant, and takes his fill of blood. In the meanwhile the keeper quietly approaches the scene of slaughter, caresses the successful animal, and throws to him pieces of meat to amuse him and keep him quiet while he blinds him with the hood and replaces' him upon the chariot, to which he is again attached by his chain. But if, as is not unfrequently the case, the herd should have taken the alarm, and the Chetah should prove unsuccessful in his attack, he never attempts to pursue them, but returns to his master with a mortified and dejected air, to be again let slip at a fresh quarry whenever a fit opportunity occurs.

The Chetah has been until of late years very imperfectly known in Europe. Linnæus was entirely unacquainted with it; and Buffon described it from the fur alone under the name of Guêpard, the appellation by 
which its skin was distinguished in the commerce with Senegal, but evidently without suspecting its identity with the Asiatic animal, the trained habits of which, misled probably by the authority of Tavernier, he erroneously attributed to his imaginary Ounce. Subsequent French zoologists had rectified this error, and it was generally believed that the tamed Leopard of Bernier; the Youze, the Guêpard, and 'Tavernier's Ounce, were one and the same animal; but it was not until a year or two ago that the possession of a living specimen, brought from Senegal, in the Menagerie of the Jardin du Roi, enabled. M. F. Cuvier to ascertain its characters with precision. The comparison of this African specimen with the skins sent from India, and with the notes and drawings made in that country by $M$. Duvaucel, to whom we are indebted for a vast deal of interesting information relative to the zoology of the East of Asia, at once put an end to all doubts of the identity of the two animals.

Several individuals have been brought alive to this country at various times; but, notwithstanding the opportunities thus afforded, it does not appear that English naturalists have paid any particular attention to the study of their character and habits. In all probability the earliest that arrived in Europe was one which was brought from India by Lord Pigot, and which was figured by Pennant under the name of the Hunting Leopard. Three others, found at the capture of Seringapatam among the rest of the state paraphernalia of the fallen Sultan, came into the possession of General, afterwards Lord, Harris, who, on his return to England, presented them to his late Majesty, by whose command 
they were placed in the Tower. They did not, however, long survive the effects of the passage and of the change of climate, which latter has proved equally fatal to the few specimens which have since been brought to this country for public exhibition. They appear, indeed, to be exceedingly delicate in their temperament, and to require considerable attention on the part of their keeper. The pair now in the Tower, if two individuals of the same sex, both of them being males, can be called a pair, were purchased by Mr. Cops a few months since from the captain of a vessel trading to Senegal, to whom they were brought by some of the natives when only a few weeks old and no larger than an ordinary cat. They were the constant inmates of his cabin, and soon became strongly attached to their master, never, as they grew up, exhibiting the slightest symptom of that savage ferocity to which all the larger cats are occasionally more or less prone, even under the most favourable circumstances. Much of this peculiar meekness of temper, which they still maintain, is doubtless owing to the very early age at which they were made captive, as well as to the mild and little stimulating nature of the food to which they have ever since been accustomed. This consists chiefly of boiled meat and meal; and during the winter season, in consequence of the delicacy of their habit, they are supplied with hot mashes, gruel, \&c. Their mode of feeding is very like that of the dog.

In size and stature these beautiful animals considerably exceed any that have been seen in this country of late years. They are truly, as may be judged from their portraits, an elegant and graceful pair, having, when led out into the yard in their couples, very much of the air 
and manners of a brace of greyhounds. When noticed or fondled they purr like a cat; and this is their usual mode of expressing pleasure. If, on the other hand, they are uneasy, whether that uneasiness arises from cold, from a craving after food, from a jealous apprehension of being neglected, or from any other: cause, their note consists of a short, uniform, and repeated mew. They are extremely fond of play, and their manner of playing very much resembles that of the cat; with this difference, however, that it never, as in the latter animal, degenerates into malicious cunning or wanton mischief. Their character, indeed, seems to be entirely free from that sly and suspicious feeling of mistrust which is so strikingly visible in the manners and actions of all the cats, and which renders them so little susceptible of real or lasting attachment. The Chetahs, on the contrary, speedily become fond of those who are kind to them, and exhibit their fondness in an open, frank, and confiding manner. There can, in fact, be little doubt that they might with the greatest facility be reduced to a state of perfect domestication, and rendered nearly as familiar and as faithful as the $\operatorname{dog}$ himself.

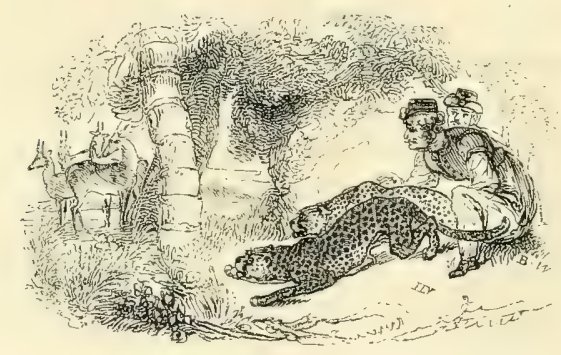




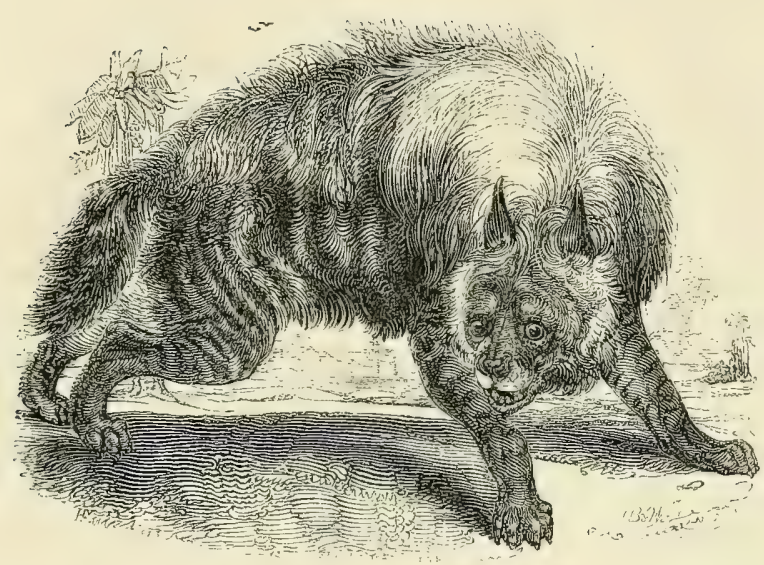

THE STRIPED HYANA.

HYANA VULGaRIS. DESM.

From the strongly marked group, to the illustration of various species of which the foregoing pages have been dedicated, we pass by a natural and easy transition to an animal, which, although closely resembling them in its zoological characters, and in the cowardly ferocity of its disposition, bears nevertheless a stronger affinity to the dogs, with which it was associated by Linnæus. From each of these groups it is, however, readily distinguished by several obvious and essential characters, of sufficient importance to sanction its separation as a genus, now universally adopted among naturalists.

Like both the cats and the dogs, the Hyænas are 
completely digitigrade; that is to say, they walk only on the extremities of their toes: but these toes are only four in number on each of their feet, and are armed with short, thick, strong, and truncated claws, which are not in the least retractile, and are evidently formed for digging in the earth, a practice to which they are impelled by a horrid and hateful propensity, which we shall have further occasion to notice in describing their habits and mode of life. Their body, in shape much resembling that of the wolf, to which they also approach very nearly in size, is considerably more elevated in front than behind, owing partly to their constant custom of keeping the posterior legs bent in a crouching and half recumbent posture. Beneath the tail, which is short and dependent, they are furnished with a pouch, in the interior of which is secreted a peculiar matter of a very strong and disagreeable smell. Their head is large and broad, flattened in front, and terminating in a short, thick, and obtuse muzzle. Like most carnivorous animals, they are armed in each jaw with six cutting teeth, and two canine, the latter of which are of considerable size and strength. The outermost pair of incisors in the upper jaw are much larger and stronger than the rest, and closely resemble the canine in form. The number of the molar or cheek teeth is five on each side in the upper jaw, and four in the lower; and all of them are remarkable for their extreme thickness and strength in comparison with those of the dogs and cats. Their tongue is similar to that of the latter animals in the roughness which it derives from the sharp and elevated papillæ with which it is covered.

Of the genus thus characterized there exist two well 
marked and unquestionably distinct species, the Striped Hyæna, or Hyæna vulgaris of modern zoologists, which there can be no doubt is also the Hyæna of the ancients; and the Hyæna crocuta, or Spotted Hyæna, the Tiger Wolf of the colonists of the Cape of Good Hope. To these may probably be added a third species, which there is good ground for believing to be distinct, and which has lately been described by Dr. Andrew Smith, the superintendant of the South African Museum, under the name of Hyæna villosa: this is also a native of the vicinity of the Cape, and is denominated by the settlers the Strand Wolf, or Strand Jut. With the two latter we have, however, on the present occasion, no concern; the only animal of this genus in the Tower belonging to the striped race, which inhabits the greater part of Asia and of Africa, penetrating in the former as far as India, and extending over all the northern part of the latter continent. It does not appear that the striped and spotted races are ever found to occupy the same ground; but the territorial limits which separate the one from the other have not yet been distinctly ascertained.

The striped Hyæna has for its ground colour a uniform brownish gray, which is somewhat darker above than beneath. On the sides of the body it is marked by several irregular distant transverse blackish stripes or bands, which are more distinct on the lower part. Towards the shoulders and haunches these stripes become oblique, and they are continued in regular transverse lines on the outside of the legs. The front of the neck is completely black, as are also the muzzle and the outsides of the ears; the latter being broad, moderately long, and nearly destitute of hairs, especially on the 
inside. The hair of the body is long, particularly on the back of the neck and on the spine, where it forms a full and thick mane, which may be said to be continued even upon the tail, the latter organ being furnished with strong tufted hairs of considerable length. The mane and the tail are both marked with blackish spots or stripes variously and irregularly placed. Much variety is indeed to be met with as well in the ground colour of the whole body as in the disposition of the markings, which are extremely different in different individuals.

The habits of the Hyænas are entirely nocturnal: while in the daytime their cowardice is so excessive that they fly from the face of man, and suffer themselves, when taken, to be ill treated with impunity and even without attempting to avenge themselves, they prowl abroad in the stillness of the night with all the temerity of brutal daring. They will frequently make prey of the lesser animals, and will occasionally venture to attack dogs and even horses; but it is seldom that they muster up sufficient courage to contend with living man, unless stimulated by strong provocation, or impelled by the most violent cravings of hunger. Congregated in numerous bands they beset the encampment of the traveller, or infest the neighbourhood of villages or even of towns, which they enter with the fall of night and do not quit until the dawn of day; disturbing the inhabitants with their peculiar moaning or wailing, which is in some measure intermediate between a grunt and a howl. Parading the streets and penetrating into the houses in search of prey, they eagerly devour the offal of animals, the refuse of the daily meal, or whatever else that is in any way eatable may happen to fall in their way. 
Nothing, however filthy, comes amiss to their voracious appetites, which are indeed unbounded. They even break into the cemeteries of the dead, and tearing open the graves by means of their powerful claws, disinter the buried corpses, on which they glut that horrid propensity for feeding on carrion, which is at once the most striking and the most disgusting of their peculiarities. Their fondness for this polluted species of food tends of course not a little to increase the natural antipathy with which they are regarded by the natives of the countries in which they abound, and renders them objects of peculiar detestation and abhorrence. The great size and strength of their teeth and the immense power of their jaws enable them to crush the largest bones with comparative facility, and account for the avidity with which they prey upon an almost fleshless skeleton. In the daytime they retire into caves, from which they issue only when the shades of evening warn them that the hour for their depredations has arrived. Their gait is awkward and usually slow and constrained; when scared, however, from their prey, or when pursued by the hunter, they fly with tolerable swiftness, but stil! with an appearance of lameness in their motions, resulting from the constant bending of their posterior legs.

Notwithstanding the brutal voracity of his habits and the savage fierceness of his disposition, there is scarcely any animal that submits with greater facility to the control of man. In captivity, especially when taken young, a circumstance on which much depends in the domestication of all wild animals, he is capable of being rendered exceedingly tame, and even serviceable. In some parts of Southern Africa the spotted species, which 
is by nature quite as ferocious in his temper as the striped inhabitant of the North, has been domiciliated in the houses of the peasantry, among whom he is preferred to the dog himself for attachment to his master, for general sagacity, and even, it is said, for his qualifications for the chase. That the Striped Hyæna might be rendered equally useful is highly probable from the docility and attachment which he manifests towards his keepers, especially when allowed a certain degree of liberty, which he shows no disposition to abuse. If more closely restricted his savage nature sometimes returns upon him; and it is for this reason that those which are carried about the country from fair to fair, pent up in close caravans, frequently become surly and even dangerous. The individual whose portrait we give is, on the contrary, remarkably tame; he is a native of the East Indies, and is confined in the same den with one of the American Bears, as we shall have occasion to notice more particularly when speaking of the latter animal.

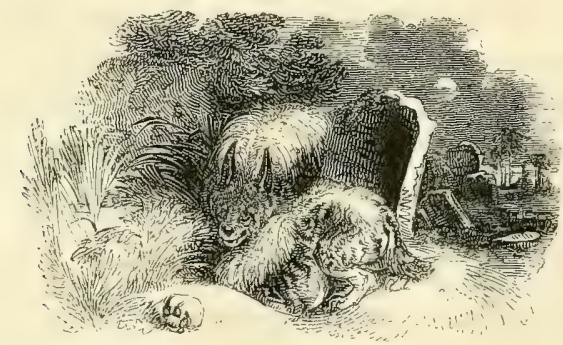




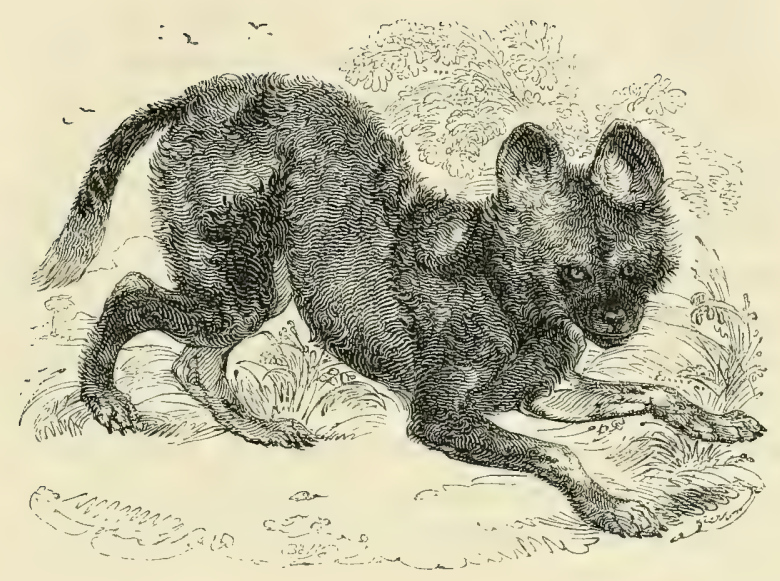

THE HY FNA-DOG.

CANis pictus. Desm.

IT is not without much hesitation that we have adopted for this animal the generic name of Canis, and referred it, in conformity with the example of most of the leading zoologists of the day, to the same group with the Wolf, the Jackal, and the Fox; from all of which it differs in such important particulars as fully entitle it, in our estimation, to the rank of a distinct and separate genus. To this rank it has, indeed, been already raised by Mr. Brookes, under the generic appellation of Lycaon; but as we are not aware that it has been any where described under that name, or that any detailed account has been given of the characters on which that separation 
is founded, we cannot consider ourselves authorized in a work of this nature to make any innovations upon science, however much we may feel, as in the present instance, that they are called for by the exigency of the case. That its position is at least doubtful is proved by the fact that M. Temminck, one of the ablest of the continental zoologists, first described it from the living animal under the designation of a Hyæna, and, having subsequently changed his opinion, is now disposed to regard it as a species of dog.

For the zoological characters of the latter genus the reader is referred to the following article: at present we shall confine ourselves to the description of the remarkable animal before us, pointing out, as we proceed, the marks by which it differs from both the groups to which it has hitherto been referred, and those by which it is assimilated to either the one or the other. In the shape and elevation of its body it is at first sight distinguished from them both, its legs being considerably longer in relation to its size, and the trunk of its body, as will be seen by the portrait prefixed, being very different in form and proportions. It is entirely destitute of the mane of the Hyæna, and its tail is very similar to that of certain dogs; but; on the other hand, its head approximates very closely, or rather bears a most striking resemblance, to the broad and flattened forehead, and the short and truncated muzzle, which characterize the former genus. It is this latter circumstance no doubt that has induced many naturalists, both popular and scientific, to identify the Wild Dog, as he is called by the settlers at the Cape, with a group of animals from which in every other particular of outward struc- 
ture, excepting one, it is remarkably and obviously distinct. The only other point of agreement between them consists in the number of its toes, which, like those of the Hyæna, are only four to each foot. This peculiarity, combined with the form of the head, unquestionably affords some ground for placing these animals in close apposition; but is by no means so important, in the absence of other and more essential characteristics, as to warrant their union into a single group. Taken together, however, and in connexion with other features of distinction, these characters may fairly be regarded as sufficiently striking to sanction the separation of the animal now under consideration from the dogs. With the latter it corresponds most completely in the number and form of its teeth, and in the general structure of its skeleton, which differs remarkably from that of the Hyæna.

In size and form it is smaller and more slender than either the Hyæna or the Wolf. Its ground colour is of a reddish or yellowish brown, which is variously mottled in large patches along the sides of the body and on the legs, with black and white intermingled together. Its nose and muzzle are completely black, and it has a strong black line passing from them up the centre of the forehead to between the ears, which are very large, black both within and without, and furnished with a broad and expanded tuft of long whitish hairs arising from their anterior margin and filling up a considerable part of their concavity. There is a lighter patch on the muzzle beneath each of the eyes. The tail is of moderate length, covered with long bushy hair, and divided in the middle by a ring of black, below which or towards 
the extremity it is nearly white, as are also the fore parts of the legs below the joint. These colours and markings are subject to variation in different individuals; but in their general disposition and appearance they constantly exhibit the greatest similarity.

The Hyæna-Dog, if this compound term may be allowed, is a native of the South of Africa, and infests the frontier settlements at no great distance from the Cape to a very extensive and troublesome degree. Mr. Burchell, to whom we are indebted for the earliest specimen brought to this country, as well as for first pointing out its distinctive characters, informs us that it hunts in regular packs, preferring the night, but frequently pursuing its prey even by day. It is not only exceedingly fierce, but also remarkably swift and active, insomuch that none but the fleeter animals can escape from its pursuit. Sheep, oxen, and horses appear to be its favourite game: on the former it makes its onset openly and without fear, but of the latter it seems to stand in awe, and attacks them only by stealth, frequently surprising them in their sleep, biting off the tails of the oxen, for which it has a particular fancy, and inflicting such serious injuries upon the horses, especially the young colts, as they rarely survive.

The individual brought home by Mr. Burchell was kept.by that gentleman chained up in his stable-yard for more than a year; at the expiration of which its ferocity continued unabated; the man who fed it being so fearful of it that he "dared never to venture his hand upon it." It is nevertheless highly probable that with a somewhat firmer and bolder treatment it might have been in some degree tamed, if not domesticated; for it 
is stated that it at length became familiar with a dog, which was its constant companion. That which is at present in the Tower was brought to England in company with the youngest of the Cape Lions. They agreed together extremely well; but as the Lion increased in size his play became too rough for his comparatively feeble companion, who was borne to the earth in a moment by the superior weight and strength of his antagonist. Mr. Cops therefore found it necessary to consign them to separate dens: Other companions for the Hyæna-Dog have, however, very recently been obtained, an interesting addition having been made to the stock of the Menagerie by the acquisition of a couple of Spotted Hyænas; a brief notice of which we subjoin, as well as their portraits by way of tail-piece, they having arrived during the progress of the present sheet through the press, and consequently too late for insertion in their proper place.

In size the Spotted Hyæna, the Hyæna Crocuta of naturalists, is somewhat inferior to the striped. Its muzzle, although short, is not so abruptly truncated; and its ears, which are short and broad, assume a nearly quadrilateral figure. Its ground colour is yellowish brown; and the whole body is covered with numerous spots of a deeper brown, tolerably uniform in size, but sometimes not very distinctly marked, and occasionally arranging themselves in longitudinal rows. Its hair is shorter than that of the Striped Hyæna, and although longer on the neck and in the central line of the back than elsewhere, does not form so distinct and well furnished a mane as in the latter animal. The tail is blackish brown, and covered with long bushy hair. 
This species appears to be peculiar to Southern Africa. In its wild state it is equally ferocious in its temper and disgusting in its habits with the common species of the North; but it has been found, as we have before mentioned, to be capable of domestication, and of rendering services to man equal to those which he derives from the dog. The pair which have just arrived in the Tower have been placed by $\mathrm{Mr}$. Cops in one den with the Striped Hyæna and with the Hyæna-Dog; and this juxta-position affords an excellent opportunity for a comparison of their characters and disposition. They agree together tolerably well; but the new-comers are hardly as yet reconciled to their abode, and consequently appear shy and reserved. The Hyæna-Dog is the most lively of the group; and his playfulness appears occasionally to give no little annoyance to the Striped Hyæna, who generally returns his solicitations with a surly snarl, but does not seem disposed to resent them farther.

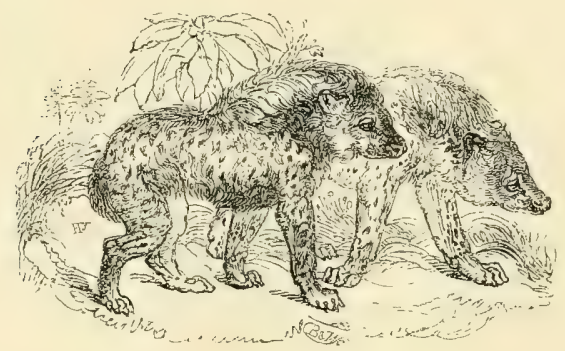




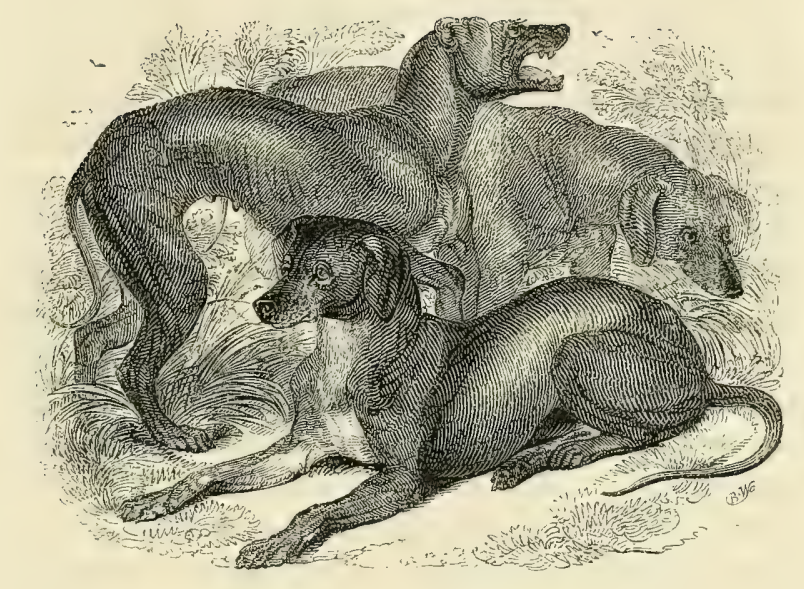

THE AFRICAN BLOODHOUND.

Canis domesticus. Linn. Var.

THE generic characters of this well known group, comprehending not only the various races of the Dog, the Wolf, and the Jackal, but also the numerous species of Foxes, which differ from the rest only in the form of the pupils of their eyes (which are round in the former, and transversely linear in the latter) may be shortly enumerated as follows. They are all furnished in the upper jaw with six sharp incisors and two canine teeth in front, and with six molars on each side; the same number of each description is also to be found in the lower, with the addition of a seventh grinder. Their tongue is perfectly smooth, the papillæ which cover it 
being soft and velvety to the touch, instead of rough and pointed as in the Hyænas and Cats. They have five toes to each of the fore feet, of which only the four outermost touch the ground, the fifth being always more or less elevated. On the hind feet the number of the toes is no more than four, for although the rudiment of a fifth is distinctly visible in the skeleton, it is rarely observable in the living animal. On these toes they constantly support themselves in walking, the soles of their feet, or rather that part of the legs which corresponds to the soles of plantigrade animals, never being applied to the surface of the ground on which they tread. Their claws are blunt, strong, but little curved, and not at all retractile; and their use is evidently limited to turning up the earth. Their muzzle is more or less elongated to afford space for the ample series of lateral teeth; and the strength of their jaws, as well as the extent of opening between them, is by this means much diminished. In most of these particulars they exhibit a striking contrast with the more perfect of the carnivorous races, and afford grounds for expecting an equally manifest falling off from their ferocious and sanguinary propensities. The dogs are in fact by no means equally carnivorous with the cats; and their teeth, especially the grinders, are fitted as well for the demolition of vegetable as of animal substances.

In a wild state, however, they subsist themselves principally by preying upon the inferior animals, feeding with nearly equal relish upon the warm and palpitating fibres of a fresh and almost living victim, and upon the mangled carcass which taints the air with its unsavoury exhalations. Their habitation is in the depths 
of the forest, where the larger species form themselves dens in the close and thick underwood, while the smaller burrow in the earth for shelter. Their lengthened muzzle and the great extent to which all the cavities connected with the nose are dilated, are admirably fitted for giving to the organ of smell the fullest developement of which it is capable. It is the perfection of this organ, combined with the general lightness and muscularity of their frame and the firm agility of their elongated limbs, which renders many of the species such excellent hunters, by enabling them to scent their prey at an immense and sometimes almost incredible distance, and to run it down in the chase with indefatigable swiftness and unrelaxing pertinacity.

The very terms of the specific character by which Linnæus attempted to distinguish the domesticated from the other dogs, "the tail curved upwards (towards the left)," may be regarded as affording in themselves a sufficient proof of the difficulty of the task, when so great a naturalist, after taking a complete review of all the particulars of their organization, was compelled to rest contented with a distinction drawn from so trifling and apparently insignificant a remark. It would in fact appear to be absolutely impossible to offer in any form of words whatever a character sufficiently comprehensive to combine the almost infinite varieties of this Protean race, and at the same time to separate them from those other races from which they are generally believed to be specifically: distinct. To this observation of Linnæus almost the sole addition that has been made by later zoologists consists in a remark of M. Desmarest, that whenever a spot of white is found upon any part of the 
tail of a domestic dog, the tip of that very variable organ is also constantly white; so that we are still driven to recur to the tail alone for the only uniform physical characteristics that have been pointed out to distinguish an animal, which every one recognises at first sight, and which indeed it is impossible to mistake.

But it is to the moral and intellectual faculties of the Dog that we must look for those remarkable peculiarities which distinguish him in so eminent a degree not only from his immediate neighbours, but also from every other quadruped. Unfortunately we have not the means of comparing him in a pure state of nature with the other animals of his tribe; for although it has been repeatedly attempted to determine his primitive stock, there can be no doubt that upon this point we are still as much as ever in the dark. There exist, however, in various parts of the world, considerable numbers of Dogs, the descendants unquestionably of races formerly domesticated, which, to all appearance, differ: but little in their habits and manners from the Wolf and the Jackal, to one or other of which they frequently approach in form, and from each of which it has been confidently asserted that the domestic species was primarily derived. But the doubts to which this striking similarity might otherwise give rise are instantly removed by the readiness with which these wild Dogs submit to the control of man, and become familiarized with that state of servitude to which nature appears to have destined them from the first. Other animals may incleed be tamed; they may become playful, familiar, and even affectionate; but none of them have hitherto been taught, even by long-continued training, to exhibit 
qualities of mind in any degree comparable to the absolute subserviency, the undeviating attachment, the submissive docility, and the acute intelligence, which these invaluable animals almost spontaneously manifest, when placed in circumstances favourable to their developement.

So much has been written by authors of every description, from the earliest ages down to the present time, upon every point connected with their history and habits, and the space which we could devote to their illustration in the present volume is so small, that we choose rather not to enter at all upon the subject than to treat of it in the very abrupt and imperfect manner to which we should necessarily be restricted. It only remains therefore to add a few observations relative to the extremely beautiful leash of hounds which are figured at the head of the present article, before passing to the consideration of the remaining species of the group which are at present contained in the Menagerie.

These are two males and one female, belonging to the most elegant as well as the most intelligent variety of the species, that to which Linnæus, on account of the high degree to which the latter quality was carried in them, gave par excellence the epithet of sagax. They were presented by Major, now Colonel Denham, on his return from the most successful expedition that has perhaps ever been made into the evil-omened regions of Central Africa, from whence they were brought by that gallant traveller, who also gave $\mathrm{Mr}$. Cops the following account of their qualifications for the chase. He had repeatedly, he said, made use of them in hunting the Gazelle, in their pursuit of which he had observed that 
they displayed more cunning and sagacity than any dogs with which he was acquainted, frequently quitting the line of scent for the purpose of cutting off a double, and recovering it again with the greatest facility. They would follow a scent after an hour and a half or even two hours had elapsed; and the breed was therefore commonly employed in Africa for the purpose of tracing a flying enemy to his retreat. They are in fact, both for symmetry and action, perfect models; and there are few sportsmen who will not regret that there appears no chance of crossing our own pointers with this interesting breed. A mixed race, combining the qualifications of both, would unquestionably be one of the most valuable acquisitions to our sporting stock; but, unhappily, this union seems to be altogether hopeless; for although they have now been more than three years in England, and are in excellent health and condition, they appear, like many other animals restrained of their liberty and kept constantly together, to have no disposition to perpetuate their race. The males are remarkably good tempered; the female on the contrary is surly and ill natured.

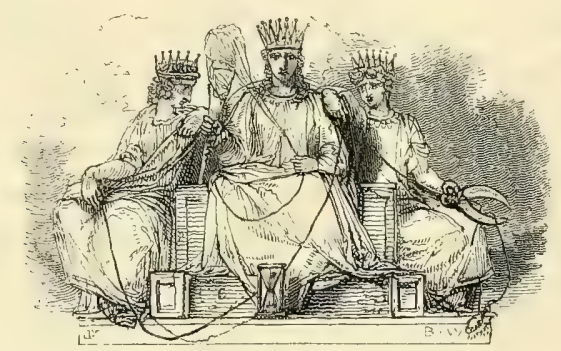




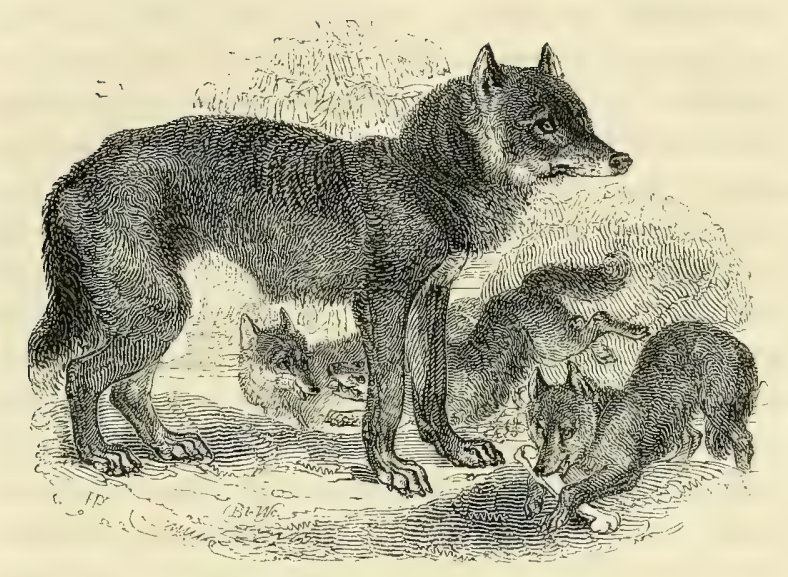

THE WOLF.

Canis lupus. Linn,

'THis sullen and forbidding-looking, animal, the most ravenous and ferocious that infests the more temperate regions of the earth, of many parts of which he is the terror and the scourge, is distinguished from the humble, generous, and faithful friend of man, the domestic dog, by no very remarkable or striking character; and yet there is something in his physiognomy, gait, and habit, which is at once so peculiar and so repulsive, that it would be almost impossible to confound a Wolf, however tame, with the most savage and the most wolflike of dogs. For the separation of the two species, Linnæus, as we have seen in the preceding article, had recourse to 
the tail; and having determined that that of the dog was uniformly curved upwards, he attributed to that of the Wolf a completely opposite direction, that is to say, a curvature inwards; assigning, at the same time, a straight or a deflected position to those of all the other animals of the group. The deflected, or down-pointing, direction is, however, equally common in the Wolf with the incurved; and this petty distinction, which has little to do with structure, and still less with habits, is hardly deserving of serious attention. More obvious and more essential differences will be found in the cast of his countenance, which derives a peculiar expression from the obliquity of his eyes; in the breadth of his head, suddenly contracting into a slender and pointed muzzle; in the size and power of his teeth, which are comparatively greater than those of any dog of equal stature; in the stiffness and want of pliability of his limbs; in his uniformly straight and pointed ears; and in a black stripe which almost constantly, and in nearly every variety of the species, occupies the front of the fore leg of the adult. His fur, which differs considerably in texture and colour, from the influence of climate and of seasons, is commonly of a grayish yellow, the shades of which are variously intermingled; as he advances in age it becomes lighter, and in high northern latitudes frequently turns completely white, a change which also takes place in many other animals inhabiting the polar regions.

Entirely dependent upon rapine for his subsistence, the nose of the Wolf is fully equal to that of the sharpest-scented hound. The size and speed of the elk and of the stag are insufficient to protect them from his violence; he pursues them with equal swiftness and 
cunning, and, when he has succeeded in running them down, finds little difficulty in rendering them his prey. To effect this purpose with the greater certainty he frequently unites himself with a numerous train of his fellows, who are however bound together by no other tie than the common object of their pursuit; and when this is once attained immediately separate and proceed each to his own retreat, whence they again emerge to reunite in the common cause whenever the necessary stimulus is supplied. In inhabited countries he seldom ventures to show himself openly or in packs, but sleeps away the greater part of the day in the shelter of the forest, and only prowls abroad by night when impelled by the cravings of his appetite. The sheep-cote and the farm-yard become then the scenes of his ravages; and such is his ingenuity, and so great the rapidity of his motions, that he will frequently carry of his prey almost before the eyes of the shepherd, although the warning voice of the watchful dog had given timely notice of the approach of the marauder. His ferocity is sometimes carried to such a pitch that he becomes dangerous to man; and when hard pressed by famine, to which in spite of all his skill in the chase and his sagacity in the pursuit of meaner rapine he is by no means a stranger, he will fall at unawares upon the solitary and unprotected traveller, or, prowling about the habitation of the villager, carry off from it his unsuspecting and defenceless children.

Happily for England this formidable beast has long been extirpated from its woods; but the comparative extent of his domain has been thereby but little reduced. It may be roughly stated as comprehending the whole 
northern hemisphere, of which only very small portions are exempted from his ravages. $\mathrm{He}$ is easily tamed when young, and may even (according to M. F. Cuvier; who has published a history of a domesticated individual bordering in many particulars very closely on the marvellous, but of the truth of which the well known character of that scientific naturalist is a sufficient guarantee) be rendered susceptible of the highest degree of attachment to his master, whom he will remember after prolonged and repeated absence, and caress with all the familiar fondness of a $\log$. Such traits as this are; however, to say the least, very uncommon; and he is, even in captivity, generally speaking, ill tempered and morose. The old male, the father of the litter now in the Tower, was extremely savage; the female, on the contrary, is very tame, and, which is more remarkable; continued so even during the period of suckling her young, which were five in number. Neither before, at, nor after this period did her temper undergo any change: she suffered her keepers to handle her cubs, of which she was excessively fond, and even to remove them from the den, without evincing the smallest symptom either of anger or alarm.

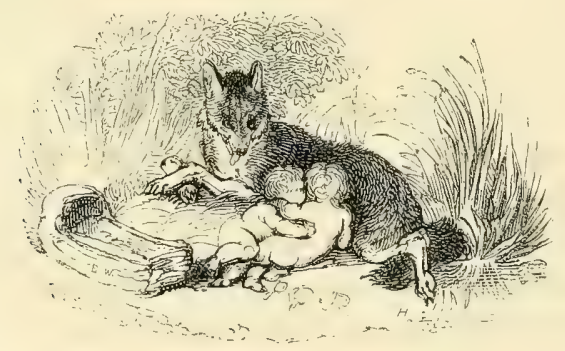




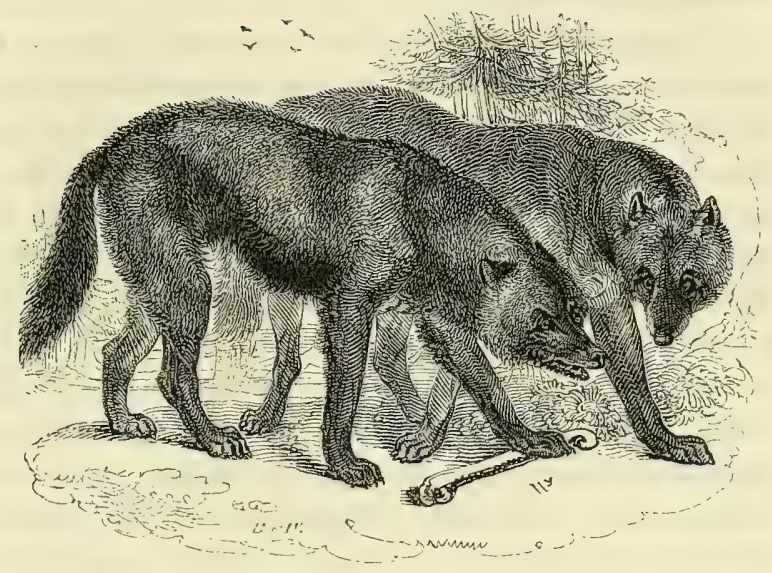

THE CLOUDED BLACK WOLF.

Canis nubilus. Say.

To distinguish between the numerous races of Wolves which are scattered more or less abundantly over nearly the entire surface of the earth; to determine that such and such variations are the result of original formation, and that such and such others are merely the product of accidental circumstances; in other words, to establish clear and tangible grounds of specific distinction between animals so varied in external appearance, but corres: ponding so perfectly in every essential particular, while the shades of character by which they differ, although in many cases strikingly marked, are for the most part so unimportant, or so little permanent, as scarcely to be 
deserving of notice,-is unquestionably one of the most difficult problems, to the solution of which the zoologist has to apply himself.

In internal and anatomical structure, on which modern naturalists are agreed that the greatest reliance ought to be placed in the distinction of closely approximating species, there is in the various races of Wolves no deviation from the common type of sufficient importance to warrant their separation from each other; neither does their outward form, excepting only in size and in the comparative measurement of parts, differ in any remarkable degree. In colour it is true that the most striking variations are observable, their hair exhibiting almost every intermediate shade between the opposite extremes of black and white. But it must be obvious that on this character, taken by itself, it would be absurd to insist as a ground of specific distinction, when we reflect on the influence which climate and other external accidents must necessarily exercise on animals so extensively dispersed, and so variously circumstanced.

There are, however, strong grounds for believing that the fine pair of animals, whose portraits are prefixed to the present article, exhibit real and substantial marks of distinction of sufficient value to sanction their separation from the other species. Considerably larger and more robust than the Common Wolf, and differing greatly in the expression of their physiognomy, neither in figure nor in countenance are they remarkable for that starved and gaunt appearance which is the common and well known attribute of the latter. In fact, they have altogether a more fierce and formidable, but at the same time a more noble and less sinister, aspect. Their hair, 
which is of considerable length, especially along the middle of the back and shoulders, where it forms a sort of indistinct and scattered mane, is mottled with various shades of black, gray, and white, giving to the whole animal that dark and clouded colour which constitutes one of its most peculiar and striking characteristics. The colouring, which, on the upper parts of the body, is deep black, becomes somewhat lighter on the sides, and assumes a yet lighter shade beneath : the chin and angles of the mouth are nearly white; the gray tinge predominating over the darker shades in various other parts, but by no means in so regular a manner as to merit a particular description. The ears are remarkably short; and the tail is also somewhat shorter in proportion than that of the common wolf, not reaching, in its solid form, beneath the posterior bend (which in all these animals is formed by the heel) of the hind legs.

The animals ai present in the Tower, the only individuals of this species that have been brought alive to Europe, were presented about four years since by the Hudson's Bay Company, by some of whose hunters they had been trapped in the northern regions of America. A fine skin of the same species was brought home by the late overland expedition to those countries, under the command of Captain Franklin, and presented to the Museum of the Zoological Society. There is also another instance of its occurrence recorded in the capture of a solitary specimen, in the Missouri territory; by the party engaged in Major Long's expedition from Pittsburgh to the Rocky Mountains. This specimen was accurately described, in the notes to the published narrative of that expedition, by Mr. Say, who at once recognised it as a 
distinct species, and affixed to it the scientific name which we have adopted without hesitation for these animals, with the most striking peculiarities of which his description coincides in every essential particular.

Their habits in a state of nature are, in all probability, perfectly similar to those which characterize their immediate neighbours, from which, in captivity, they differ in no remarkable degree. Like the common kind, they are exceedingly voracious, tearing their meat and swallowing it in large gobbets, and afterwards gnawing the bones (for which they frequently quarrel) with truly wolvish avidity. Although they have been so long confined, they retain their original ferocity undiminished: a circumstance, it may be mentioned by the way, which has prevented us from giving their measurement. Judging, however, from the eye, we may confidently venture to assert that their size, especially that of the male, is considerably superior to that of the specimen described by $\mathrm{Mr}$. Say, which measured about four feet and a quarter from the tip of the nose to the origin of the tail.

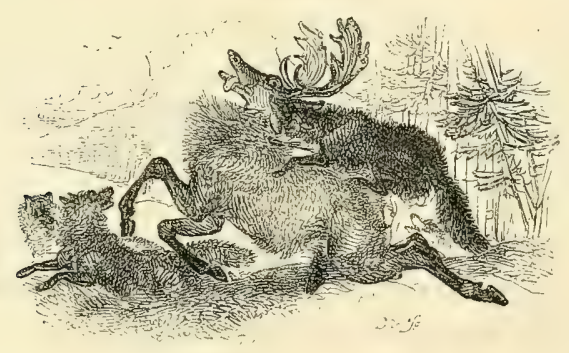




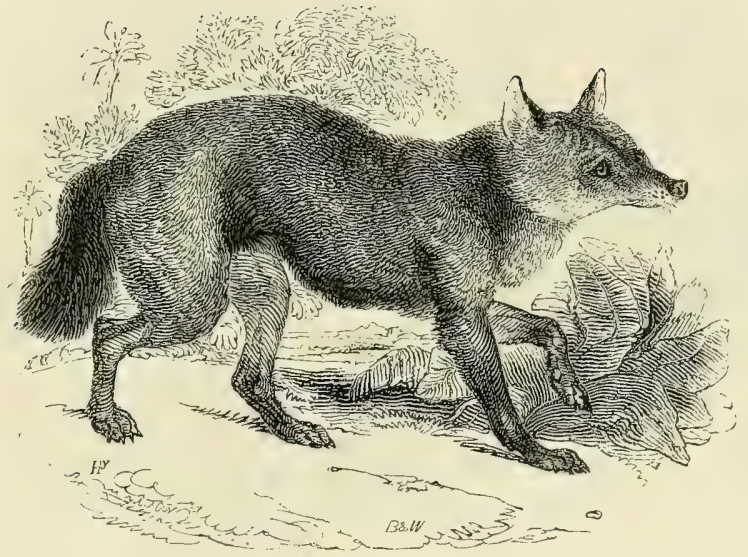

THE JACKAL.

CANIS AUREUS. LINN.

The Jackal, one of the greatest pests of the countries which he inhabits, is spread over nearly the whole of Asia and the north of Africa, occupying in the warmer regions of those continents the place of the Wolf, of whom in many particulars he may be considered as offering a miniature resemblance. In size he is about equal to the common fox, but he differs from that equally troublesome animal in the form of the pupils of his eyes, which correspond with those of the dog and of the wolf, in the comparative shortness of his legs and muzzle, in his, less tufted and bushy tail, and in the peculiar marking of his coat. The colouring of his back and sides consists 
of a mixture of gray and black, which is abruptly and strikingly distinguished from the deep and uniform tawny of his shoulders, haunches, and legs : his head is nearly of the same mixed shade with the upper surface of his body, as is also the greater part of his tail, which latter, however, becomes black towards its extremity; his neck and throat are whitish, and the under surface of his body is distinguished by a paler hue.

Unlike the wolf or the fox, he always associates himself with his species in numerous troops, which burrow together in the earth, hunt in concert, and act in conjunction for their mutual defence. These bands not only prey upon the smaller quadrupeds and domestic poultry, but, emboldened by their numbers, give chase to and attack the larger animals. They frequently follow in the train of more noble beasts, and make their meal off the remains of the carcases which have been half devoured by the Lion or the Tiger. When taken they become almost immediately tame and docile; offering no resistance and evincing no signs of ferocity. The specimen in the Tower is remarkably quiet; it is a male, and has been a resident for upwards of three years.

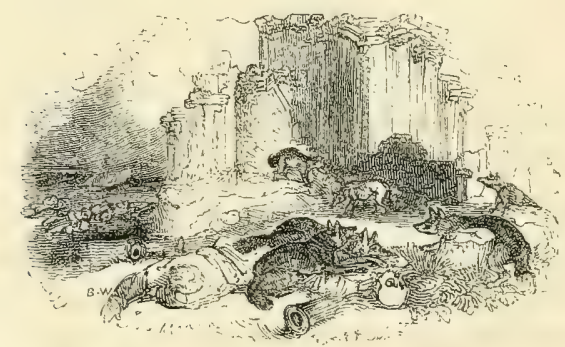




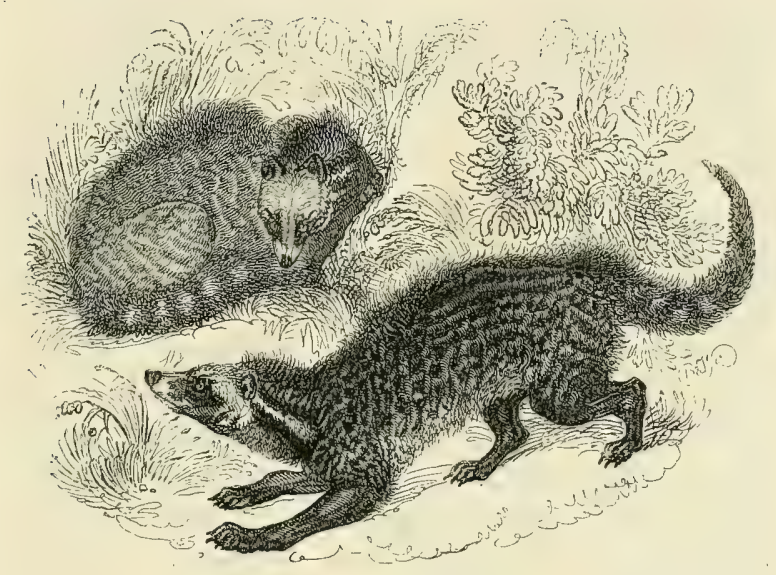

THE CIVET, OR MUSK CAT.

Viverra CiVetTa. Linn.

THE group of animals to which we have next to turn our attention is perhaps the most puzzling, and certainly the least understood, among the true Carnivora; hence there exists no little difficulty in defining its limits and distinguishing the species which compose it: Under the generic name of Viverra, Linnæus comprehended a series, or; to speak more properly, a congeries; of quadrupeds, differing from each other so remarkably in form, in structure; and in habits; as to render it absolutely impossible to find characters by which they might be circumscribed and isolated from their fellows. His definition of the genus therefore, although purposely 
expressed in terms the most vague and indistinct, neither excludes such animals as from their obvious affinities he could not refrain from referring to other groups, nor includes full one half of the species which he has arranged beneath it. The Ichneumon of the Nile, the Suricate of the Cape, the Coati of South America, the Stinking Weasels of the North, the Civet of Barbary, the Genette of the East, the Ratel of South Africa, and others equally distant in affinity, were sweepingly compelled into this ample receptacle, which was converted into a genuine "refuge for the houseless," in which every carnivorous quadruped, known, unknown, or imperfectly known, that appeared to be without a place elsewhere, was charitably afforded a temporary asylum.

In this arrangement, which brought animals truly digitigrade, with retractile claws, tongues covered with sharp papillæ, canine teeth of great power, and molars formed for tearing flesh, consequently in a high degree sanguinary and carnivorous in their habits, into close and intimate contact with others, which are positively plantigrade, with exserted claws, smooth tongues, and teeth of little power and evidently incapable of lacerating animal food, and which are therefore in all cases more or less, and in several instances wholly, vegetable eaters, it was impossible for naturalists long to coincide. The genus thus formed presented so heterogeneous a combination, that the difficulty was rather where to stop in the dispersion of the dissimilar materials of which it was composed, than where to commence the necessary operation; and in consequence nearly a dozen genera, not hanging together in one continued series, but scattered through various parts of the system, and most of them 
essentially distinct, have been the result of the dismemberment of this single group.

The true Civets, to which the genus Viverra is now restricted, yield in the extent of their carnivorous propensities to the cats alone, whom they approach very closely in many points of their zoological character, as well as in their predatory, sanguinary, and nocturnal habits. In addition to the six incisors and two canines, which are common to the whole of the true Carnivora, they have on each side and in each jaw six molars, one of which is peculiarly adapted for lacerating flesh, while the rest are more or less of the ordinary form. Their tongues are furnished with the same elevated and pointed papillæ which give so remarkable an asperity to those of the cats; and their claws are half retractile. The toes are five in number on each of the feet, and their extremities alone are applied to the ground in walking; the animals are consequently completely digitigrade. But the most distinctive character of the group consists in an opening near the tail, leading into a double cavity of considerable size, furnished with glands and follicles for the secretion of the peculiar odoriferous substance so well known as the produce of the Civet, and from which the animal derives his name.

The present species is from two to three feet in length, exclusive of the tail, which is nearly half as much more; and stands from ten to twelve inches high. His body, which is more elongated in its form than that of any of the animals hitherto described, is covered with long hair, the ground colour of which is of a brownish gray intermingled with numerous transverse interrupted bands or irregular spots of black. A series of longer hairs of the latter colour occupy the middle line of the back, from 
between the shoulders to the extremity of the tail, and form a kind of mane, which may be raised or depressed at pleasure. The legs and greater part of the tail are perfectly black, and the upper lip and sides of the neck nearly white. A large patch of black surrounds each eye, and passes from it to the angle of the mouth; and two or three other bands of the same colour pass obliquely from the base of the ears towards the shoulder and neck, the latter of which is marked by a broad black patch.

In his natural habits the Civet closely resembles the fox and the less powerful species of cats, subsisting by rapine, and attacking the birds and smaller quadrupeds, which form his principal food, rather by night and by surprise than by open force and in the face of day: reduced to a state of captivity, he becomes moderately tame, but not sufficiently so to allow himself to be handled with impunity. In many parts of Northern Africa large numbers of them are kept for the purpose of obtaining their perfume, which bears a high price and is much esteemed. The individual sketched above is a male of large size, and remarkable for never having deposited any of the perfume, although for more than twelve months an inhabitant of the Menagerie.

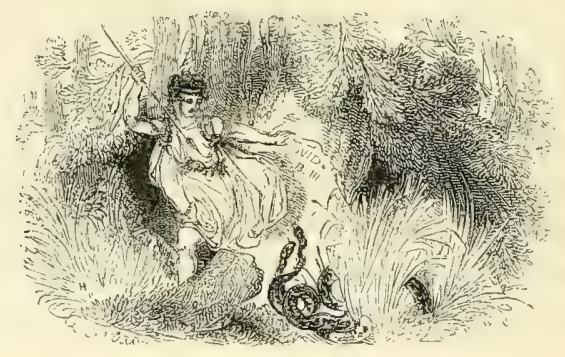




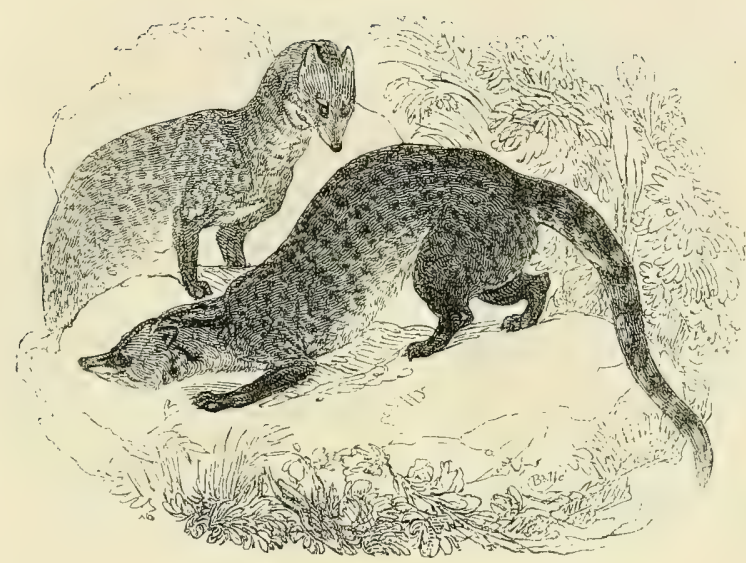

\section{THE JAVANESE CIVET.}

Viverra Rasse. Horsf.

THE present species is remarkably distinct from the preceding both in form and colour. Its ground is of a much lighter gray, on which it offers a broad longitudinal dorsal line of black, and two or three narrower ones of the same colour on each side, composed of confluent spots. These spots are also thickly but somewhat irregularly scattered over the rest of the body, and may be considered as forming a series of flexuous dotted lines. The legs are black externally; and the head is grayish and without spots. A deep longitudinal black line occupies the side of the neck above, and a second more oblique is placed below. The body, which is from fifteen to eighteen inches in length, is narrow and com- 
pressed, and more elevated behind than before; the back is strongly arched. The line of the profile is perfectly straight, the muzzle narrow and tapering, and the ears short and rounded. The tail is of equal length with the body, and tapers gradually to the tip; it is marked with eight or nine broad rings of black, alternating with an equal number of grayish.

Like the other animals of its group, its habits are predatory; in confinement it retains much of its original ferocity, and is extremely spiteful and savage. The two individuals from which our figure was taken have inhabited the Menagerie for nearly twelve months; they are both males, and occupy different dens. They are fed, like the preceding, and indeed like all the carnivorous quadrupeds which it remains to mention, on a mixture of vegetable and animal food; and deposit large quantities of civet, which strongly impregnates the air of the apartment in which they are kept. This perfume is highly esteemed by the Javanese, who apply it not only to their dresses, but also to their persons. Even the apartments and furniture of the natives of rank are generally scented with it to such a degree as to be offensive to Europeans.

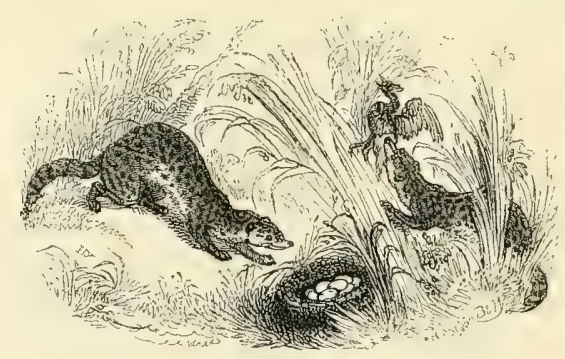




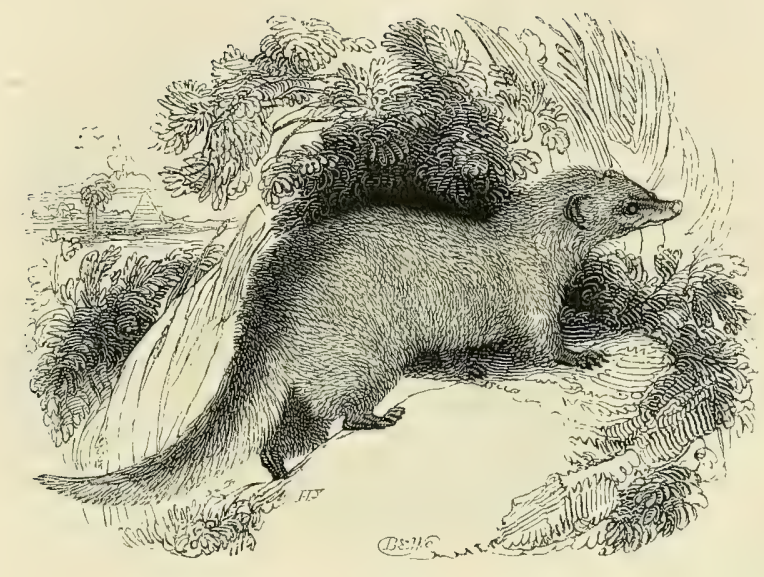

THE GRAY ICHNEUMON.

ICHNEUMON GRISEUS. GEOFF.

From the Civets, to which it closely approaches in the number and in some degree also in the form of its teeth, in the asperity of its tongue, and in the semi-retractility of its claws, the group of which the Egyptian Ichneumon forms the type is distinguished by its narrower and more pointed muzzle, by the shortness of its lower lip, and more especially by the absence of the double cavity beneath the tail, which is replaced by a single pouch of considerable size, but destitute of secreting glands. Their hair is long, crisp, brittle, and always more or less variegated in colour, in consequence of each separate hair being marked by alternate rings of different shades.

The colour of the species now before us, which is a 
native of India, is a pale gray, the hairs being for the most part of a dirty yellowish white, relieved towards their extremities by narrow rings of brown. The head and limbs are darker than the rest of the body.

The habits of the Ichneumons are very similar to those of the ferret. In the localities where they ábound, their sanguinary disposition and predatory inclinations render them a real pest to the farm-yard, to which they pay their nocturnal visits for the purpose of destroying the poultry. They also make war upon rats, birds, and reptiles, and devour the eggs of the latter with the greatest avidity. Endowed with a remarkable degree of courage in proportion to their size, they do not hesitate to attack any animal that is not obviously more than a match for them. Even in captivity they retain much of their native spirit; and so great is their activity and determination that the individual now in the Tower actually on one occasion killed no fewer than a dozen full grown rats, which were loosed to it in a room sixteen feet square, in less than a minute and a half. They are very easily tamed, become attached to those with whom they are familiar and to the house in which they live, and will follow their master about almost like a dog.

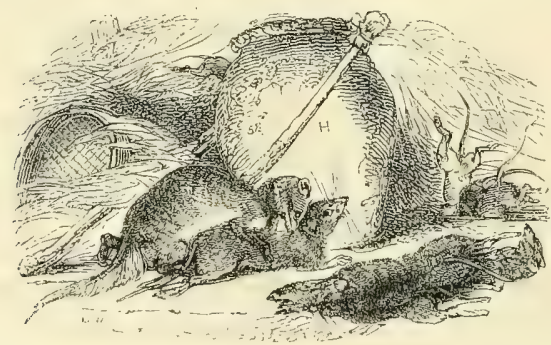




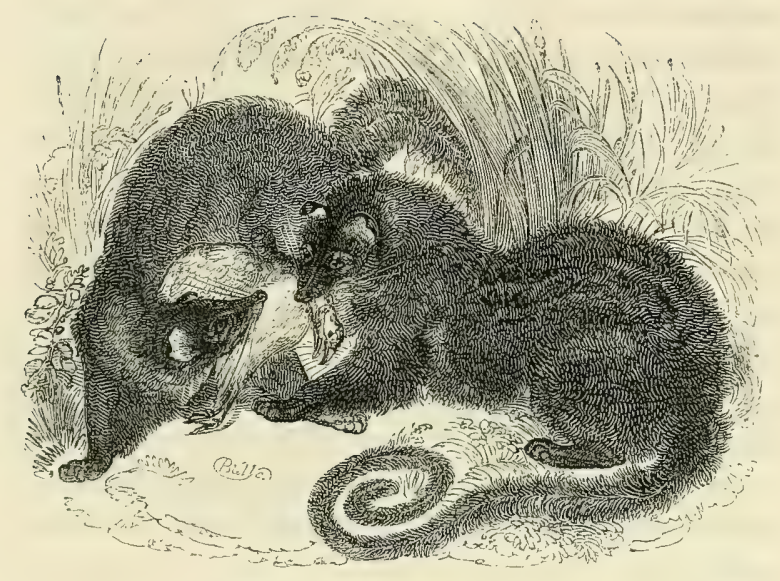

THE.PARADOXURUS.

Paradoxurus typus. F. Cuv.

Although the division of the true Carnivora into digitigrade and plantigrade is in many respects objectionable, we feel compelled, in conformity with established rules, to remove the animal before us from its most obvious affinities, to arrange it among the latter; placing it, however, at the commencement of that division and nearly in contact with the viverrine groups, to which it is so intimately allied, as to have been actually confounded by Buffon with the common Genette; a mistake, which was first clearly pointed out by M. F. Cuvier, but which has obtained so generally among naturalists, that the Paradoxurus is still commonly exhibited under that erroneous name. From the Genettes and Civets it differs 
little in its general form and habits; its teeth are nearly similar; and its toes and nails closely correspond in number and in their degree of retractility. But it is entirely destitute of the secretory pouch; and, in addition to its plantigrade walk, it exhibits a very peculiar structure in the tail. This organ is as long as the body, and flattened above and below; when extended, the further half is turned over so as to place its lower side uppermost, and the animal has it in its power to roll it up into a spire, commencing from above downwards, to the very base.

The colour of the species varies in different lights: in general it may be described as grayish black, with a tinge of yellow. On this ground it is marked with one broad dorsal, and on each side two or three narrower, indistinct black lines. The under jaw, the legs, and the greater part of the tail are entirely black; and there is a whitish spot above and under each of its eyes.

India and the larger Asiatic Islands appear to be its native country; but nothing certain is known of its habits in a state of nature: in captivity it is sullen and irascible, and evinces no affection for its keeper, appearing in fact totally insensible to the attentions which it receives.

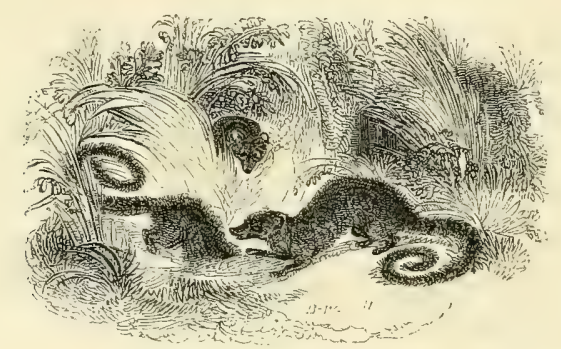




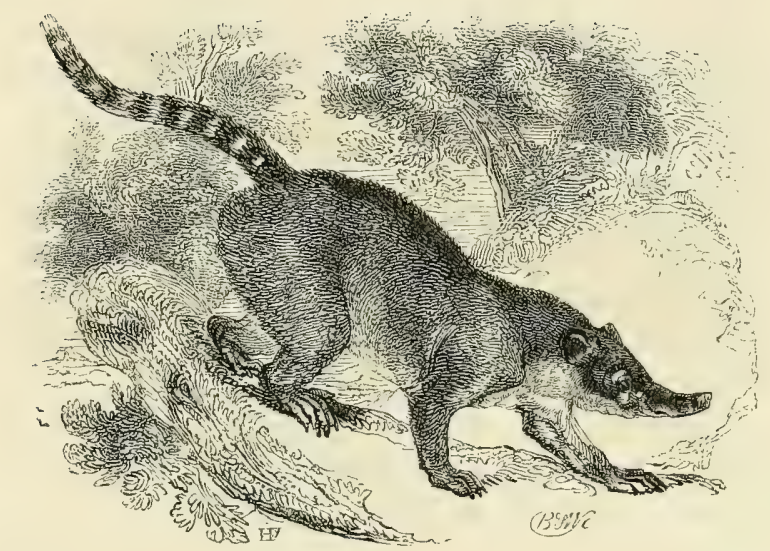

\section{THE BROWN COATT.}

\section{NASUA NARICA. F. Cuv.}

THE characters of the genus to which this curious little animal belongs resemble so closely in the most important particulars those of the other plantigrade Carnivora, that it will here be sufficient to explain those points alone in which the Coatis differ from their immediate affinities. From the Bears they are essentially distinguished by the general form of their body, which in some measure approaches that of the viverrine group; by their physiognomy, which is altogether peculiar, and by their elongated tail, which is nearly equal in length to their body. From the Racoons their generally lengthened form, and especially that of the snout, which is 
in fact their most obvious and striking characteristic, are fully sufficient to distinguish them. In the Coatis this organ is produced in a most remarkable degree; and it is terminated by a muzzle so extremely flexible that, when the attention of the animal is excited, it is kept in constant action and moved about in all directions.

The Coatis are barely equal in size to the common fox: they inhabit the woods of 'South America, and live upon fruits, insects, and reptiles; climbing trees in pursuit of their prey with great agility. In captivity they are easily tamed, and are fond of being caressed; but exhibit no peculiar symptoms of attachment.

Three supposed species have been described; but naturalists in general are at present inclined to admit of no more than two; and even with regard to these we have yet no sufficient proof that they are really more than strongly marked varieties. The one from which our figure was taken belongs to the brown kind, which is distinguished from the other chiefly by its darker colour both above and below, and by the blackness of the sides of its snout. The tails of both species are usually encircled by rings alternately black and fulvous; and each has the eye surrounded by three white spots.

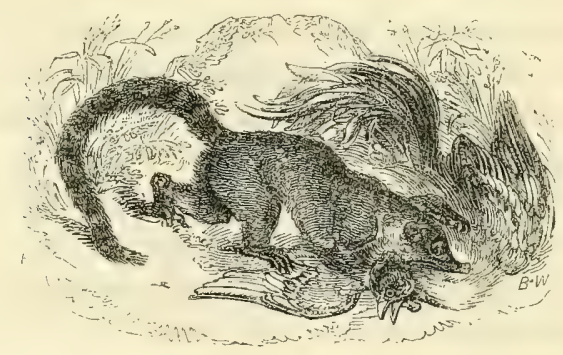




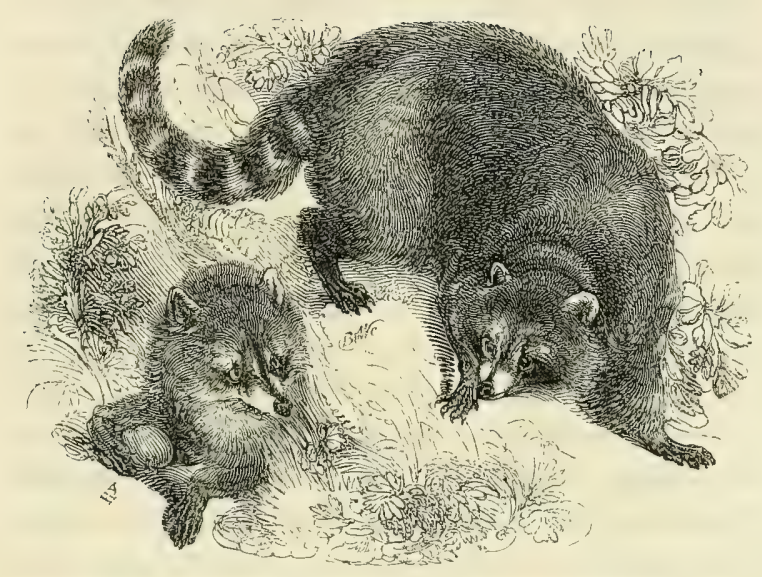

\section{THE RACOON.}

Procyon Lotor. Cuv.

LARger in size and more robust in stature than the Coatis, and approximating still more closely in their physical characters to the Bears, which may be considered as the typical group of the plantigrade Carnivora, the Racoons naturally occupy an intermediate station between the playful, timid, and harmless little creatures just noticed, and the powerful, clumsy, and dangerous animals next to be described. Like both Bears and Coatis they have in each jaw six sharp incisors, two strong canines, and twelve cheek teeth, six on each side. But these latter differ from those of the Bears, inasmuch as the whole six form a regular series, the three anterior 
ones of which are small and pointed, and the three posterior broad and surmounted by prominent and blunted tubercles; while in the Bears the three anterior appear rather to form a supplemental appendage, being placed irregularly and at unequal distances, and not unfrequently falling out altogether as the animal advances in age: the tubercles on the crowns of the posterior ones are also much less strongly marked. The Coatis exhibit nearly the same mode of dentition as the Racoons; but striking marks of distinction between them are afforded by the comparative length of the tail, which in the latter is scarcely half as long as the body; and by that of the snout, which, instead of being prolonged into an extensible muzzle, capable of being moved about in all directions, as in the Coatis, is scarcely produced beyond the lower lip, and has very little motion. The strongly marked difference in physiognomy arising from this circumstance is increased by the width of the head posteriorly, which is so great as to give to the general outline of the face of the Racoons the form of a nearly equilateral triangle. Their ears are of moderate length, upright and rounded at the tip; their legs strikingly contrast in their slender and graceful form with the strong and muscular limbs of the Bears; and their nails, five in number on each of the feet, are long, pointed, and of considerable strength. The whole body is clothed with long, thick, and soft hair; and its general shape, notwithstanding its intimate connexion with the Bears, and its short and thickset proportions, is not without a certain degree of elegance and lightness.

The Racoons are natives of America, and the species which has been most frequently observed by naturalists, 
and which we are now to describe, is most fiequent in the northern division of that continent. Indeed it may admit of doubt whether it ever advances further south than the Isthmus of Darien, the animal described by M. D'Azara as identical with it being evidently a distinct species. Its fur is usually of a deep grayish black, resulting from the intermixture of those two colours in successive rings on each individual hair. The shades of colour vary on different parts of the body, and are as usual much lighter below and on the inside of the legs. The face, which is nearly white, is surrounded bv a black band of unequal breadth, passing across the forehead, encircling the eyes, and descending obliquely on each side towards the angle of the jaw. The whiskers are of moderate length; and the hair of the face generally, as well as of the legs, is short and smooth. The tail, which is thick at the base, tapering gradually to the tip, and covered with long hairs, has five or six brownish rings, alternating with an equal number of the lighter colour which is prevalent on the lower parts of the body.

All that we know of their habits in a state of nature may be comprehended in the single fact, that, in addition to the vegetable substances, and more particularly fruits, which form the principal part of their subsistence, they feed on the eggs of birds, and even on the birds themselves, their agility and the structure of their claws affording them the means of reaching the tops of the tallest trees with quickness and facility. In captivity they are easily tamed, and even appear susceptible of some degree of attachment; but they never entirely lose their sentiment of independence, and are consequently incapable of complete domestication. When placed 
under a certain degree of restraint they appear contented and happy, are fond of play, and take pleasure in the caresses of their friends, and even of strangers; but however long this kind of domestication may have continued, and how much soever they may seem reconciled to their confinement, the moment the restraint is withdrawn and they feel themselves again at liberty, the love of freedom prevails over every other consideration, and they become as wild as if they had never been reclaimed. In eating, they commonly support themselves on their hind legs, and carry their food to the mouth between their fore paws, having first plunged it in water, if the liquid element, of which they are remarkably fond, is within reach. This singular peculiarity, the object of which is not very obvious, but from which the animal derives his specific name, does not, however, appear to be constant and uniform, being frequently entirely neglected. The same may be said of their fondness for shell-fish and mollusca, for which they are generally stated to have a great partiality; some of them, like the handsome pair now living in the Menagerie, displaying the greatest address and dexterity in opening the shell of an oyster, and extracting its contents, while others absolutely refuse to touch it.

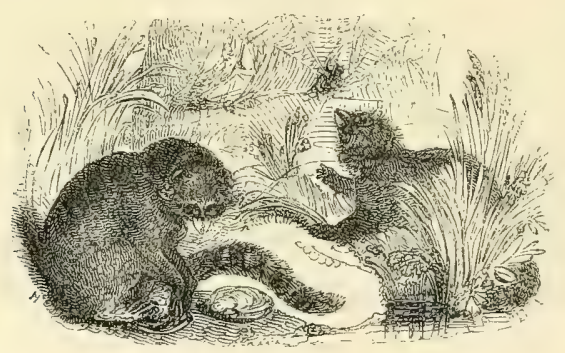




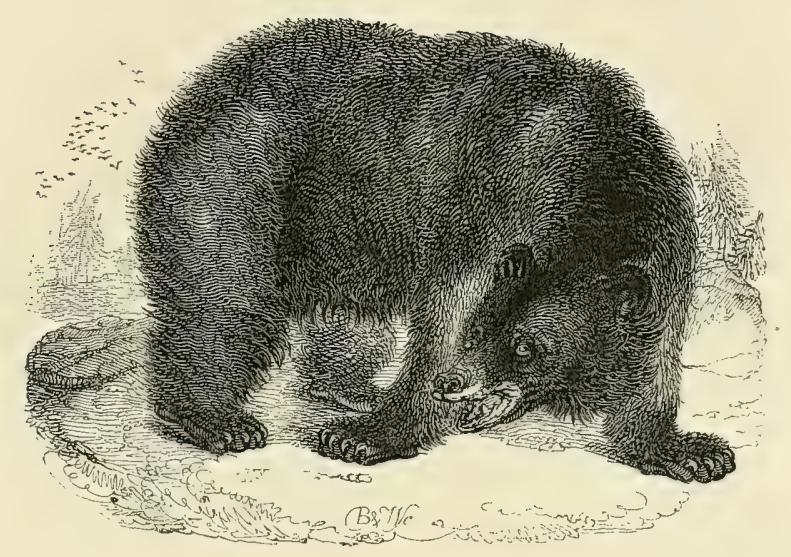

THE AMERICAN BLACK BEAR.

Ursus americanus. Pallas.

WE have now arrived at the closing group of the true Carnivora; a group which, although less sanguinary in its habits than almost any of those which we have hitherto had occasion to notice, and endowed by nature with a capacity of subsisting entirely on vegetable substances, comprehends nevertheless, among the closely allied species of which it is composed, not merely the largest, but even some of the most formidable, of the carnivorous Mammalia.

Both in outward shape and internal characters, these clumsy, sluggish, and uncouth animals offer a perfect contrast to the light, active, and elegant forms of the 
tribe with which we commenced our series. Instead of the compressed and lengthened body, with its soft, sleek, and variegated covering, and the long and graceful tail by which it is terminated, we have a broad, awkward, and thickset figure, covered with a rough, shaggy, and unattractive fur, and ending in a scarcely visible appendage, serving neither for ornament nor use. The difference in gait and motion is as remarkable as that of shape; for while the one glides gently along, as it were on tiptoe, or bounds onwards with the velocity of thought, the other appears to be oppressed by the weight of his ponderous and unwieldy bulk, and supporting himself on the full expansion of his dilated paws, scarcely moves without the semblance of an effort. The short and rounded jaws of the cats, with their close and regular series of powerful cutting and lacerating teeth, and their rough and rasplike tongue, are supplied by a broad and lengthened snout, teeth of a character totally different in almost every essential point, and a soft, smooth, and extensible tongue. The claws too, which in the cats are strongly curved, exceedingly sharp at their edges, tapering gradually to a fine point, and capable of being entirely retracted within their sheaths, are here indeed of great power, and sometimes even considerably arched, but rounded in their surfaces, more or less blunted at their extremities, and constantly protruded to their full extent. In this manner might the contrast be pursued through almost every organ; but our limits warn us that we must at once proceed to the enumeration of the essential characters which combine the Bears into a well marked group.

These characters are derived, first, from their com- 
pletely plantigrade walk, the whole sole being at all times closely applied to the surface on which they tread; secondly, from their claws, of which they have five on each foot; thirdly, from the extreme shortness of their tail ; and lastly, from the form and arrangement of their teeth. These consist of the usual number of incisors and canines, the latter being in general yery robust, and of a series of molars, which, when complete, amount to six on each side in each jaw; the posterior three having flat and expanded surfaces surmounted by broad and blunted tubercles, and lying closely in contact with each other. Between them and the canines exists a considerable space, which is or should be occupied by three smaller and obtusely pointed teeth; but this number is seldom found entire, one or more of them being generally absent, and the series being thus rendered incomplete.

The Black Bear of America is distinguished from his fellows, and more especially from the brown bear of Europe, which he approaches most nearly in size and form, by few very striking external differences, except the colour of his fur. His forehead has a slight elevation; his muzzle is elongated, and somewhat flattened above; and his hair, though long and straight, has less shagginess than that of most of the other species of the group. In colour it is of a uniform shining jet-black, except on the muzzle, where it is short and fawn-coloured, becoming almost gray on the lips and sides of the mouth. This, however, it should be observed, is the character only of the full-grown animal: the young are first of a bright ash colour, which gradually changes to a deep 
brown, and finally fixes in the glossy black tint of mature age.

The habits and manners of the Black Bear resemble those of the brown almost as closely as his physical characters. In a state of nature he seeks the recesses of the forest, and passes his solitary life in wild and uncultivated deserts, far from the society of man, and avoiding even that of the animal creation. His usual food consists of the young shoots of vegetables, of their roots, which he digs up with his strong and arcuated claws, and of their fruits, which he obtains by means of the facility with which the same organs enable him to climb the loftiest trees. He possesses indeed the faculty of climbing in a most extraordinary degree, and frequently exercises it in the pursuit of honey, of which he is passionately fond. When all these resources fail him, he will attack the smaller quadrupeds, and sometimes even animals of considerable size; familiarity with danger diminishing his natural timidity, and the use of flesh begetting a taste for its continued enjoyment. 'He is also said, like the Polar Bear, to have a peculiar fondness for fish, and is frequently met with on the borders of lakes and on the coast of the sea, to which he has resorted for the gratification of this appetite. Notwithstanding his apparent clumsiness, he swims with the greatest dexterity, the excessive quantity of fat with which he is loaded serving to buoy him up in the water; in this way he frequently crosses the broadest rivers, or even very considerable arms of the sea.

The entire continent of North America, or perhaps it might be more correct to say, that immense portion of 
its surface which still remains uncultivated and desolate, furnishes an abode to this species of bear, which is consequently as widely dispersed as any of his tribe. As his fur is of some value in commerce, although not so much sought after at the present day as it was formerly, his race has become an object of the cupidity of man, by whom they are frequently hunted for the sake of their skins. This chase is principally followed by the Indians, who are also attracted by the flavour of his flesh, of which, and especially of the fat, they partake with an avidity truly disgusting. Travellers, however, who have been reduced to the necessity of having recourse to this sort of food, speak of it as by no means despicable: the fat yields moreover a quantity of oil, which is often extremely serviceable. The Indians will sometimes attack these animals single-handed; and if they can manage to keep beyond the reach of their powerful grasp, which is almost irresistible, are sure of gaining the victory; as the bears, in the rampant posture which they always assume in self-defence, unconsciously expose their most vulnerable parts to the attack of the hunter. Snares are sometimes laid for them; but these are most fiequently unsuccessful; that extreme caution, which is so strongly pourtrayed in their actions and demeanour, rendering them mistrustful of every thing. Nevertheless their gluttony will sometimes get the better of their prudence, and the bait of honey offers too tempting an allurement to be always resisted. At other times a whole tribe of Indians will assemble for the chase, and after having performed a variety of superstitious observances, beat the entire country for their game, drive a great number of them into a spot selected 
for the purpose, and deal forth upon them wholesale destruction. They will also trace them to their retreats in the season of their lethargy, which occupies several of the winter months, and during which the bears are incapable of offering any effectual resistance.

In captivity the Black Bear is distinguished from the brown only by the less degree of docility and intelligence which he evinces: and the habits of the latter are so universally known that it would be useless to dwell upon them here. The specimen figured at the head of this article was presented to the Menagerie, in 1824, by Sir George Alderson, and is remarkably tame and playful. He has, until very lately, shared his den with the Hyæna, with whom he maintained a very good correspondence, except at meal-times, when they would frequently quarrel, in a very ludicrous manner, for a piece of beef, or whatever else might happen to furnish a bone of contention between them. The Hyæna, though by far the smallest of the two, was generally master; and the Bear would moan most piteously, and in a tone somewhat resembling the bleating of a sheep, while his companion quietly consumed the remainder of his dinner.

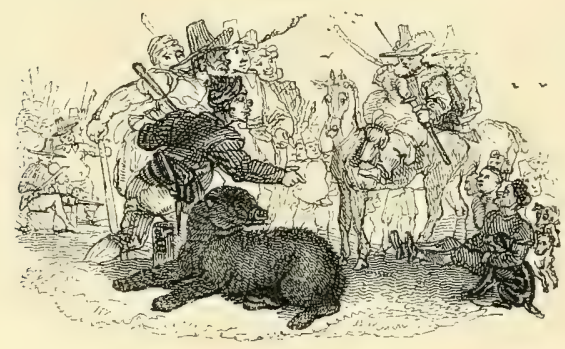




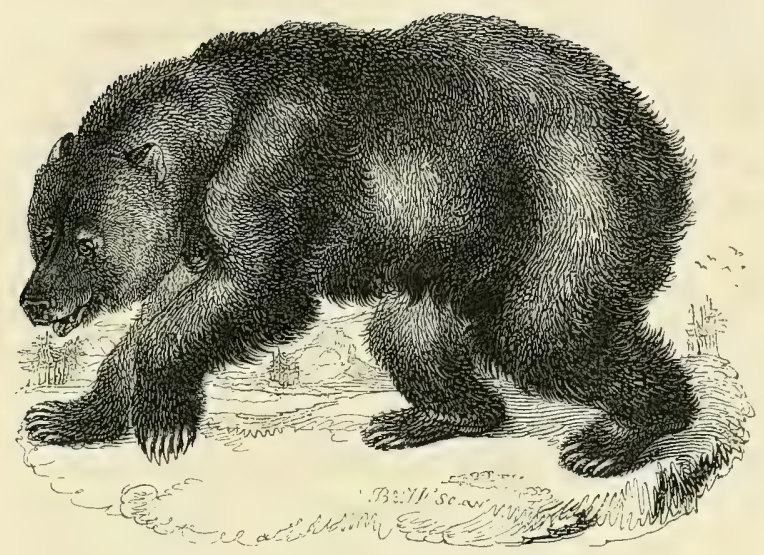

THE GRIZZLY BEAR.

Ursus ferox. Lewis and Clarke.

A Native also of the northern division of America, and more particularly of that extensive tract of country which constitutes the newly erected State of Missouri, the Grizzly Bear differs in many striking points, both of character and habits, from the subject of the preceding article, as well as from every other animal of the very natural group of which he forms part. By his elongated, narrowed, and flattened muzzle, added to the slight elevation of his forehead, he is closely connected with the Black Bear of America, and as remarkably distinguished from the common Brown Bear of Europe, and from the White Bear of the polar regions, which last, in 
size and general form, offers perhaps the nearest approximation to the present species. But his enormous magnitude, which may be stated as averaging twice the bulk of the Black Bear; the greatly increased size and power of his canine teeth; and, above all, the excessive length of his talons, on the fore feet especially, afford characteristic differences so obvious and so essential, that it is difficult to conceive how they could have been so long overlooked by naturalists as well as travellers, who have all, until within little more than twenty years of the present time, passed him over without even a casual hint that he presented any claims to be considered as distinct from the common species of his country.

His hair, generally speaking, is longer, finer, and more abundant than that of the Black Bear, and varies in colour to an almost indefinite extent, passing through all the intermediate shades between a light gray and a black brown. The brown tinge is, however, the most common; and it is always more or less grizzled either by the intermixture of grayish hairs, or by the brown hairs being tipped with gray. The hair of the legs and feet is darker and coarser, and diminishes in length as it descends; on the muzzle it becomes remarkably pale, and is so much shortened as to give to the animal an appearance of baldness. His eyes are very small and hardly at all prominent; and the line of the profile is consequently nearly straight. His tail is scarcely visible, being almost entirely concealed by the long hairs which surround it. Of the great size of his feet and talons, some judgment may be formed from the measurements given by Captains Lewis and Clarke, the first travellers by whom the Grizzly Bear was accurately described. 
These gentlemen inform us that the breadth of the fore foot in one of the individuals observed by them exceeded nine inches, while the length of his hind foot, exclusive of the talons, was eleven inches and three quarters, and its breadth seven inches. The claws of the fore feet of another specimen measured more than six inches. The latter are considerably longer and less curved than those of the hind feet, and do not narrow in a lateral direction as they approach their extremity, but diminish only from beneath: the point is consequently formed by the shelving of the inferior surface alone, their breadth remaining the same throughout the whole of their enormous length, and their power being proportionally increased; an admirable provision for enabling the animal to exercise to the fullest extent his propensity for digging up the ground, either in search of food or for other purposes. It appears, however, on the other hand, to unfit him for climbing trees, which he never attempts; and this remarkable circumstance in his habits affords a striking distinction between him and all the other Bears, which are essentially climbers.

Of all the quadrupeds which inhabit the northern regions of the American continent, the Grizzly Bear is unquestionably the most formidable and the most dreaded. Superior to the rest of his tribe, not excepting even the polar species, in bulk, in power, in agility, and in the ferocity of his disposition, it is not to be wondered at that he should be regarded by the native Indians with an almost superstitious terror, and that some portion of this feeling should have been communicated even to the civilized travellers, who have occasionally met with him in the wild and desolate regions which are subject to his devastations. In the Journals of some of these 
travellers we find recorded such astonishing instances of his strength, ferocity, and extraordinary tenacity of life as would indeed amaze us, were we not aware how much the human mind is prone, under certain circumstances, to fall into exaggeration, in many cases most certainly unintentional. Making, however, all due allowances for the existence of this very natural feeling, we are bound to acknowledge that there are few animals who can compete with this terrible beast; and that to be made the object of his pursuit is an occurrence well calculated to alarm the stoutest heart, even when provided with the most certain and deadly weapons of human invention, guided by the most experienced eye, and directed by the steadiest hand.

This tremendous animal appears to be most commonly found in the neighbourhood of the Rocky Mountains, especially on the well wooded plains which skirt the eastern declivity of that lofty and extensive range, among thick copses of brush and underwood, and on the banks of the water-courses which descend in innumerable petty streams from their sources in the hills. In these wild solitudes, rarely trodden by the foot of civilized man, and visited only by the savage Indians of the neighbouring tribes, who have not yet learned to bow the neck beneath the yoke of the exterminating conqueror, he reigns the almost undisputed tyrant of the forest. Few among the animals which share with him his barbarous habitation are fleet enough to escape him in the chase; and none, when fairly placed within his reach, are powerful enough to withstand his overwhelming force. Even the sturdy and formidable Bison, the wild bull of North America, is incapable of offering any effectual resistance to the furious impetuosity of his attack; and 
an illustration of the extent of his muscular power is afforded by the fact that after having destroyed his victim, he will drag its ponderous carcase to some convenient spot, where he will dig a pit for its reception, and deposit it for a season, returning to his feast from time to time as the calls of hunger may dictate, until his store is exhausted and he is again reduced to the necessity of looking abroad for a fresh supply.

But although endowed with so strong a propensity for animal food, as well as with the power to gratify the appetite thus grafted in his very nature, he is not, like the more perfect of the carnivorous tribe, left entirely dependent upon that which, in the climate in which he has been placed, must of necessity be a precarious, and frequently even an impossible, source of subsistence. Of a more fierce and sanguinary temper than the other bears, he does not hesitate to attack whatever living creature may fall in his way, and man himself seems to inspire him with little dread: but in the absence of his favourite food, he makes a less savoury, but equally congenial, meal of vegetable substances, of fruits, or more commonly of roots, the latter of which he digs up with the greatest facility with his enormous claws; and in some parts of the country these more simple productions form almost his sole subsistence. On the quality of his food depends much of the ferocity of his temper; for it appears that the bears of the western side of the Rocky Mountains, who live almost entirely upon vegetables, are of a much less fierce and savage disposition than their fellows of the eastern side, where animal food is more abundant and more easily procured.

Next to his great size and excessive ferocity, one of 
the most striking peculiarities of this animal is his extreme tenacity of life. For the instances of this we are indebted almost wholly to the narrative of the Travels of Captains Lewis and Clarke, whose statements are no doubt founded in truth, although it may be suspected that they require to be received with some grains at least of allowance. According to these gentlemen one bear which had received five shots in his lungs, and five other wounds in various parts of his body, swam a considerable distance to a sand bank in the river, and survived more than twenty minutes; another that had been shot through the centre of the lungs, pursued at full speed the man by whom the wound was inflicted for half a mile, then returned more than twice that distance, dug himself a bed two feet deep and five feet long, and was perfectly alive two hours after he received the wound; and a third, although actually shot through the heart, ran at his usual pace nearly a quarter of a mile before he fell. There is no chance, they add, of killing him by a single shot, unless the ball goes directly through the brain; a single hunter runs consequently no little risk in venturing to attack an animal upon whom the most dangerous wounds, if not instantaneously fatal, produce no obvious immediate effects.

Notwithstanding the horror with which the natives regard this animal, it is said that they sometimes succeed in rendering him tame; and a whimsical story is told by the late Governor Clinton, on the authority of an Indian trader, of an insult offered to a domesticated bear of this species by an Indian of a different tribe from that to which the master of the bear belonged, being regarded as a national affront, and producing a 
war between the two tribes. The same veracious trader, it should be added, did not scruple to affirm that the Grizzly Bear had actually been seen fourteen feet long: the greatest measurement given on any credible authority being somewhat less than nine feet. It may, however, well be doubted whether the Grizzly Bear is capable of being domesticated ; for it would appear that all the known attempts that have hitherto been made to render him docile and obedient have completely failed. In the narrative of Major Long's expedition, Mr. Say has given some particulars relative to the manners of a half-grown individual which was kept chained in the yard of one of the stations of the Missouri Fur Company; but which, though far from having attained his full strength, was by no means trusted even by those who were most familiar with him. They occasionally ventured to play with him; but this was always done with caution and reserve; and when, as was sometimes the case, he chanced to break loose from his confinement, the whole establishment was thrown into a state of confusion and alarm. The same gentleman also gives the history of two individuals which were presented when very young to the Philadelphia Museum, where they were kept for several years confined in a strong cage; until at length their strength and ferocity, which no kind of treatment appeared capable of subduing, had reached such a pitch that it was found absolutely necessary to destroy them.

In no respect has the subject of the present notice, whose portrait admirably illustrates the peculiarities of his species, degenerated from the race of which he appears to be the sole representative in Europe. He 
was presented to his late majesty, more than seventeen years ago, by the Hudson's Bay Company, and has long been the oldest inhabitant of the Tower Menagerie. The name of Martin, which was originally bestowed upon him, in imitation probably of that of the most celebrated bear ever exhibited in Europe, has consequently been of late years generally preceded by the epithet of antiquity, and Old Martin has become under that title almost as well known as his famous namesake. His size is far superior to that of any other bear that has ever been seen in this quarter of the globe; and his ferocity, in spite of the length of time during which he has been a prisoner, and of all the attempts that have been made to conciliate him, still continues undiminished. He does not offer the slightest encouragement to familiarity on the part of his keepers, but treats them with as much distance as the most perfect strangers; and although he will sometimes appear playful and good tempered, yet they know him too well to trust themselves within his clutch.

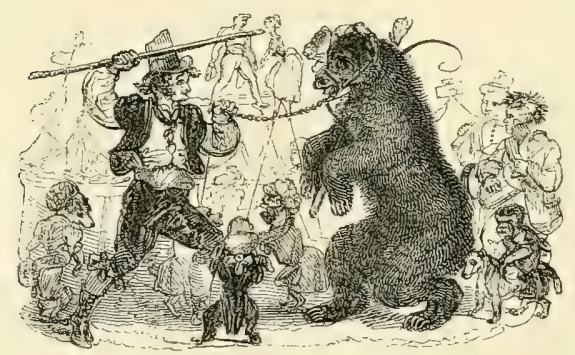




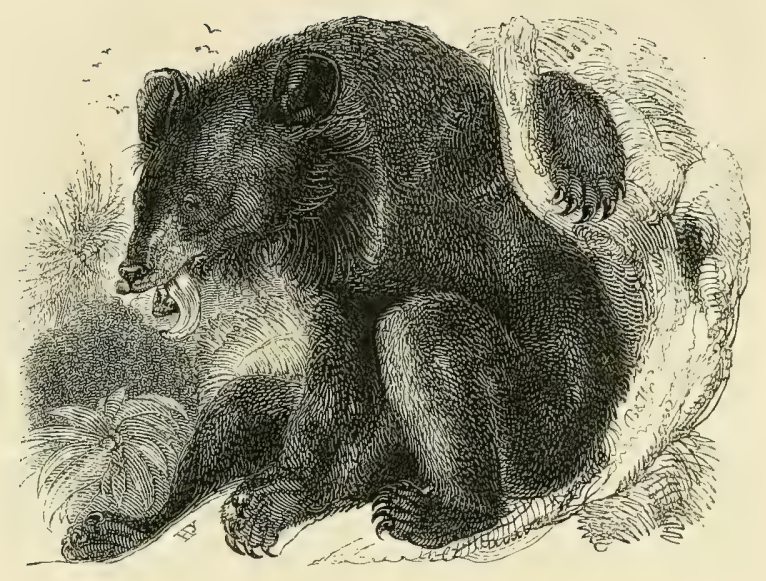

THE THIBET BEAR.

URSUS Thrbetanus. F. Cuv.

IT is with no slight feelings of regret that we find ourselves unable to furnish a complete and satisfactory account of the animal from whom the portrait above given was taken. Very soon after the drawing was completed, and before we had availed ourselves of the opportunity of making the necessary examination, we were unfortunately precluded from so doing by his sudden transfer to another country. His likeness alone, and a faithful and spirited likeness we will venture to pronounce it, remains with us. From this, and from the very imperfect notes which we possess, we have little hesitation in referring it provisionally to the species first 
established by M. Duvaucel, and since published by M. F. Cuvier in his splendid Histoire Naturelle des Mammifères. The circumstance, however, of our animal, the only individual of his species ever seen in Europe, having been brought from the Island of Sumatra instead of the continent of India, in which alone the Ursus Thibetanus had hitherto been discovered, is so remarkable, that we should have felt bound, had the means still remained open to us, to institute a close and severe comparison between the living specimen and the figure and description furnished by $\mathbf{M}$. Duvaucel and M. Cuvier. As it is, we can only repeat the characters of the Thibet Bear as given by them, and refer to our figure for all the proof which we have it in our power to offer of its identity with the present animal. We trust that M. Temminck, or some other competent naturalist of the country to which the latter has been conveyed, will amply supply a deficiency which certainly would not have existed had we received timely notice of the intended transfer.

M. Duvaucel enumerates three species of bears inhabiting India and the neighbouring islands. The first of these is the Ursus labiatus, which was strangely mistaken on its first arrival in Europe, nearly forty years ago, for a Sloth, and received from the naturalists of that day the name of Bradypus pentadactylus, or ursinus, the Five-fingered, or Ursine, Sloth; an appellation which has been productive of no little confusion in nomenclature, and is still frequently employed in menageries and exhibitions to distinguish the same animal, and sometimes even nearly related species. With the true Sloths it has nothing in common; and the only circum- 
stance which can at all account for the blunder, consists in the accidental deficiency of the incisor teeth in the animal first examined; a deficiency, which, according to the strict principles of the artificial system then adopted, was alone sufficient to convert a Bear into a Sloth. The second is the Ursus Malayanus, the Malay Bear, admirably illustrated, both with regard to character and habits, by the late lamented Sir Stamford Raffles in the thirteenth volume of the Linnean Transactions. Another species, intimately connected with this, and unknown to M. Duvaucel, will form the subject of the following article. In the present we must confine ourselves to his third form, the Thibet Bear, which, according to his observations, made on the living animal, is distinguished by the following characteristics.

In size it is intermediate between the two other species which he describes. Its most remarkable distinction is derived from the thickness of its neck and the flatness of its head, its forehead forming almost a straight line with its muzzle. The latter is moderately thick and somewhat lengthened; and the ears are very large. The body is compact, and the limbs heavy; a conformation from which we might be led to infer great muscular strength, together with a capacity for climbing trees and performing other feats of a similar description, were it not for the comparative weakness of the claws, which are scarcely more than half as long as those of the other Indian bears. Like the latter, its colour is invariably of a uniform glossy jet-black, except on the lower lip, which is white; as is also a patch occupying the front of the neck, and in shape like a $\mathbf{Y}$, the two upper limbs of which pass in front of the shoulders, while the lower 
one occupies the middle line of the chest. The upper part of the muzzle is black, with a slight reddish tint on the sides; and the edges of the lips flesh-coloured. The hair, which is smooth on the muzzle, becomes shaggy on the back part of the head, from the base of the ears downwards, and adds considerably to the apparent volume of that part, but not quite to the same extent as in the Ursus labiatus, in old individuals of which it almost touches the ground. It was found by Dr. Wallich in the mountains of Nepaul, and by M. Duvaucel in those of Sylhet; and from this limited range the latter gentleman infers, perhaps a little too hastily, that its habitat is less extensive than that of its fellows. He also regards it as being more ferocious in its habits.

In this latter point alone, so far at least as we can at present judge, does the animal from which our figure was taken offer any remarkable discrepancy from the foregoing account. He could never be prevailed on to touch flesh either raw or cooked; and bread and fruits were the substances on which he was constantly fed. In his disposition he was moderately tame, and particularly fond of play, after his own rough and ludicrous fashion.

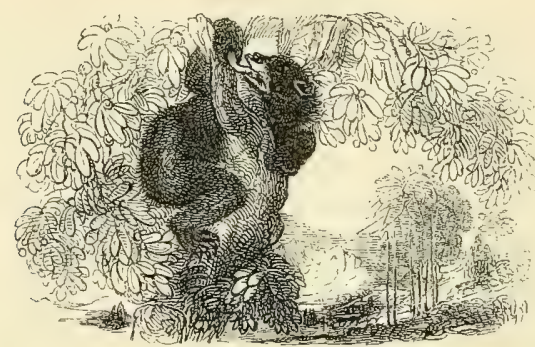




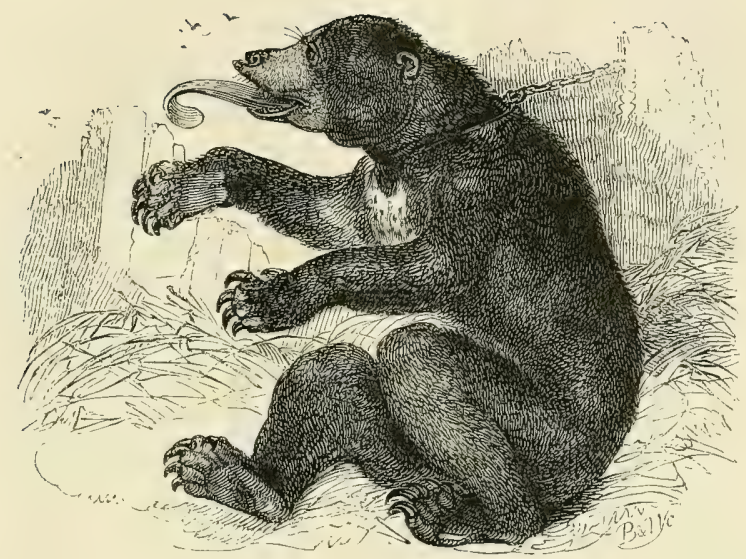

THE BORNEAN BEAR.

URSUS (HELARCTOS) EURYSPILUS. HoRSF.

OF this very remarkable animal, the only individual of the species ever seen in Europe, and in fact the only one that has yet fallen under the notice of zoologists, so complete an account has been published by Dr. Horsfield, in the second volume of the Zoological Journal, that it would be presumptuous in us to attempt to add any thing to the masterly details which are there furnished both of its organization and habits. We shall therefore in the present instance, and with the less reluctance as the animal is no longer living for further reference, content ourselves, with abstracting from that paper, as nearly as possible in the words of its author, 
the more interesting and prominent features of the history which is there given of the Bornean Bear; which, in conjunction with another closely related species, the Ursus Malayanus, Dr. Horsfield has separated from the other bears under the sub-generic title of Helarctos.

One of the most striking points on which this distinction is founded consists in the form of the head, which, instead of being flattened, as in the more northern species of the group, is nearly hemispherical above, the forehead rising in a strong arch immediately behind the nose, which is obtuse and very gradually attenuated. The gape of the mouth is considerable; and the tongue, which is long, narrow, and very extensile, is capable of being protruded for nearly a foot, and then curved inwards in a spiral manner, a habit in which the animal appears frequently to indulge. In the teeth the difference between this subdivision of the genus and the rest of the animals which compose it is unessential, the incisors and canines having no distinguishing characters, and the molars being apparently subject to the same variations as in the genuine bears.

The Bornean Bear is perhaps somewhat shorter in his proportions than the rest of the group, and the great proportional breadth of his head extends also to the neck and body. The claws are very long, strongly arched, and very gradually attenuated to the point, which is transversely truncated and chiefly fitted for digging the earth; but probably also enabling it to climb with great agility. The fur is short and glistening, somewhat rigid, but closely applied to the skin, and smooth to the touch. On the body, head, and extremities, the Bornean Bear has the same pure, saturated, 
jet-black tint which is observed in the Malayan. The muzzle, including the region of the eyes, has a yellowish brown colour; and the anterior part of the neck is marked by a large broad patch of a more vivid and nearly orange tint, which is of an irregular quadrangular form, and deeply notched above. The difference in the form and colour of this patch constitutes the chief distinction between the present animal and the Malayan species, in which latter it is crescent-shaped and white.

The specimen from which this description was taken measured along the back, from the muzzle to the tail, three feet nine inches. It arrived in this country about four years ago, and formed until lately one of the most attractive and interesting spectacles among the animals confined in the Menagerie. It was brought from Borneo when very young, and during its passage was the constant associate of a monkey and of several other young animals. It was thus domesticated in early life, and its manners in confinement greatly resembled those of the Malayan Bear observed by Sir Stamford Raffles, to which it was probably not inferior in sagacity or intellect. It could rest entirely on its posterior feet, and could even raise itself without difficulty to a nearly erect posture; but was more generally seen in a sitting attitude at the door of its apartment, eagerly surveying the visiters and attracting their attention by the uncouthness of its form and the singularity of its motions. When a morsel of bread or cake was held at a small distance beyond its reach, it would expand the lateral aperture of its nostrils and thrust forwards its upper lip as a proboscis in a most ludicrous manner, at the same time making use of its paws to seize the object. After obtaining it and filling 
its mouth, it would place the remainder with great calmness on its posterior feet, and bring it in successive portions to its mouth. When craving for food, and also while consuming it, it emitted a coarse, but not unpleasant, whining sound, accompanied by a low grunting noise; but if teased at this time, it would suddenly raise its voice to a harsh and grating tone. It was excessively voracious, and appeared disposed to eat almost without cessation; a propensity which finally cost it its life, having overgorged itself at breakfast one morning in the course of last summer during the hot weather, and dying within ten minutes afterwards. This was a severe loss to Mr. Cops, who prized it highly, and to whom, in return, it was greatly attached. On seeing its keeper it would often place itself in a variety of attitudes, to court his attention and caresses, extending its nose and anterior feet, or, suddenly turning round, exposing its back and waiting for several minutes in this posture with its head placed on the ground. It delighted in being patted and rubbed, even by strangers; but violently resented abuse and ill treatment. Its principal food was bread.

Our figure was taken from the stuffed skin which is preserved in the Museum of the Zoological Society.

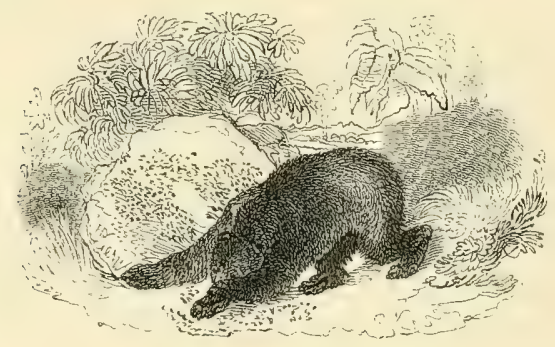




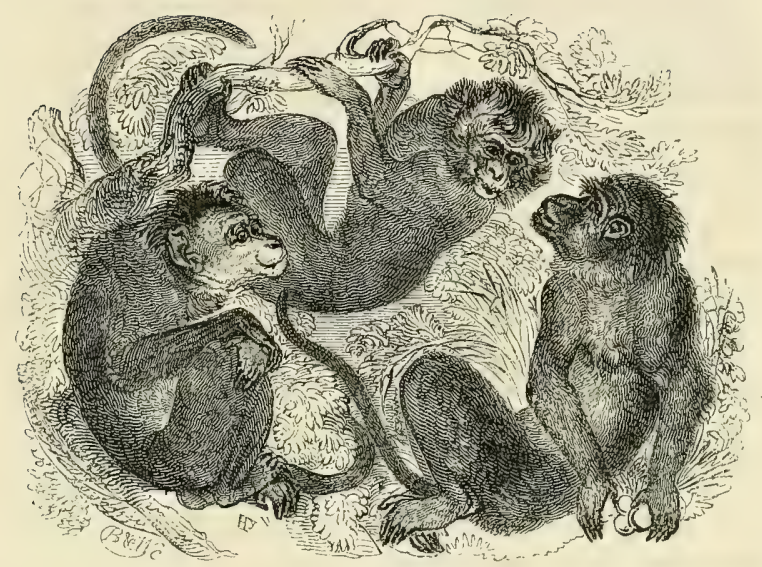

\section{MONKEYS.}

SIMITE. LINN.

IT may perhaps seem to require some apology that we' have ventured so far to depart from the ordinary system of arrangement as to remove the Monkeys from the station which they have hitherto usually been permitted to occupy at the head of the class, and to transfer them to their present position. We will not attempt to conceal that in so doing we were chiefly actuated by the desire of placing at the commencement of our series the largest and most attractive of the animals of which it was composed; and those which, in a Menagerie like that which we have undertaken to illustrate, always constitute the most imposing feature. But while we 
acknowledge the influence of this feeling to the fullest extent, we cannot refrain from expressing at the same time our firm conviction that the carnivorous quadrupeds possess in reality a better title to the place which we have assigned them, than the Monkeys which we have displaced to make room for them. The supposed transition from man, on which the received arrangement is founded, has little to do with the question; and it would surely require no great subtilty of argument to prove that the Carnivora are more highly typical of the great class, of which they form so important a part, than any other tribe whatever. But this is not the proper place for entering into so abstract a question; to which we have only referred en passant, for the sake of justifying ourselves upon broader principles for a deviation from established custom, which we should not have hesitated to adopt, in the present instance, on the narrow ground of expedience alone. Before, however, we take leave of it altogether, we cannot avoid asking, why, if the Monkeys are to take precedencè of the Carnivora among Mammalia, the analogous tribe of Birds, the Pies and the Parrots, should not also rank above the ornithological representatives of the beasts of prey, the towering Eagle and the rapacious Vulture?

To return, however, to our Monkeys; to which, be it observed, we do not pretend to assign this as a definite position. They form by far the largest portion of the Quadrumana; all the other animals of that order being comprehended, or rather confounded, in a distinct family, under the name of Lemurs, from the rightful owners of which appellation many of them differ most essentially. In addition to the hands on the posterior as well as 
anterior members, with long and flexible fingers and opposable thumbs, which constitute the primary characters of the order, the Monkey tribe in general is distinguished by the following peculiarities. Their incisor teeth are invariably four in each jaw, and their molars, like those of man, are flat and surmounted by blunted tubercles. The latter are five in number on each side of either jaw in all the Monkeys of the Old Continent, and in one very distinct tribe belonging to the New; but most of the American species are furnished with a sixth. Their canines vary considerably in size, from a trifling projection beyond the remaining teeth to a long and powerful tusk, almost equalling those of the most formidable Carnivora; and from this structure it necessarily follows that a vacant space is left between the incisors and the canines of the upper jaw, and between the canines and the molars of the lower, for the reception and lodgment of those organs when the mouth is closed. The nails of all their fingers, as well as those of the thumbs, are invariably flat and expanded.

In almost every other point they are subject to infinite variations of form and structure. The shape of the head, which, in one or two species, offers a close approximation to the human form, passes through numerous intermediate gradations, until it reaches a point at which it can only be compared with that of the hound. The body, which is in general slight and well made, is in some few instances remarkably short and thick-set, and in others drawn out to a surprising degree of tenuity. Their limbs vary greatly in their proportions; but in most of them the anterior are longer than the posterior: in all they are admirably adapted to the purposes to which they 
are applied, in climbing and leaping, by the slenderness of their form, the flexibility of their joints, and the muscular activity with which these qualities are so strikingly combined. But of all their organs there is perhaps none which exhibits so remarkable a discrepancy in every particular as the tail; which is entirely wanting in some, forms a mere tubercle in others, in a third group is short and tapering, in a fourth of moderate length and cylindrical, in a fifth extremely long but uniformly covered with hair; in others, again, of equal length, divested of hair beneath and near the tip, and capable of being twisted round the branch of a tree or any other similar substance in such a manner as to support the whole weight of the animal, even without the assistance of his hands.

In none of them, it may be observed, are the hands formed for swimming, or the nails constructed for digging the earth; and in none of them is the naked callous portion, which corresponds to the sole or the palm, capable of being applied, like the feet of man or of the bear, to the flat surfaces on which they may occasionally tread. Even in those which have the greatest propensity to assume an upright posture, the body is, under such circumstances, wholly supported by the outer margins of the posterior hands. The earth, in fact, is not their proper place of abode ; they are essentially inhabitants of trees, and every part of their organization is admirably fitted for the mode of life to which they were destined by the hand of nature herself. Throughout the vast forests of Asia, Africa, and South America, and more especially in those portions of the three continents which are comprehended within the 
tropics, they congregate in numerous troops, bounding rapidly from branch to branch, and from tree to tree, in search of the fruits and eggs which constitute their principal means of subsistence. In the course of these peregrinations, which are frequently executed with a velocity scarcely to be followed by the eye, they seem to give a momentary, and but a momentary, attention to every remarkable object that falls in their way, but never appear to remember it again; for they will examine the same object with the same rapidity as often as it recurs, and apparently without in the least recognising it as that which they had seen before. They pass on a sudden from a state of seeming tranquillity to the most violent demonstrations of passion and sensuality; and in the course of a few minutes run through all the various phases of gesture and action of which they are capable, and for which their peculiar conformation affords ample scope. The females treat their young with the greatest tenderness until they become capable of shifting for themselves; when they turn them loose upon the world, and conduct themselves towards them from that time forwards in the same manner as towards the most perfect strangers.

The degrees of their so much vaunted intelligence, which is in general very limited, and rarely capable of being made subservient to the purposes of man, vary almost as much as the ever-changing outline of their form. From the grave and reflective Oran-Otang, whose docility and powers of imitation in his young state have been the theme of so much ridiculous exaggeration and sophistical argumentation, to the stupid and savage Baboon, whose gross brutality is scarcely relieved by a 
single spark of intelligence, the gradations are regular and easy. A remarkable circumstance connected with the developement of this faculty, or perhaps we should rather say, with its gradual extinction, consists in the fact that it is only in young animals which have not yet attained their full growth, that it is capable of being brought into play; the older individuals, even of the most tractable races, entirely losing the gaiety, and with it the docility, of their youth, and becoming at length as stupid and as savage as the most barbarous of the tribe.

The Monkeys of the Old and of the New World differ from each other in several remarkable points, some of which are universally characteristic of all the species of each, while others, although affording good and tangible means of discrimination, are but partially applicable. Thus the nostrils of all the species inhabiting the Old World are anterior like those of man, and divided only by a narrow septum. In those of the New World, on the contrary, they are invariably separated by a broad division, and consequently occupy a position more or less lateral. In the former again the molar teeth are uniformly five in number, crowned with obtuse and flattened tubercles; while in the latter they are either six in number, or in the few anomalous cases in which they, are limited to five, and which are peculiar to a group that ought to occupy an intermediate station between the Monkeys and the Insect-eating Carnivora, their crowns are surmounted by sharp and somewhat elevated points. The tails of all the American Monkeys are of great length, but they differ more or less from each other in the power of suspending themselves by means of that organ, a faculty which is nevertheless 
common to the greater number of them, and of which those of the Old World are entirely destitute. On the other hand the American species never exhibit any traces of the callosities or of the cheek-pouches, which are so common among the Asiatic and African races.

Each of these grand divisions has been subdivided into several minor groups or genera; but zoologists have hitherto been by no means unanimous with respect to the principles on which this subdivision ought to be effected. The arrangement which appears to be most generally adopted at the present day is that of $\mathrm{M}$. Cuvier and M. Geoffroy-Saint-Hilaire, which is essentially founded on the application of an imaginary rule, first employed by Camper for ascertaining the degree of intelligence, and consequently of ideal beauty, expressed by the human face in its various gradations of elevation or debasement, and called by him the facial angle. Unfortunately, however, the operations of nature in the animal creation can never be subjected to geometrical laws; nor can her innumerable phases be expressed with the precision of a mathematical theorem. This assumed point of comparison varies almost indefinitely, not merely in different species, but even in the same individual; and the Oran-Otang himself, who is supposed to approach most nearly to the human form, offers the most striking illustration of the truth of this observation; inasmuch as in his young and intellectual state his facial angle is equal to $65^{\circ}$, while in his aged and debased condition, in which he has actually been repeatedly described as a different animal under the name of Pongo, it sinks below $30^{\circ}$; degrading him even beneath the level of the most savage and stupid of the Baboons. 
In the foregoing observations we may perhaps be considered as giving too much space to the generalities of the subject; an objection to which we can only answer that nearly the whole of our knowledge of the Monkey tribes consists in generalities. Of the great number of species, upwards of one hundred, which are now known and characterized, very few are distinguished from their immediate fellows by striking and strongly-marked characters, either physical or moral. The groups too are connected by such gradual and easy transitions, that although the typical forms of each, isolated from the mass and placed in contrast with each other, unquestionably exhibit many broadly distinguishing peculiarities, yet the entire series offers a chain so nearly complete and unbroken as scarcely to admit of being treated of in any other way than as one homogeneous whole.

A no less striking than apposite instance of the close affinity between the species, and of the difficulty of distinguishing them from each other, especially in their young state, is furnished by the animals whose figures stand at the head of the present article. They are all three very evidently young individuals, and have not yet reached the period when it would be safe to pronounce with positiveness upon the species, or, were we to adopt the Cuvierian system in its full extent, upon the genera even, to which they respectively belong.

The specimen from which the central figure was taken is in all probability the earlier age of a species of Cercopithecus; but to which of them it should be referred, or whether it belongs to any hitherto characterized species, we may not venture to determine until its characters shall have become more fully developed. The distinctive 
marks of this genus, which comprehends the smallest Monkeys of the Old Continent, consist in a depressed forehead, with a facial angle of $50^{\circ}$; a flat nose, with the nostrils directed upwards and outwards; cheek-pouches, generally of large size; callosities behind; and a tail of considerable length. The individual before us, in addition to these characters, is remarkable for the reddish brown colour of his upper parts, which gradually disappears in a lighter hue, mingled with a bluish tinge beneath; for the elevated and compressed toupet which advances considerably forwards on his forehead; for the hairs which are thinly scattered over his livid face; and for the spreading tufts of a somewhat lighter colour which occupy the sides of his head and face posteriorly.

The animal which occupies the right hand in the cut appears to be the young of the Macacus cynomolgus, Cuv., the Common Macaque; or rather perhaps, if the colour of the face is to be regarded as affording a sufficient specific distinction, of a new species lately described by M. F. Cuvier under the name of Macacus carbonarius. The Macaques are characterized by the greater elongation of their muzzles, which reduces their facial angle to $40^{\circ}$ or $45^{\circ}$; by the strong developement of their superciliary ridges; by the oblique position of their nostrils in the upper surface of their nose; and by the presence of cheek-pouches and callosities. The young animal figured is blackish brown above, and, as is very common among the Monkeys, lighter and of a bluish cast beneath; his hands and face are nearly black; the hairs which cover his forehead form a thick tuft advancing forwards; and his face is almost naked.

We have little hesitation in referring the left hand 
figure to the Cercopithecus pileatus of M. Geoffroy St. Hilaire, the Guenon couronnée of Buffon, which M. Cuvier suspects, with great appearance of truth, to be nothing more than a variety of the Macacus Sinicus, the Bonnet Chinois of the same popular author. It differs from that in fact in little else than in a shorter muzzle, and in a less regularly radiated and depressed disposition of the hair of the upper part of the head; characters which may be fairly regarded as resulting from its immature age. We may also observe that the Macacus radiatus, Geoff., described in the succeeding article, does not appear to be by any means clearly distinguished from the Bonnet Chinois; and that it is highly probable that these three Monkeys form in reality but a single species.

All these animals, which are at present confined in one cage along with several young individuals of the common species of Baboon and with the Bonneted Monkey, exhibit a mixture of playfulness and malice, which renders them extremely amusing. Their gambols with each other are often truly laughable.

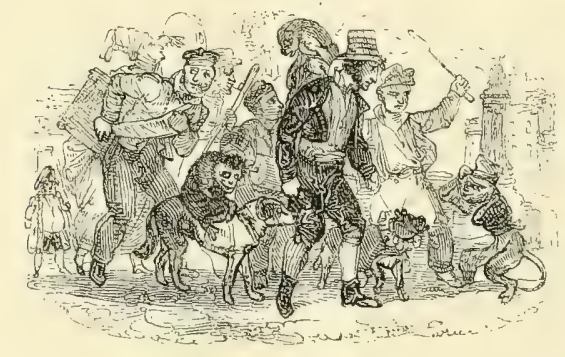




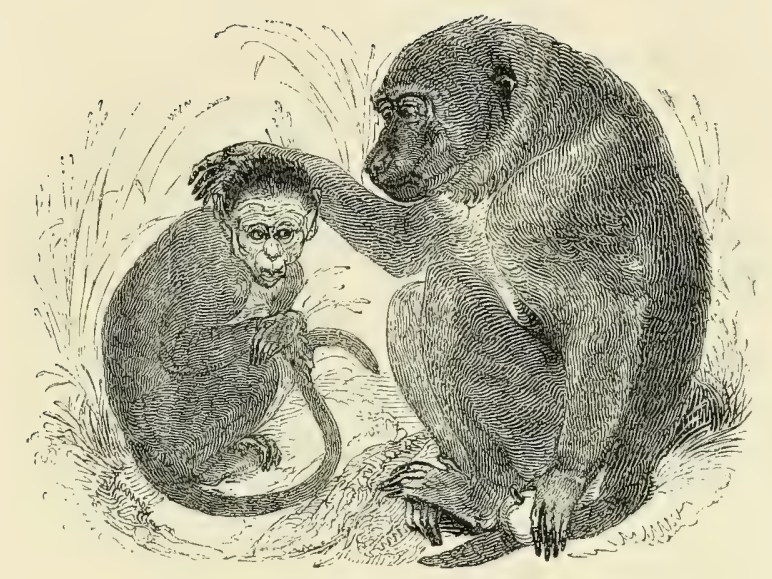

THE BONNETED MONKEY.

Macacus radiatus. Dism.

\section{THE PIG-FACED BABOON.}

Cynocephalus porcarius. Desm.

THE Monkey which occupies the left hand in the present cut forms part of the same group with the subjects noticed at the end of the preceding article, from which it is distinguished by the peculiar manner in which the hair of the upper part of its head diverges, and, as it were, radiates horizontally, from a central point towards an imaginary circumference, assuming a form not unlike the object to which it is usually compared, the round bonnet of a Chinese. Its forehead is also more flattened, its superciliary crests less developed, and its muzzle 
considerably lengthened and laterally compressed. The length of its body is from twelve to fifteen inches, and its tail when entire measures quite as much. The forehead, which is strongly wrinkled, is nearly naked, and the whole of the face is entirely destitute of hair. That of the upper parts of the body is of a uniform yellowish gray, the under surface deriving a bluish tinge from the skin, which is but thinly covered. Its native country is the east of Asia.

The right hand figure represents the Chacma, or Pigfaced Monkey, one of the true Baboons, whose generic characters will be found in the succeeding article. The forehead of this species is remarkably depressed, and the nose much prolonged. Its general colour is dusky, approaching to black. Its body measures from two to three feet in length; but the tail is short, and does not reach the ground when the animal stands upon all fours. It is a native of Africa, and was formerly very troublesome in the neighbourhood of the Cape.

Both these animals, although lively and tolerably good humoured when young, become mischievous in their dispositions and disgusting in their habits as they advance in age. The voice of the latter closely resembles the bark of a dog.

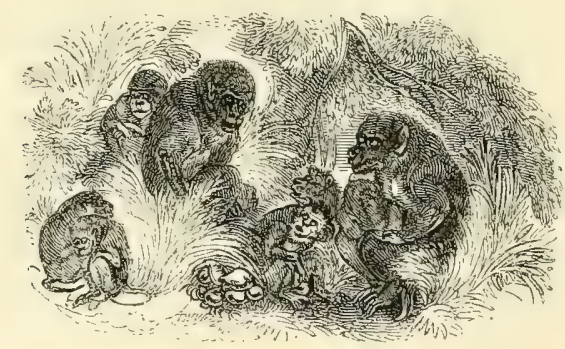




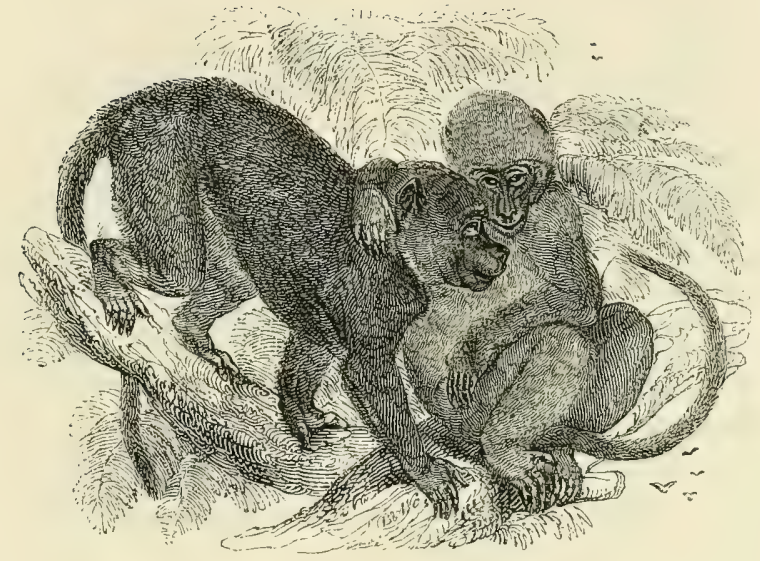

THE BABOON.

Cynocephalus Papio. Desir.

Is the true Baboons the facial angle of the adult varies from $30^{\circ}$ to $35^{\circ}$, and the superciliary crests are for the most part considerably elevated, as is also the ridge on the back of the head formed by the attachment of the temporal muscles, which, as well as the canine teeth, are large and powerful. The cheeks are furnished with pouches capable of much distension; and the muzzle terminates in a flattened extremity like that of the dog, on which the openings of the nostrils are situated. The tail is generally as long as, and sometimes even longer than, the body; but in several of the species it is extremely short. The callosities are frequently of large 
size and disgustingly conspicuous. This genus is generally considered as the lowest in organization, and consequently in capacity and intelligence, of the tribe to which it belongs.

The colour of the common Baboon is reddish brown; his face and hands are black, and his upper eyelids white. The hair of his cheeks forms a considerable tuft on each side; and the under surface of his body is but sparingly covered. In bulk he is equal to a middle sized $\operatorname{dog}$; his proportions are thickset and inelegant; but he is by no means dull or inactive. When young, he is gay, playful, and docile; but as he grows older he becomes untractable, malicious, and ferocious. $\mathrm{He}$ is sometimes even dangerous, his muscular strength and agility, together with the great power of his teeth and jaws, rendering him a formidable opponent. On this account it is absolutely necessary to keep him strictly confined. He is a native of Africa, and more especially of the tropical parts of its western coast.

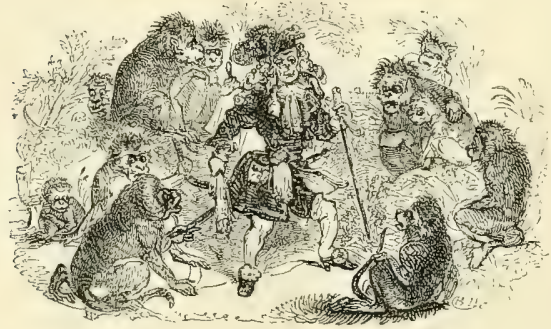




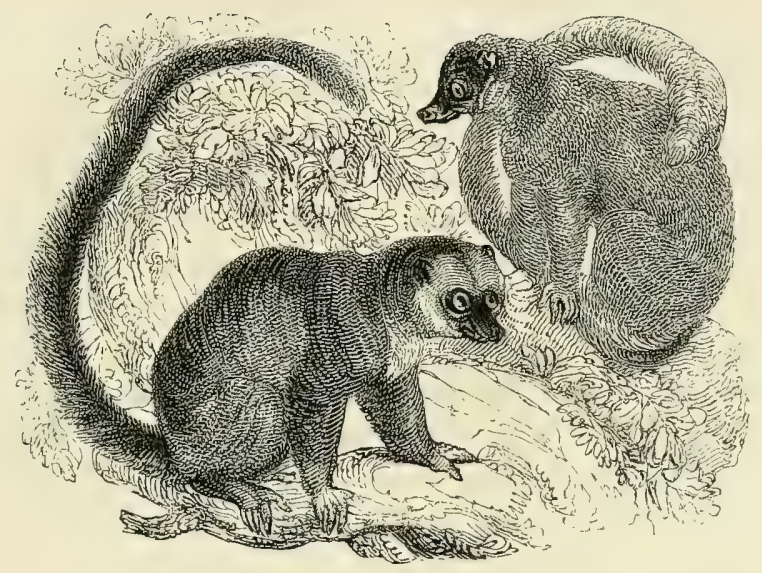

THE WHITE-HEADED MONGOOS.

Lemur aldifrons. Geoff.

Belongrag to a different tribe of the same grand division with the true Monkeys, from which they are more readily distinguished by their general form and habit than by any very remarkable deviation in their structure or organization, these agile and playful little creatures form a group which naturally follows in immediate succession. The technical peculiarities on which their separation from the Monkeys is founded are usually deduced from their teeth and nails; but other and more obvious characteristics are afforded by the form of their heads, of their tails, and of their hinder extremities, and these assist in confirming a distinction which might 
otherwise be regarded as arbitrary and unnecessary. The teeth of the Lemurs are, like those of man and of the Monkeys of the Old World, thirty-two in number, and consist of four incisors, two canines, and ten molars in the upper jaw, and of six incisors, two canines, and eight molars in the lower. Such at least is the usual statement with respect to their dentition; but M. Geoffroy maintains, on the other hand, that the number of incisors is equal in both jaws, and coincides with that of the Monkeys; the two outermost of the six, which are larger than the rest, being in his opinion the true canines; while the canines, commonly so called, are in fact only the first of the series of molars. This conjecture unquestionably derives considerable strength from the fact that, when the animal closes its mouth, the supposed canines of the lower jaw pass behind those of the upper, a position directly contrary to that which they uniformly assume in every other animal that is furnished with that kind of teeth. On each of their four hands they have four fingers of moderate length, and a thumb which is capable of being opposed to them almost equally well with that of the other Quadrumana; they are consequently enabled to grasp whatever they seize with the greatest precision. The peculiarity of their nails consists in the shape of that of the index of the hinder hands, which forms an elongated, curved, and pointed claw, approaching in some degree to those of the carnivorous quadrupeds. All the rest of their nails are broad and flat like those of the Monkeys. Their posterior extremities are longer than their anterior; and their body and limbs are light, graceful, and well proportioned. The tail, which is of uniform thickness 
throughout, is longer than the body, and, in common with it, is clothed with long, soft, and woolly hair. The head is long, triangular, and gradually tapering into a slender and pointed muzzle, which, in proportionate length, far exceeds that of any of the Monkeys; the ears are short and rounded; and the whiskers but little developed.

The whole of the genus thus characterized are natives of Madagascar and of two or three of the smaller islands in its immediate vicinity. They appear to occupy in that remarkable and very imperfectly known country the place of the Monkeys, none of which have yet been detected within its precincts. They are said to live in numerous troops upon the trees, and to feed upon fruits and insects; but their habits in a state of nature have not yet been observed with sufficient accuracy to enable us to form any clear idea of their mode of existence. In captivity they are particularly tame and good tempered, fond of being noticed, delighting in motion, and climbing and leaping with surprising agility. They are, however, in some degree nocturnal; and when undisturbed pass a considerable portion of the day in sleep. If alone, they roll themselves up in the form of a ball, and wind their long tail in a very curious manner round their body, apparently for the purpose of keeping themselves warm; for they are naturally chilly, and delight in basking in the rays of the sun, or in creeping as close as possible to the fire. When two of them are confined together, they interlace their limbs and tails after a singular fashion, and placing their heads in such a position as that each may, if disturbed, see what is going on behind the other's back, fall comfortably asleep. 
The species to which the beautiful pair in the Menagerie belong has all the habits of its group. It is characterized by the clear fulvous brown colour of the upper surface of the body and outer side of the limbs, gradually becoming lighter on the under and inner surfaces, and deepening in its shade towards the tail, the greater part of which is nearly black. The muzzle and the hands are bluish black. The male has the whole of the forehead, the sides of the cheeks, and the under part of the lower lip covered with a white fur, which in the female is of a blackish gray and much less developed; her general colour is also of a lighter tinge. This remarkable difference would lead us to question the specific identity of the two animals, were we not assured by M. F. Cuvier that he had verified the fact by what is usually regarded as an unequivocal test. Mr. M'Leay has, however, thrown considerable doubt upon the accuracy of the inference thus attempted to be drawn, by exhibiting to the Linnean Society a female, in whom the white fur of the head was as dictinctly developed as in her male companion. The whole of the species of this group require, in fact, an accurate revision.

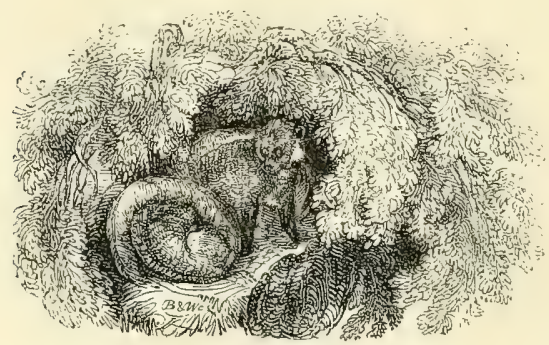




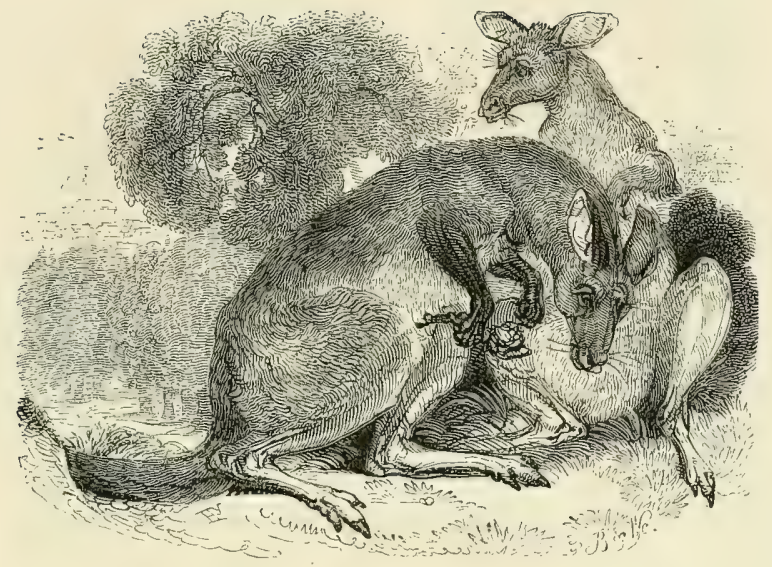

THE KANGUROO.

MaCropus maJor. ShaW.

The very peculiar structure from which the Marsupial animals derive their name has been regarded by almost every naturalist who has written on the subject as so essential a deviation from the common type, that, setting aside all considerations of form or habits, and regardless even of those technical characters on which so much reliance is usually placed, they have for the most part agreed in uniting under the same family designation every animal in which it occurred. This peculiarity consists in a folding or doubling of the skin and its appendages beneath the lower part of the belly in the females, in such a manner as to form an open pouch or 
bag, in which the young are contained from a very early period, in which the process of suckling takes place, and in which, even for some time after they have acquired sufficient size and strength to leave it, the little ones continue to take refuge.

But the presence of this one anomalous characteristic is accompanied by so many striking discrepancies in other parts, that, limited as this tribe is in number, most of the principal forms of Mammalia find analogous representations among its groups. Thus the Opossums exhibit characters in some measure intermediate between the Quadrumana and the Carnivora, to which latter the Dasyuri, another Marsupial group, closely resembling the Civets in form and habits, approach very nearly; while the herbivorous races of the tribe might occupy a station between the Rodent and Ruminant Orders, with each of which they exhibit various degrees of relation. ship. This want of uniformity in the essential parts of their organization necessarily gives rise to much difficulty in determining their position in the system. The mode of classification now most generally followed is perhaps, under all the circumstances, the best that could at the present moment be adopted; although it must be owned that the purely herbivorous species arrange themselves with a very ill grace under a subdivision of the order Carnivora. Placed, however, as they are at the end of that order, and immediately before the Rodentia, the regular gradations from the type of the former to that of the latter, which occur in their different groups, become most distinctly manifest.

With the exception of the Opossums, which are natives of America, the tribe is peculiar to New Holland and its 
appendages, and to some of the islands which form the great chain of connexion between that insular continent and South-eastern Asia. The former is, however, their head quarters, and the species which are found beyond its limits are few in number compared with those which people its territory, and, what is more remarkable, people it to the exclusion of nearly all the other Mammalia; the dog alone, the universal concomitant of man, and one or two species of rats, disputing with them their title to its exclusive possession; for those paradoxical creatures, the Ornithorhynchus and Echidna, if really mammiferous, approximate closely in structure to the Marsupial tribe.

The largest of these animals are the Kanguroos, whose generic characters we shall now proceed to describe. Their teeth are only of two kinds, the canines being altogether wanting. The incisors are six in the upper jaw, and two only in the lower; the former short, and arranged in a curved line, and the latter long, pointed, closely applied to each other, and directed forwards. The molars are separated from the incisors by a considerable vacant space, and are five in number on each side of each jaw. The most remarkable peculiarity in the external form of these animals consists in the extreme disproportion of their limbs, the anterior legs being short and weak, while the posterior are extremely long and muscular. The tail too is excessively thick at its base, of considerable length, and gradually tapering; and this singular conformation enables it to act in some measure as a supplemental leg, when the animal assumes an erect or nearly erect posture, in which position he is supported as it were on a tripod by the joint action of 
these three powerful organs. By means of this combination they will, when flying from danger, take a succession of leaps of from twenty to thirty feet in length and six or eight in height; but even in their more quiet and gradual mode of progression they also make use of their tail in conjunction with their four extremities. The fore feet are furnished with five toes, each terminating in a moderately strong and arcuated claw. The hinder extremities, on the contrary, have only four toes, the two interior of which are united together so as to form the appearance of a single one furnished with two short and feeble claws; the third is long, of great strength, and terminated by a large and powerful claw having the form of a lengthened hoof; and the fourth, the most external of the series, is similar in character to the third, but of much smaller dimensions. The head and anterior part are small and delicate, and appear quite disproportioned to the robust posterior half of the body ; and this disproportion is equally striking, whether the animal assumes an erect position or crouches forwards upon all fours. In either case the whole extent of the soles of the posterior feet, which are of great length, is applied to the surface of the ground. Although differing from all the Rodent animals in the number of the cutting teeth of the upper jaw, the Kanguroo has the deep fissure in the upper lip, with which nearly all that order are furnished, and of which the hare offers a familiar and proverbial instance.

These singular animals were among the first fruits which accrued to natural history from the discovery of New South Wales, a country which has since proved so fertile in new and remarkable forms both of the animal 
and vegetable creations. Their natural habits in a wild state are still, however, very imperfectly known. They appear to live in small herds, perhaps single families, which are said to submit to the guidance of the older males, and to inhabit in preference the neighbourhood of woods and thickets. They are, as might be inferred from the small size of their mouths and the peculiar character of their teeth, purely herbivorous, feeding chiefly upon grass and roots. Their flesh is eaten by the colonists, by whom it is said to be nutritious and savoury, an assertion which is confirmed by those who have partaken of it in England. In order to procure this they are frequently hunted in their native country; but the dogs who are employed in this service sometimes meet with dangerous wounds, not only from the blows of their powerful tail, which is their usual weapon of defence, but also from the claws of their hind feet, with which they have been known to lacerate the bodies of their assailants in a shocking manner. But, unless when thus driven to make use of such powers of self-defence as they possess, they are perfectly harmless and even timid; and, when domesticated, are not in the least mischievous. In several collections in this country, and particularly in the Royal Park at Windsor, from which the specimens in the Menagerie were obtained, they have become almost naturalized, and appear to be but little affected by the change of climate. When confined in a small enclosure, they uniformly make their path round its circuit, seldom crossing it or passing in any other direction except for the purpose of procuring their food. Their whole appearance, and especially their mode of progression, is singularly curious and even to a certain extent ludicrous. 
Modern naturalists have attempted to distinguish several species among the Kanguroos; but as the characters on which these are founded consist merely in difference of size and slight modifications of colour, a much more complete acquaintance with them than we yet possess is requisite before they can safely be adopted. Our specimens are of a brownish gray above, somewhat lighter beneath, with the extremity of the muzzle, the back of the ear, the feet, and the upper surface of the tail, nearly black, and the front of the throat grayish white. Since they have been confined in the Menagerie, the female has once produced young; a circumstance by no means unfrequent even in this country among those which are less restricted of their liberty and are suffered to roam at large in a meadow or a park. They are fed, like the domesticated Ruminants, upon green herbage and hay; and are extremely tame and good tempered.

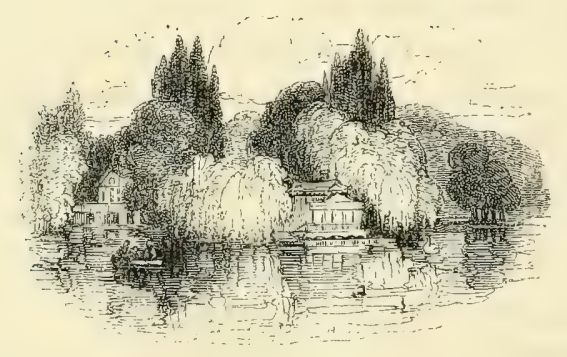




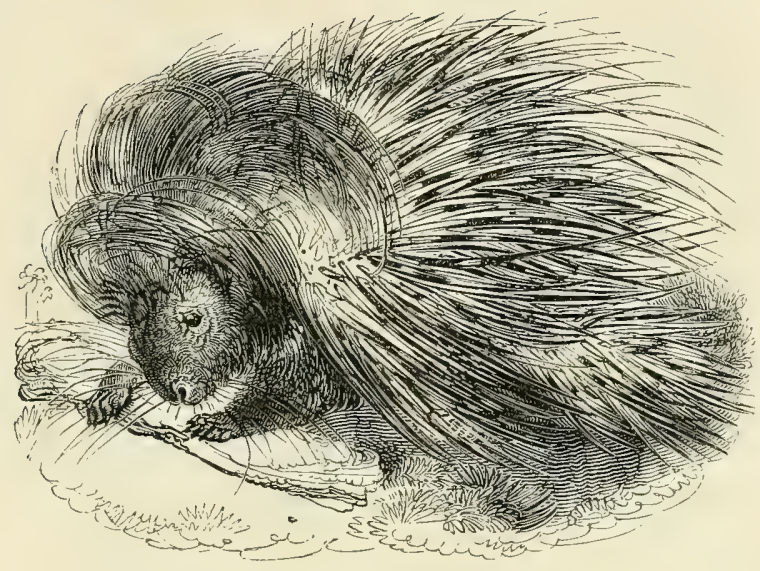

THE AFRICAN PORCUPINE.

\section{Hysteix cristata. LinN.}

Althovgh the Rodent order, next to the Carnivorous, is the most numerous in species, the Porcupine is the only animal belonging to it which is at present contained in the Menagerie. The animals of this division, consisting chiefly of "rats and mice and such small deer," have indeed, with some few exceptions, so little of interest for the mere casual visiter of an exhibition, that it is rarely that they are sought after unless by the scientific collector. They are at once distinguished from the Carnivora by the total absence of canine teeth; and have uniformly two incisors in each jaw, projecting forwards and generally of considerable size, separated from a variable number of grinders by a vacant space.

From the other animals of the order the Porcupines 
are so readily distinguished by the long and pointed spines with which their body is armed, that it is unnecessary to dwell on their generic characters. The common Porcupine, when fully grown, as in the remarkably fine specimen figured over leaf, measures more than two feet from the tip of the nose to the origin of the tail. The spines, which are supported by a slender pedicel, thickly clothe the upper and posterior parts of the body, the largest being more than a foot in length; they are regularly surrounded by alternate rings of black and white. The head and neck are crested with long, bristly, black hairs, forming a kind of mane, and all the rest of the body is covered with short black hair.

The Porcupine is a native of Africa and the south of Europe; he chooses for his abode the most arid and solitary situations, and passes the daytime secluded in the burrows which he digs for his habitation, quitting them only at night to provide his subsistence, which consists entirely of vegetable substances. He is a remarkably timid animal, and never makes use of his formidable weapons except in self-defence; if alarmed, his spines immediately become erected, and woe be to the enemy who should dare to attack him open-mouthed when in that posture.

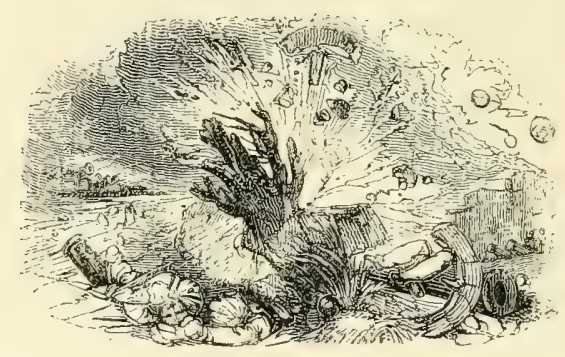




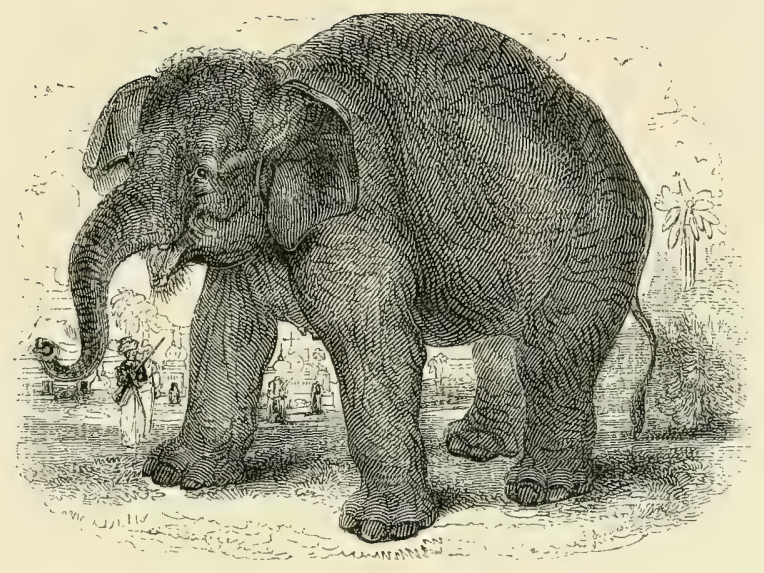

THE ASIATIC ELEPHANT.

Elephas Indicus. Cuv.

THE opportune arrival of a beautiful little Elephant, an animal which has for some time been a desideratum to the Menagerie, fortunately enables us to add to our list of subjects that which in all probability presents the most generally attractive spectacle among the whole class of Mammiferous Quadrupeds. The strong and peculiar interest which the Elephant possessies above all other beasts arises in fact not so much from his gigantic bulk and immense muscular power, as from the high opinion usually entertained of those intellectual qualities with which he has long been supposed to be preeminently endowed, and which have rendered him a 
theme of exaggerated encomium to the careless abserver, while even in some philosophic minds they have furnished the groundwork on which perverted ingenuity has built up theory after theory as baseless and imaginary as the foundation on which they have been made to rest, the reason and reflection of a brute.

It is on this account that we feel it incumbent upon us, notwithstanding all that has been written on the subject, to dwell with some little detail on the natural history of this singular animal; but we shall nevertheless endeavour to compress our observations within the smallest possible compass. We shall commence as usual with his zoological characters, and shall then take a glance at his habits, such as they appear in a pure state of nature, unfettered by any laws but those of necessity, and uncontrolled except by the inevitable influence of the circumstances in which he is placed. And lastly we shall view him when under the control of man, and reduced to that half-domesticated condition to which even his stubborn nature is bowed by the application of those means which man alone can employ, and by which he maintains his ascendancy as undisputed lord of the creation over the mightiest even more effectually than over the meanest of its works.

The Elephants belong to the Pachydermatous order, in which they constitute a family readily distinguishable from the other enormous beasts which form part of it, the Hippopotamus and the Rhinoceros, by a combination of characters of the most remarkable description. To the immense size and clumsy figure of the two last named animals, which indeed they commonly surpass in both those particulars, they add the following distinctive 
zoological characters. Their teeth consist of two formidable tusks, which, occupying the place of the incisors of the upper jaw, project forwards in a nearly horizontal direction, generally with a slight curvature upwards; and of one or occasionally two cheek teeth of considerable magnitude on each side of each jaw, formed of vertical layers of bony matter surrounded by enamel, and connected together by a third substance called cortical. These latter are not, as in almost all the other Mammalia, renewed for one only time and at a certain age by the growth of others to supply their places from the cavity of the jaw beneath them; but, on the contrary, are pushed forwards by the advance of those which are destined to replace them from behind, and are renewed, according to the statement of $\mathrm{Mr}$. Corse, no less than eight times at different periods of the animal's existence. On each successive change the number of laminæ of which they are composed is increased, the earliest not offering more than four, while the later ones frequently exceed twenty; and it is in consequence of the new teeth generally making their appearance for some time prior to the total failure of their predecessors that their number occasionally appears to be double its proper and more usual amount. The tusks on the contrary admit but of a single displacement and renewal; the first or milk pair seldom exceeding two inches in length, and falling out between the first and second year. The permanent ones which succeed are much larger and more powerful in the adult male than in the female, and not unfrequently project as much as two feet. They are well known as furnishing one of the most beautiful and ornamental productions which the animal kingdom 
affords, as well as a valuable article of commerce, in the pure and polished ivory of which they are formed. They have been known to weigh as much as one hundred and fifty pounds, but their usual average is from fifty to seventy.

The ears of the Elephant are large, not elevated like those of other quadrupeds so as to form a kind of trumpet for the reception of sound, but flattened down upon the side of the head, and forming a broad and uninterruptedly expanded surface. His eyes, remarkably small in proportion to his bulk, are sheltered above by a cluster of long hairs, which, with a few others scattered over the head and still more rarely on the body, and a kind of brush at the extremity of the tail, constitute the only covering, if covering it may be called, with which he is provided. His skin in fact is throughout nearly destitute of hair; but in return it is, as in the rest of the order, of excessive thickness and extreme tenacity, insomuch as to be capable of repelling a common musket ball, which scarcely makes the slightest impression upon its surface. His feet are enveloped by a large hoof of a callous and almost horny consistence, and are divided; in the skeleton at least, into five toes, the extremities only of which, rendered obvious by the nails by which they are surmounted, are externally visible... On the hind feet the number of apparent toes varies from three to four.

But of all the peculiarities by which the Elephant is distinguished, the most singular and at the same time the most useful is the projection which is formed by the blending and extension of the nose and upper lip into an elongated and tapering tube, considerably longer than 
the head, and truncated at the extremity, where it is surrounded by a slightly elevated margin, which is prolonged anteriorly and superiorly into a finger-like appendage of various and invaluable use. This trunk or proboscis, as it is called, is divided throughout its whole extent into two equal cavities, which are continuous with the nostrils, but appear to have no other connexion with the organ of smell than as being the medium of the passage of odours to the olfactory apparatus, which is confined within the bones of the head, and is indeed seated much higher than usual in consequence of the large space occupied by the roots of the tusks and by the cavities of the maxillary bones. The real uses of the trunk are far higher and more important; and it is to this unique and unexampled structure that the Elephant owes whatever superiority he possesses over other beasts. In general capacity he is inferior to most, and the intellectual qualities of a $\operatorname{dog}$ or a horse are unquestionably of a far more elevated order; but with the assistance of this curious organ, with some little sagacity, a tolerable memory, and a certain degree of docility, the Elephant is enabled to execute such a variety of actions, either of his own accord or at the command of his keeper, as have gained him the credit not only of being the cleverest of brutes, but of possessing qualities of a superior cast and even the divine gift of reason itself.

The structure of the trunk is entirely muscular, and the fibres of which it is composed are arranged in such a manner that it is capable of being inflected in almost any direction; but to twist itself spirally inwards appears to be its most natural action. In this manner it will 
grasp with the utmost firmness, for its strength is fully equal to its flexibility, whatever it may seize; and it is by this means that the Elephant conveys his food to his mouth. Being purely herbivorous, but encumbered with a head and appendages so weighty as to require all the support to be derived from an excessively short and almost unyielding neck, it would be utterly impossible for him to browse upon the herbage from which his sustenance is chiefly derived, and he would consequently run no small risk of absolute starvation, were it not for this admirable provision, by means of which he collects and enfolds his food, and conveys it to his mouth with as much ease and precision as a Monkey would execute the same motions with his hands. In drinking too the trunk offers the same facilities and performs the same useful and necessary office. Placing its extremity in the fluid which he is about to drink, the Elephant pumps up, or rather inhales, a sufficient quantity to fill its cavities, and then transferring it to his mouth pours its contents quietly down his throat. When his thirst is satisfied he will frequently continue the same process of filling his trunk for the purpose of discharging the liquid contained in it over his body, an indulgence in which he appears to take no little pleasure; and will even sometimes amuse himself by directing the fluid to other objects.

The Asiatic Elephant was until very lately considered as forming one species with the African, the clear and obvious distinctions which exist between them never having been noticed until pointed out by M. Cuvier, notwithstanding that both have been familiarly known for more than two thousand years to the nations of 
Europe, the former having formed an important part of the armament with which Porus withstood the conquering arms of Alexander, and having been subsequently introduced even into Italy by Pyrrhus; and the latter, as we may fairly presume, furnishing those individuals which were employed in the warlike array of the Carthaginians. The Asiatic animal appears when fully grown to attain a larger size than the African, the females commonly measuring from seven to eight, and the males from eight to ten feet in height, and sometimes weighing six or seven thousand pounds. His head is more oblong, and his forehead presents in the centre a deep concavity between two lateral and rounded elevations; that of the African being round and convex in all its parts. The teeth of the former are composed of transverse vertical laminæ of equal breadth, while those of the latter form rhomboidal or lozenge-shaped divisions. The ears of the Asiatic are also smaller and descend no lower than his neck, and he exhibits four distinct toes on his hind feet: the African on the contrary is furnished with ears of much greater size, descending to his legs, and no more than three toes are visible on his posterior extremities. These differences are so striking and important, and indeed, so far as regards the form of the head and the structure of the teeth, so essential, that it is impossible not to adopt the division which has been founded upon them, and to consider the natives of the two continents as originally and specifically distinct.

The Asiatic Elephants themselves vary considerably in several minor particulars, such as the comparative length and thickness of their trunks and of their tusks, the latter of which are sometimes, even in the males, of 
very small dimensions. But these variations are evidently the result of locality and other fortuitous circumstances, the species appearing gradually to degenerate as it recedes from the tropics, and to improve as it advances towards the line. The Elephants of Ceylon are consequently in the highest esteem for size, beauty, and hardihood, and those of Pegu are but little inferior to them; while those of the northern districts of India are held in comparatively trifling estimation.

These animals are by nature sociable, and congregate together in herds, which frequently amount to more than a hundred. The imposing spectacle furnished by such a collection of these immense masses of animated matter may well be imagined. They generally seek the shade of the forest, in which they find additional means of subsistence in the young shoots of the trees, which supply the place of other and more congenial herbs. They frequently issue from it, however, in quest of the latter, and also to indulge in a propensity possessed by them in common with all those animals which like them are furnished with thick and almost naked, or with bristly, skins, that of bathing in the water or wallowing in the mud. It is for this reason that they are usually met with in the neighbourhood of large streams, which their great size and the quantity of fat with which they are commonly loaded enable them to swim with facility. Their trunk is also extremely serviceable in this operation, as it enables them to bury as it were the whole of their body beneath the water, retaining above the surface no more than the extremity of that organ for the admission and expulsion of the air. After having been for some time in the water, it is said that their skin loses the 
dusky hue by which it is usually distinguished in consequence of the dirt and other matters with which it is incrusted, and assumes a perfect flesh-colour marked with numerous round and blackish spots. This natural colour is, however, lost almost immediately on their reaching the land, when they uniformly scatter themselves all over by means of their trunk with the mud or dust which first falls in their way. So fond are they of this process that they commonly recur to it whenever an opportunity offers. The bathing appears to be absolutely necessary in order to keep their skins to a certain extent supple and flexible; for which purpose their keepers, in captivity, occasionally have recourse to the smearing them with oil as a substitute.

Like other herbivorous quadrupeds they are, generally speaking, quiet and harmless, intent solely upon providing for their wants, and never attacking man or other animals unless provoked or when under the influence of excitement. In this latter case they make use not only of their proboscis, which they wield with great dexterity as a weapon of offence, but also of their tusks, with which they inflict the most tremendous wounds. Their speed in pursuit corresponds rather with the cumbrousness than with the magnitude of their frame, the excessive weight of which soon renders them weary, and compels them to slacken their pace; which, when urged to the utmost, is barely equal to that of a horse of moderate fleetness. They will sometimes penetrate in quest of food into the rice fields and sugar plantations, in which they commit the most extensive ravages, not so much by the quantity which they consume as by that which they destroy. The solitary individuals, which are 
occasionally met with separate from the general herd, indulge perhaps more frequently in these excesses than the community, which generally avoids as much as possible the habitations of man. It has commonly been imagined that these stray Elephants were the younger and weaker males, who had been driven from the herd by their more powerful fellows; but the fact that they are usually adults of the largest size completely negatives this supposition, and proves that it is of their own free will that they wander thus alone. They attain their full growth between the ages of eighteen and twentyfour, and well authenticated instances have occurred in which they have reached the age of a hundred and thirty years. Indeed there is reason to believe that their life may be sometimes prolonged to two centuries.

The usual mode of catching the wild Elephants for the purpose of domestication has been so often described that it would be superfluous to repeat it here. It may be sufficient to observe that a herd of them having been driven by the hunters into an enclosure surrounded by palisades and ditches, and provided only with a narrow pass by way of egress, they are there made prisoners one after the other, and attached to the tame elephants, which are employed on such occasions partly as decoys and partly as guards over their captive brethren. The necessity of having recourse to this mode of supplying the wants, or rather of ministering to the pride, of the sovereigns of the East, both native and European, who alike regard these animals as the indispensable appendages of their rank, arises from the circumstance of the breed being very rarely propagated in captivity; the Hindoos being either too ignorant or too careless to adopt the requisite 
measures for securing its continuance, and relying upon the certainty of being enabled by their hunting to keep up a sufficient supply. But there can be little doubt, from what we observe in other animals, that had a domesticated breed of Elephants existed from the times when their services were first made available to man, they would have been far superior both in sagacity and docility to the half-reclaimed individuals at present employed.

It may readily be supposed that the taming of these wild and unwieldy creatures is a task of no little difficulty and delicacy: but the experienced keepers by whom it is undertaken seldom fail to execute it with success. It is effected partly by reducing the strength of the animal by restricting him in the quantity of his food, by the employment of caresses or of castigation according to the dispositions he may manifest, by occasionally indulging him in sweetmeats or in other dainty fare, and by subjecting him to the control of the tame elephants, and especially of the females, which are more commonly employed for this purpose. By the application of these means the space of a fortnight is generally sufficient to reduce him to a certain degree of tameness, and in less than six months he is trained to the various exercises which it is intended that he should perform; and his education is regarded as complete. They do not, however, always become familiar and habituated to their new mode of life even within this period of time; for, according to the statement of $\mathrm{Mr}$. Corse, Elephants have been known to stand twelve months at their pickets without lying down to sleep; and this is regarded as a certain sign of want of confidence in their keepers and of 
a longing desire to regain their liberty. It is probably to some such circumstance as this that we are indebted for the erroneous idea so generally prevalent that these animals always sleep standing; whereas the truth is, that when perfectly at ease and reconciled to their fate, they lie down on their sides and sleep like other beasts.

The purposes for which they are commonly employed are rather those of pomp, of luxury, and of ostentation, than of utility. As a means of warlike offence they have been, since the introduction of firearms, absolutely disused; and it is only as beasts of burden that they are turned, to any useful account. In this respect the services of a single Elephant are equal to those of five or six horses, as they will carry from fifteen to twenty hundred weight, and travel from forty to fifty miles a day. They generally consume a hundred weight and a half or two hundred weight of solid food, and thirty or forty gallons of fluid, in the course of the day. They are fond of wine, spirits, and other intoxicating articles, by the attraction of which they are frequently induced to exert their powers, and to perform various feats of dexterity, when all other methods have failed to render them tractable. They become strongly attached to their keepers; but, if irritated by ill usage, their hatred is as violent as their affection, and is carefully stored up until a favourable opportunity occurs, when they seldom fail to remember an insult or an injury, even at very distant periods of time.

With regard to their sagacity much has been written, and many exaggerated and many incredible stories have been told; but it would appear that those who have attributed to the Elephant a degree of intelligence 
superior to every other beast, have been misled by outward appearances, and by the natural prepossession arising from his gigantic and imposing figure. Without his trunk, upon the singular and admirable structure of which most of that skill and dexterity which have been regarded as the result of mental reflection is entirely dependent, he would be, in all probability, as very a brute as the rhinoceros, the hippopotamus, or the hog. By means of that organ, however, he unquestionably acquires the capacity of performing feats of which other animals are incapable; but here his superiority ends. In intelligence, as in docility, he is far inferior to the dog; and many other quadrupeds might fairly compete with him in both. Thus to turn a key in a lock, to push back a bolt, to untie a rope, to uncork a bottle, to search in the pockets of his keepers for apples or oranges, these and many other tricks of a similar kind, for which he is famous, are evidently nothing more than mechanical actions, to the performance of which he is stimulated, like other beasts, at first by the promise of reward or the fear of chastisement, and afterwards by the mere force of habit. In like manner the dexterity with which he learns to load and unload himself, or to place a man or child upon his back by means of his trunk, without offering them the slightest injury; and on the other hand the precision with which he is made to execute the will of the Asiatic despot on the unhappy victims of his displeasure, by seizing them and casting them beneath his feet, to be there dispatched, according to the tenor of the orders which he receives, either with a single crush, or with all the horrors of a lingering death; these also are actions of no higher order than many other animals are 
equally capable of in a moral point of view, although not so well fitted for them by physical conformation.

In conclusion we have only to add that the fine little Elephant from which our figure was taken appears from his dimensions and from the very small size of his tusks to be little more than three years old. He is extremely good tempered, and became reconciled to his situation almost from the very moment of his arrival.

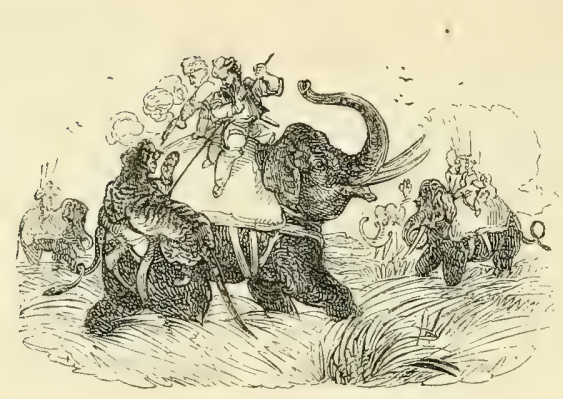




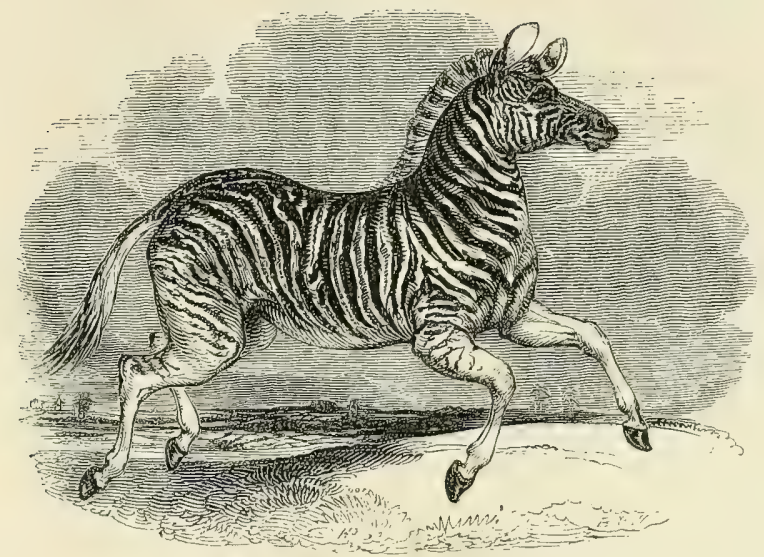

THE ZEBRA OF THE PLAINS.

EQUUS BURCHELLII.

THE well known group of which the Horse, the Ass, and the Zebra constitute the leading species, is distinguished from all other quadrupeds by the form of their hoof, which is single and undivided, rounded in front, of considerable thickness, and enveloping the extremity of their only apparent toe. They have in each jaw six powerful cutting teeth, accompanied gn either side by the same number of grinders with square crowns flattened at the top: the males have two canines in the upper jaw, and frequently in the lower also; and this structure is sometimes shared by the females of the domesticated races. Between the canines and the molars 
there is a vacant space, which, our readers scarcely need to be reminded, receives the bit, the small but irresistible instrument by means of which man has for ages exercised the most complete control over the services of these useful animals. Although purely and essentially herbivorous, their anatomy, as well as their habits, separates them most thoroughly from the Ruminants, and approximates them in several respects to the Pachydermatous order, with which, in spite of their many discrepancies, both physical and moral, M. Cuvier has associated them. It is needless to point out the incongruity of this union, and it would be equally so to say more of the general form and external characteristics of a group, the principal species of which are so constantly before our eyes.

It may, however, be observed, that it has been proposed to divide it into two distinct genera, the one containing the Horse alone, and characterized by the flowing tail uniformly covered with long hair, by the absence of a line of darker coloured hairs along the back, and by the presence of callous protuberances on the hind legs as well as on the fore: the other comprehending the Asses and Zebras, and distinguished by the tail having a brush of long hairs at its extremity only, by the presence of the dorsal line, and the absence of the protuberances on the posterior legs. Such a division, resting as it does on striking but not very essential differences, may fairly be admitted for the purpose of separating the genus into sections; but can hardly be regarded as founded on characters of sufficient importance to disunite so well marked and strongly connected, as well as so limited, a group. In the same paper in 
which this new arrangement was proposed, the beautiful animal which we have now to describe was first specifically distinguished by $\mathrm{Mr}$. Gray from the Common Zebra, with which it had previously been confounded, and characterized by him under the name of the Asinus Burchellii. Still there exists so much confusion between the two Zebras, many naturalists falling into the same error with Mr. Burchell, who first remarked the distinction between them, and regarding the present animal as the Zebra of zoologists, and the common one in reality as the new species; while others have absolutely counterchanged a part of the characters of each, and thus made confusion worse confounded; that we cannot do better than describe with some little detail the markings of the individual now before us.

The ground colour of its whole body is white, interrupted by a regular series of broad black stripes extending from the back across the sides, with narrower and fainter ones intervening between each. Over the haunches and shoulders these stripes form a kind of bifurcation, between the divisions of which there are a few transverse lines of the same colour; but these suddenly and abruptly cease, and are not continued on the legs, which are perfectly white. Along the back there is a narrow longitudinal line, bordered on each side with white. The mane is throughout broadly and deeply tipped with black, and is marked by a continuation of the transverse bands of the neck. The lines of the face are narrow and beautifully regular; from the centre of the forehead they radiate downwards over the eyes; along the front of the muzzle they are longitudinal, the outer ones having a curve outwards; and on the sides they form broader 
transverse bands. From the confluence of these bands on the extremity of the muzzle, the nose, and the lower lip, those parts become of a nearly uniform blackish brown. The tail is white: there is no longitudinal ventral line: and a large black patch occupies the posterior part of the ear near the tip. The hoofs are moderately large, deep in front, shallow behind, and much expanded at their margin.

Of the habits of these animals in a state of nature we know but little. They inhabit the flat parts near the Cape of Good Hope, the common Zebra being confined to the mountains. All the attempts that have been made to domesticate either the one or the other, and to render them serviceable, have hitherto failed; but there seems no good reason why they should not, with proper management, be brought as completely under subjection as the other species of the genus. The subject of the present article, which has now been about two years in the Menagerie, will suffer a boy to ride her about the yard, and is frequently allowed to run loose through the Tower, with a man by her side, whom she does not attempt to quit except to run to the Canteen, where she is occasionally indulged with a draught of ale, of which she is particularly fond.

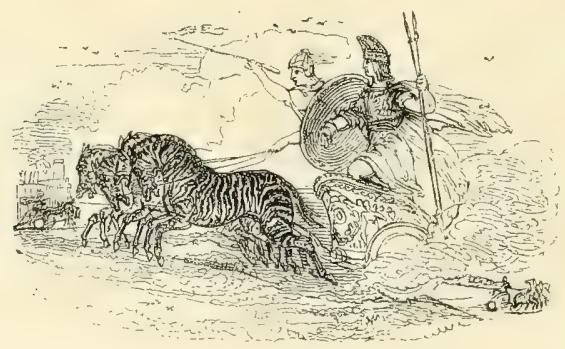




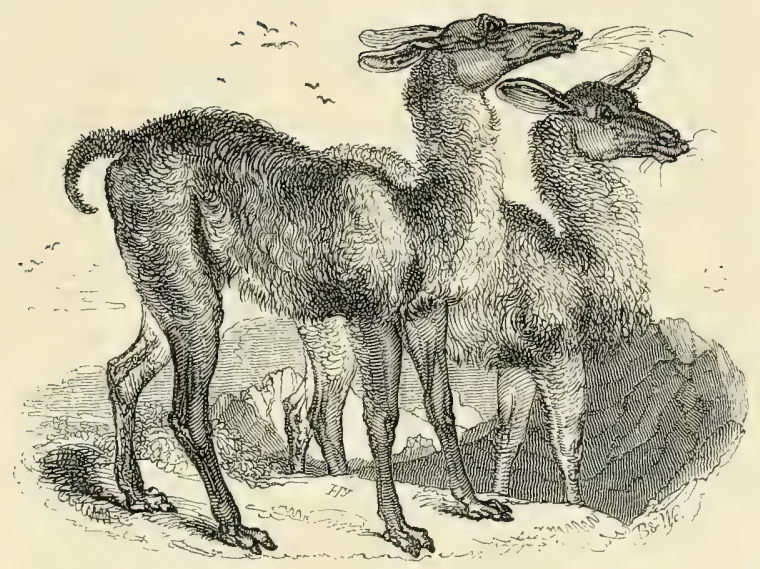

THE LLAMA.

Llama Perutiana. Cuv.

IN common with the Camels, the Llamas are distinguished from all other Ruminating animals chiefly by the absence of horns, by the structure of their feet, and by their mode of dentition, in all of which these two closely allied groups very nearly correspond with each other. In their general form there is also some similarity; but the latter are much lighter in their proportions, and far more lively and spirited in their motions. They exhibit no traces of the clumsy and unsightly humps which disfigure the backs of the former, and their necks and limbs, of greater comparative length, appear to be far less oppressed by the superincumbent weight of the head 
and body, which are consequently maintained in a more upright and graceful position. The principal difference in their internal structure consists in the want of that extensive appendage to the first stomach, which renders the Camel so peculiarly valuable in situations where water is with difficulty procured, by enabling him to lay in at once a sufficient stock of that indispensable necessary to supply his wants for many days. But even without this appendage the Liamas are observed to be by no means so much exposed to frequent thirst as the generality of animals, and to drink but rarely and in moderate quantity.

The feet of the Camels and of the Llamas are very different in form from those of all the other Ruminants. They are, it is true, deeply divided, like those of the latter, into two apparent toes; but cannot be said, like them, to part the hoof, for they have no real hoof, and the extremities of their protruded toes are armed only with short, thick, and crooked claws. These toes are in the Camels united posteriorly by a horny process, which is wanting in the Llamas. The teeth of both are nearly similar: they consist of six incisors in the lower jaw and two in the upper; of two canines in each; and of six molars in the upper, and five in the lower, on each side. None of the other Ruminants exhibit the least appearance of cutting teeth in the upper jaw. The nostrils of both consist externally of mere fissures in the skin, which may be opened and closed at pleasure, and which are surrounded by a naked muzzle; and their upper lip is divided into two distinct portions, which are very extensible, and capable of much separate motion.

The species of the group, of which the Llama forms 
the type, have been involved by the imperfect descriptions of naturalists in almost inextricable confusion. No less than five have been admitted; but the variations of colour and of size, and the degree of length and fineness of the wool, differences rather commercial than natural, afford almost the only positive distinctions that have yet been laid down between them; and when we consider that some of them have been for ages in a state of domestication, it will readily be allowed that such characters as these are, to say the least, trivial and uncertain. Our animals, which are nearly four feet in height at the shoulder, and somewhat more than five feet to the top of the head, have the neck, the back, the sides, and the tail, which is rather short, covered with a beautiful coat of long, bright brown, woolly hair. The long and pointed ears, and the small and attenuated head, on which the hair is short, close, and even, are of a grayish mouse-colour; the outside of the legs is of the same colour with the sides of the body; and their inside, as also the under part of the body and the throat, pure white. The hair on the limbs is short and smooth. In these respects they offer but little to distinguish them from any of the animals which have been exhibited in this country under the various names of Llamas, Pacos, and Guanacos. There is, however, at present in the Garden of the Zoological Society, an animal, which besides being of larger size, covered with longer and coarser wool, and entirely white (which latter circumstance may be purely accidental), differs remarkably in the form of the forehead, which in it is perfectly flat, while in our animals it rises in a strong curve. This character, it is probable, affords a permanent ground of 
distinction, although we venture not at present to speak decidedly respecting it.

The Llamas congregate together in considerable herds on the sides of the Andes, and generally in the colder and more elevated regions. When the Spaniards first arrived in Peru they were the only beasts of burden employed by the natives; and even at the present day, when horses have become so excessively common, they are usually preferred for passing the mountains, on which their sureness of footing, exceeding even that of the mule, gives them a manifest superiority. Generally speaking they are quiet, docile and timid; but they occasionally exihibit much spitefulness, especially if teased or ill treated. Their mode of evincing this is very peculiar, and consists in darting their saliva through their nostrils with considerable force. Like all the other Ruminants they subsist entirely on vegetables. Those in the Tower Menagerie have a particular fondness for carrots; and if one of these is abstracted from them while they are eating, their anger is immediately roused, and they spit, as it is termed, with the greatest vehemence, covering with their saliva a surface of three or four yards in extent. One of the animals in the cut is represented in the act.

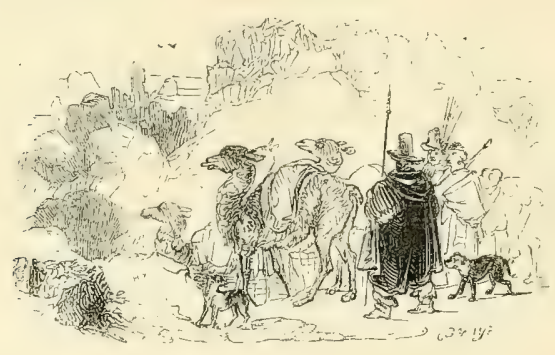




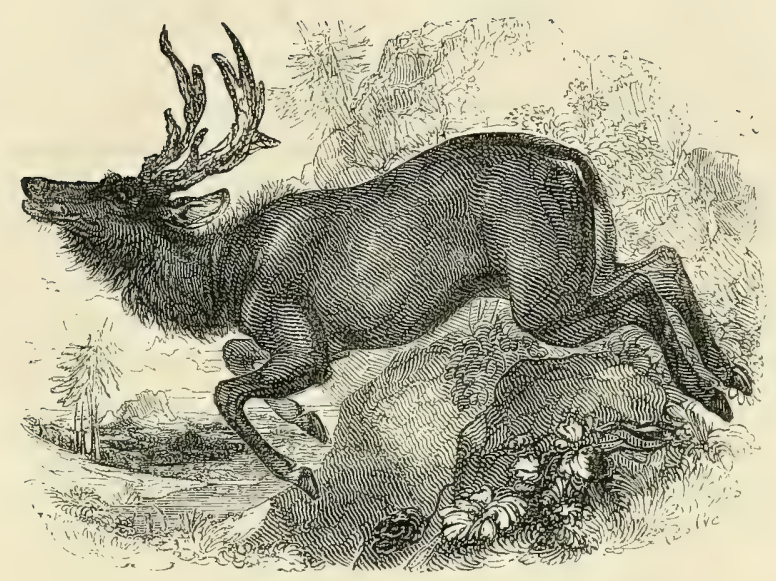

THE MALAYAN RUSA-DEER.

Cervus Equinus. Cuv.

The Deer constitute a numerous and beautiful group of Ruminants, which are readily distinguished by the graceful symmetry of their form, by their long and slender, but firm and sinewy, legs, by their broad and pointed ears, and by the comparative shortness of their tails; but more especially by the generally large and branching horns which ornament the heads of the males. Like all the ruminating animals, with the exception of those mentioned in the preceding article, they are furnished with eight cutting-teeth in the lower jaw, opposed to a callous and toothless surface in the upper; and with expanded, flat, and deeply bifurcated hoofs, constituting 
two distinct and apparent toes, above which they have also the rudiments of two others. Some of the species have canine teeth in the upper jaw, generally in the males alone; and they have all six molars on each side. In the greater number of them the nostrils are surrounded by a naked muzzle; and most of them are also provided with a sinus or sac, of greater or less extent, immediately beneath the inner angle of the eye, called the suborbital sinus, the larmier of the French zoologists.

The horns, which form the most distinguishing character of the genus, are perfectly solid throughout their whole extent. Their form varies very considerably in the different races; but they are constantly uniform in the same species, unless accidentally or artificially perverted from their natural growth. In some they are simple at the base and terminate in a broad and palmate expansion, which is variously lobed and divided; in others they are more or less branched, giving off antlers in different directions; and in some few they are short and nearly simple. They fall off and are renewed annually in all the species which inhabit the northern and temperate regions of the earth, and in those in which they attain any considerable size; but Sir T. Stamford Raffles was of opinion, and his opinion has been in some measure confirmed by the observations of Major C. Hamilton Smith, that several of the tropical species with small and nearly simple horns are exempted from this general law. The horns are smaller and less developed in the young than in the full grown and adult animal, and diminish again in size, and frequently become irregular, as he advances in age. In one species alone, the Rein-Deer of the North, the female wears the 
same palmy honours with the male; but they do not in her reach the same enormous extent.

The high degree of domestication to which this latter species has been brought, and the invaluable services which it renders to the Laplander, added to the tranquil content which most of the deer manifest in a state of captivity, afford sufficient proofs that there is nothing in the constitution of the group repugnant to their being tamed and familiarized with man; but from none of the other races have any real or essential advantages been as yet derived. The quiet confidence, mixed with a certain air of cautious timidity, which they exhibit in their halfrestricted state, in the park or the chase, where they are kept more for ornament than use, is perfectly indicative of their general character. But the very mildness of their disposition has been turned to their disadvantage, and one of the gentlest of animals, because endowed by nature with a high degree of fleetness, with some sagacity, and with a certain share of timidity, has been marked out by man as the chosen victim of his cruelty, disguised under the captivating name of sport.

The Samboo Deer, as the present species is called by his keepers, belongs to the Rusa group, which are distinguished from the rest of the genus by their horns being provided with a single antler at the base, and with a lateral snag which forms a kind of bifurcation towards the extremity. They are usually of large stature and nearly uniform colours, and are, for the most part, furnished with a rough and shaggy mane, a broad and expanded muzzle, and sub-orbital openings of considerable size. The handsome Stag now before us is dark cinereous brown above, nearly black on the throat and 
breast, and light fawn, intermixed with dirty white, on the inside of the limbs. His eyes are surrounded by a fawn-coloured disc, and patches of the same colour occupy the fore knees, and a space above each of the hoofs in front. His nose, which is black, is enveloped in an extensive muzzle; his ears are nearly naked on the inside, and marked by a patch of dirty white at the base externally; and his mane, which spreads downwards over the neck and throat, is remarkably thick and heavy. His tail is black above, and light fawn beneath; and a disc of the latter colour occupies the posterior part of the buttocks, having on each side a blackish line which separates it from the lighter tinge of the inside of the thighs. His horns, when properly grown, consist of a broad burr, from which the pointed basal antler rises almost perpendicularly to the extent of nine or ten inches; of a stem, which is first directed outwards, and then forms a bold curve inwards; and of a snag, or second antler of smaller size, arising from the stem near its extremity on the posterior and internal side, and forming with it a terminal fork, the branch however being shorter than the stem, and not exceeding five or six inches in length. The entire length of the horns is about two feet; they are of a dark colour, very strong, and deeply furrowed throughout.

The foregoing description of the horns, it should be observed, is taken from those of the year before last, which were of the genuine or normal form. Those of the last year, which are represented in the cut prefixed, were from some cause or other remarkably different, that of the right side especially exhibiting a singular monstrosity in the production of additional branches of 
irregular form. Whether this was the effect of disease or of advancing age, or whether it arose solely from some temporary and accidental cause, will probably be determined by the growth of the present year, which is not yet sufficiently advanced to enable us to ascertain its probable form.

With regard to the sub-orbital sinus, which in this and all the neighbouring species is of very considerable size, its uses are evidently connected with the function of respiration, and probably also with the sense of smell. It is denoted externally by a longitudinal fissure, placed beneath the inner angle of each of the eyes, and leading into a sac or cavity, which in some cases communicates internally with the nose; and its inner surface is lined by a membrane abundantly supplied with follicles for the secretion of mucus, which is sometimes produced in very large quantities. This latter circumstance has induced some naturalists to regard these openings as mere cuticular appendages. That they really, in some species at least, communicate with the nostrils, is proved by the observations of Mr. White of Selbourne, who states that in consequence of this communication the Fallow-Deer are enabled to take long-continued draughts with their noses deeply immersed in the water, the air in the mean time passing through the sub-orbital slits. So singular a statement was naturally enough doubted and called in question; but it has never, so far as we know, been impugned on ocular testimony; while it has received the fullest confirmation from other observations made upon the very species now under consideration, in which the air passing from the sub-orbital sinus, while the animal drinks, may be felt by the hand, and even 
affects the flame of a candle. Another proof of the connexion of these cavities with the nose is derived from the fact that the animals which are provided with them frequently apply their orifices, equally with those of the nostrils, to the food which they are about to take, opening and shutting them with great rapidity.

The subject of the present article, which, like all the rest of the minor group of which he forms a part, is a native of India and of the Indian Islands, was a present to his Majesty, who kept him for some time, in company with another of the same species, at large in the great park at Windsor. As both, however, happened to be males, they disagreed so violently, and their quarrels at length rose to such a pitch, that in order to preserve peace it was found absolutely necessary to separate them; and our animal, as the most outrageous of the two, was dismissed the royal service, and condemned to the captivity of the Tower. Since this period he has become exceedingly tame, the cause of his former ill temper being removed, and demeans himself as quietly as the most harmless and gentlest of his tribe.

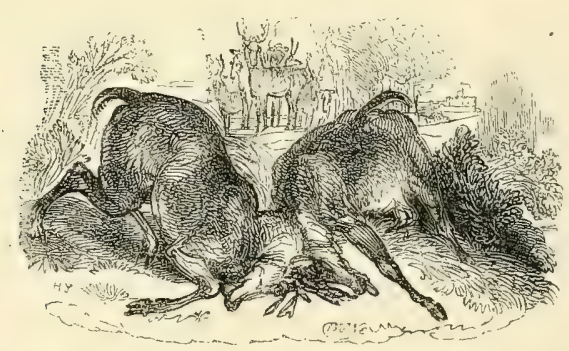




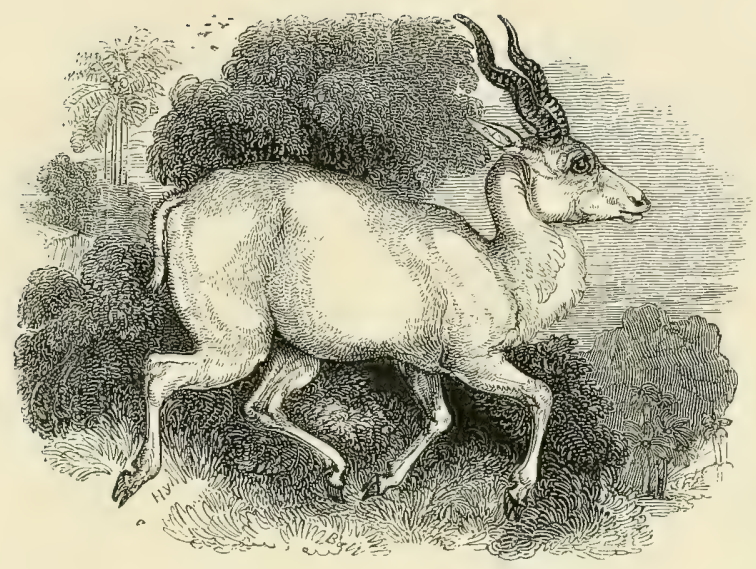

\section{THE INDIAN ANTELOPE.}

Antilope Cervicapra. Pall.

In the elegant symmetry of their form and the light and graceful agility of their motions, the Antelopes are superior even to the Deer, whom, however, they closely resemble, not merely in outward shape, but also in internal structure. Like them, in addition to the coincidence of a slightly made and beautifully proportioned figure, they are frequently furnished with a naked muzzle, and with the same remarkable sinus beneath the inner angle of the eye; and their ears are generally of considerable size, erect, and pointed. But they are strikingly distinguished from them and from all the other animals of the order by the peculiar character of 
their horns, which are formed of an elastic sheath enclosing a solid nucleus, and are for the most part common to the females as well as to the males. They have no canine teeth, and exhibit no appearance of a beard such as is seen in the Goats. The horns vary greatly in the different races; they are sometimes straight and upright, at other times slightly curved, and frequently spirally twisted with the most beautiful regularity : they are usually surrounded by elevated rings or by a spiral ridge, are constantly of the same form in the same species, and are not subject to an annual falling off and renewal, as in the Deer, from which they differ also in their mode of growth, the horns of the latter group lengthening at their apices, while those of the former receive their increase at the base.

In their natural habits the numerous species of which this group is composed approach very closely to the Deer; there is, however, considerable variety in their mode of life. They inhabit almost every description of country; the sandy desert, the open plain, the thicket, the forest, the mountain, and the precipice, being, each in its turn, the favourite haunt of the different races; but, with the exception of a few species, they do not advance much beyond the limits of the tropics. The smaller ones usually prefer a solitary life, but the larger, for the most part, congregate together in herds; which are generally few in number. In their manners they exhibit much of that cautious vigilance and easily startled timidity, combined with a certain degree of occasional boldness and not a little curiosity, which are the natural consequences of their wild and unrestricted habits, of their trivial means of defence against the 
numerous enemies to whose attacks they are exposed, and of the unequalled fleetness of their speed. In some this latter quality consists of a continued and uniform gallop, which in others is interrupted at every third or fourth stroke by a long and generally a lofty bound, producing a beautiful effect by its constant and rapid recurrence.

The Indian Antelope, of which the specimen in the Tower constitutes a remarkable and highly interesting variety, is not only one of the most beautiful, but also the most celebrated species of the group. It occupies the place of Capricorn in the Indian Zodiac, and is consecrated to the service of Chandra or the Moon. In size and form it closely resembles the Gazelle of the Arabs, the well known emblem of maiden beauty, typified, according to the poets, in the elastic lightness of its bound, the graceful symmetry of its figure, and the soft lustre of its full and hazel eye. From this truly elegant creature our Antelope is, however, essentially distinguished by several striking characters. Its horns, which are peculiar to the male, are spirally twisted, and form, when fully grown, three complete turns; they are closely approximated to each other at the base, but diverge considerably as they proceed upwards. They occasionally attain a length of nearly two feet, and are surrounded throughout by elevated and close-set rings. The two horns taken together have frequently been compared to the branches of a double lyre. The extremity of the nose is bare, forming a small and moist muzzle; the sub-orbital openings are larger and more distinct than in almost any other species; and the ears are pointed and of moderate size. The natural colours 
vary with the age of the animal, but correspond in general pretty closely with those of the common deer. They may be shortly described as fawn above and whitish beneath, becoming deeper with age, and lighter in the females than in the males. The occasional stripes of a lighter or darker colour, which are generally visible on various parts of the body, can scarcely be considered as occurring with sufficient regularity to allow of their being described as characteristic of the species.

But for these shades of colour, or for any other, we should look in vain in the animal of the Tower Menagerie, which, in consequence of a particular conformation, not unfrequent in some species of animals, and occasionally met with even in the human race, is perfectly and purely white. In order to explain this phenomenon, which is one of the most curious, but at the same time one of the most simple in physiology, it is necessary to observe that there exists beneath the epidermis, or outer covering of the skin, both in man and animals, a peculiar membrane of very fine and delicate texture, which is scarcely visible in the European but sufficiently obvious in the Negro, termed by anatomists the rete mucosum. In this net-work is secreted, from the extremities of the minute vessels which terminate upon its surface, a mucous substance which varies in colour according to the complexion of the individual, of the varieties in which it is the immediate cause; and from the substance thus secreted the colouring matter of the hairs and of the iris is derived. The pure whiteness then of the covering of the animal in question, and of all those which exhibit a similar variation from their natural tinge, is attributable solely to the absence of this secretion from whatever 
cause. It is always accompanied, as in the present instance, by a redness of the eyes, arising from the blood-vessels of the iris being exposed to view in consequence of the want of the usual coating formed by this secretion, by which they are naturally protected from the too great influence of the light. In the human race the individuals who are thus afflicted, characterized by the dull whiteness of their skins, the deep redness of their eyes, and their colourless, or, as it is generally termed, flaxen, hair, are called Albinos. They are generally timid in disposition, languid in character, and weak both in mind and body. The same original conformation, for it is always born with the individual and never acquired in after life, although sometimes prolonged beyond its limits in the shape of an hereditary legacy, is common to many animals. Perhaps the most familiar instances among these are the white mice, the white rabbits, and the white pigeons, which are known to every one. But it has also been occasionally seen in many other species, as monkeys, squirrels, moles, pigs, and even cows and horses, and, to come a little closer to our present subject, in goats and deer. Not even that massive and stupendous beast the Elephant is exempted from its influence. It can hardly be necessary to recall to the reader the title on which the ruler of millions of not uncivilized Asiatics, the Burmese monarch, prides himself more than on any other, inasmuch as it is the emblem of power and prosperity, that of Lord of the White Elephant; a title, which, while it demonstrates the fact of the existence of this deviation in the Elephant as well as in other animals, proves also 
the extreme rarity of its occurrence. It has moreover been noticed in many species of birds.

The present species of Antelope is spread over the whole of the Peninsula of Hindoostan and a part of Persia; but it is questionable whether it has been found in Africa, as is commonly asserted. They are said to bound with apparent ease over a distance of from twentyfive to thirty feet, and mounting to the height of ten or twelve. It is consequently useless to attempt to chase them in the common mode with hounds; and their pursuit is restricted to the higher nobility, who employ for the purpose either hawks, who pounce upon their quarry and detain it until the dogs can come up, or Chetahs, who attack them by surprise in the manner before described.

The elegant Albino now in the Tower was brought from Bombay by Captain Dalrymple of the Vansittart, and remained for a considerable time at Sand Pit Gate, where it was an especial favourite with his Majesty, as well on account of the gentleness of its disposition, as for its rarity and beauty. It bears its confinement in the Menagerie with perfect resignation, and is remarkable for the mildness and tranquillity of its deportment.

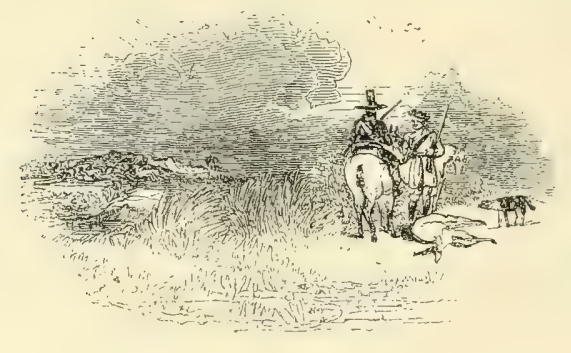




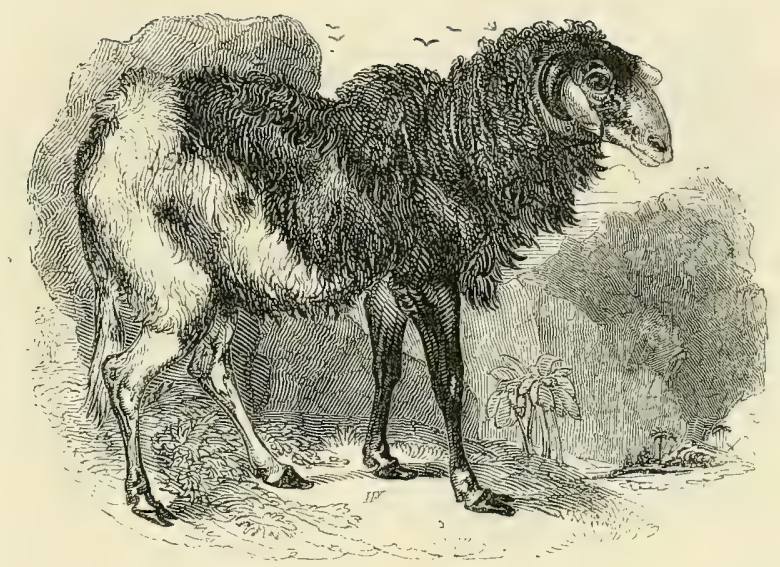

THE AFRICAN SHEEP.

OVIS ARIES. Linn.—Var. GuineEnsis.

Is characterizing the present genus, were we to look solely at the animal such as we have it daily before our eyes, the distinction between it and all the other Ruminants is too striking to be for a moment mistaken. But the insensible gradations which connect this familiar denizen of our downs and pastures with the untamed native of the desert and the precipice, and the close affinity which subsists between the latter and the goats, render it almost impossible to isolate them by any satisfactory characters. On the present occasion we shall content ourselves with observing that the sheep may generally be distinguished by the direction of their 
horns, by the elevation of their profile, and by their want of beard : characters neither essential nor infallible, but the best that can be offered.

The variety figured over leaf is in one of the many intermediate stages between unreclaimed barbarism and complete domestication. It is an awkward looking creature, high on the legs, narrow in the loins, and covered with a rough and shaggy coat. The back and sides are nearly black; the shoulders reddish brown; and the posterior part of the body, the haunches, the hind legs, and the tail, white; as are also the ears, which are rather large, the nose, and a spot over each eye. The horns, although the specimen is a male, are remarkably small, and enclose the ears within their curve. If the ears are freed from their confinement, the animal becomes very uneasy, and never rests until he has succeeded in replacing them, which he cannot accomplish without considerable difficulty. He was presented to the Menagerie by Lord Liverpool about six years ago, and is extremely mild in his temper.

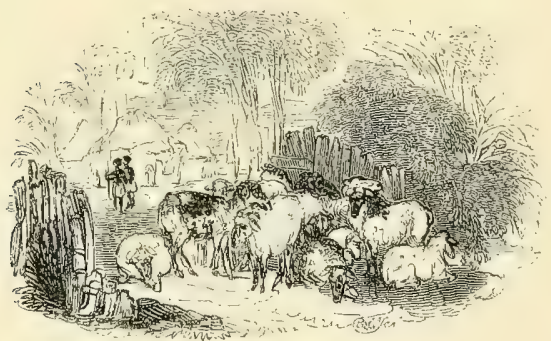




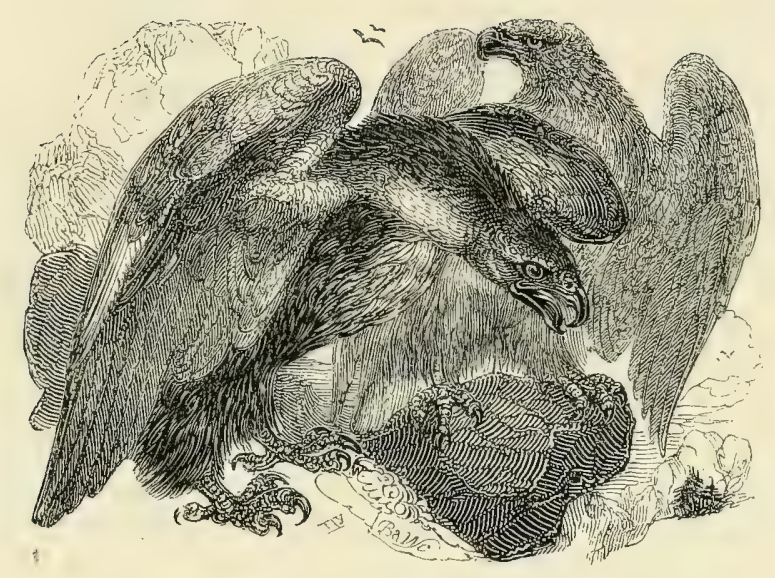

THE GREAT SEA-EAGLE..... THE GOLDEN EAGLE.

HaLIAETOS OSSIFRAGUS. SAV. AqUila CHRYSAETos. $\mathrm{S}_{\text {AV. }}$.

Having in the preceding article terminated the series of Mammiferous Quadrupeds at present existing in the Tower Menagerie, we must next direct our attention to the illustration of the Birds, a Class which, although fully entitled to the second place in the arrangement of the Animal Kingdom, is separated by a wide and almost unoccupied interval from that which unquestionably claims the foremost rank.

To commence then with the Eagles, which form a prominent group of the Rapacious Order, and are universally regarded as the most majestic, as well as the most powerful; of birds. In common with the whole 
Order, they are remarkable for the strong incurvation of their bill and talons, the latter of which are four in number on each of the feet, and are moved by means of a thick and strong muscular apparatus, which gives to the grasp of the larger species that extreme tenacity by which they are distinguished, enabling them to seize and carry off fish and birds, and even quadrupeds of moderate size. This innate propensity to rapine, derived from their peculiar conformation which renders them essentially flesh-eaters, indicates at once the analogical relationship borne by the Rapacious Birds to the Carnivorous Quadrupeds; and the high degree to which it is carried by the Eagles, their vast powers of flight, their towering majesty, their irresistible might, their uniform preference of living victims and rejection of the offal, render them superior to all other birds, in the same proportion as the Lion is allowed to take the lead among mammiferous quadrupeds.

The Eagles, properly so called, are characterized by a head covered with plumage and flattened above; eyes large, lateral, and deep-seated; a bill of great strength, arched and hooked at its extremity alone, and furnished at its base with a naked membrane, called the cere, in which the openings of the nostrils are situated; the wings broad and powerful; the tarsus, or that joint of each leg which is immediately above the toes, strong, short, and covered with feathers down to the very base; the toes thick and naked, three of them pointing forwards, and the fourth constantly directed backwards; and the talons of great power and strongly curved. The Golden Eagle, which occupies the right hand in the cut, is frequently three feet and a half in length from the 
extremity of the beak to that of the tail. His general colour is blackish brown both above and below, assuming on the legs a grayish or sometimes a reddish tinge. His beak is bluish black, covered at the base by a yellow cere; and his toes, which are also yellow, terminate in strong black talons, the posterior one of which frequently attains an enormous length. He is met with throughout the Old Continent, and more especially within the limits of the temperate zone, building his aiery, which he shares with a single female, in the clefts of the loftiest rock, or among the topmost branches of the alpine forest. From this retreat he towers aloft in search of his prey, which he pursues by sight alone, subsisting principally on other birds and on the smaller quadrupeds, which he carries off in his powerful clutch. When his hunger is extreme he sometimes pounces upon the larger animals; but in such circumstances he is compelled to content himself with sucking their blood upon the spot, and with stripping off portions of their flesh, on which to satiate his appetite at home. Instances have been known of his attaining in captivity to an age of more than a hundred years.

The principal distinguishing mark of the group which has been separated under the name of the Sea-Eagles, consists in the plumage of the tarsus, which in the latter extends only half way down, the lower part being consequently left entirely bare. The species figured on the left, at the head of this article, is commonly more than three feet in length, and the expansion of his wings measures seven or eight feet. His bill is usually of a bluish black colour towards the extremity, and yellow at the base. His general hue is blackish brown, deeper 
above than beneath, and relieved on the breast and under parts by numerous white spots. The larger feathers of his wings are nearly black; but those of the tail are not so deeply tinged. The raked portion of the legs, as also the toes, are covered with bright yellow scales; and the talons are of a bright black.

The Great Sea-Eagle is a native of the Northern Hemisphere, in the colder regions of which he appears to be most at home. He builds his nest in similar situations with the last, but prefers the neighbourhood of the sea, or of lakes and rivers, over which he is frequently to be seen, especially in the morning and towards nightfall, hovering in quest of prey, and pouncing down upon the fish which rise to the surface, or even diving after those which are visible beneath. These form his principal sustenance; but he seldom suffers flesh or fowl to escape him if they chance to fall in his way. His flight is less rapid and less lofty than that of the Golden Eagle; and he neither perceives his prey at such a distance, nor pursues it with such pertinacity.

The noble birds which illustrate the present article were presents from the Marchioness of Londonderry.

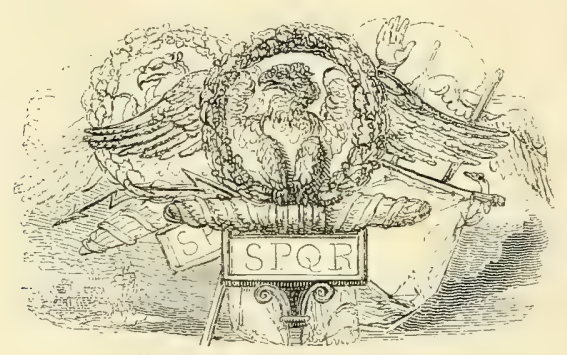




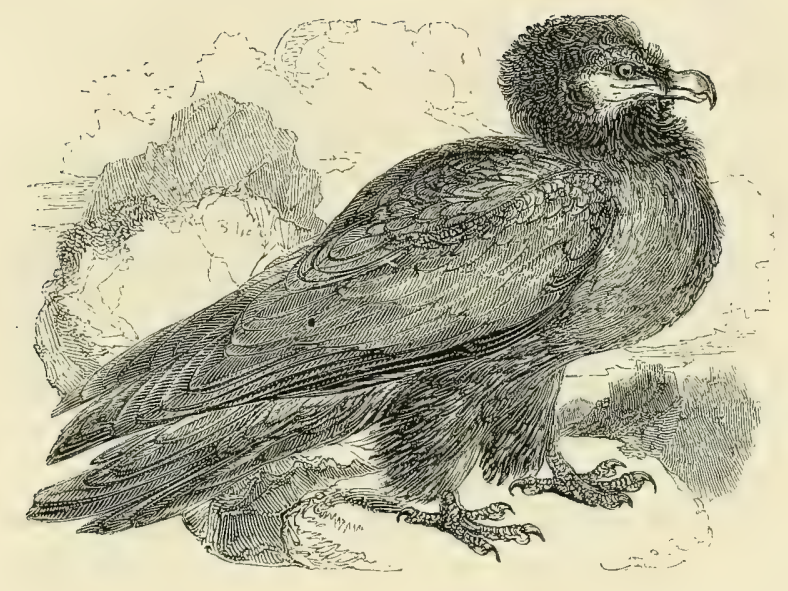

\section{THE BEARDED GRIFFIN.}

\section{GypaETOS BARbatUS. STORr.}

The Bearded Griffin takes an intermediate station between the Eagles and the Vultures, with the former of which it agrees more closely in general appearance and external form, and with the latter in internal structure and habits. The principal point in which it differs from them both consists in the tuft of bristly hairs which take their origin partly from the cere that covers the base of the beak, and partly from the under mandible, and are directed outwards and downwards in such a manner as to give rise to that appearance from which the bird has received his epithet of Bearded. His beak is strongly arched at the extremity, and is remarkable for its great 
vertical thickness, more especially at the point where the curvature commences. His head, flat like that of the Eagle, is covered with short feathers, which are of a dirty white; and his eyes are nearly on the same plane with the surface of his head. The general tint of his plumage is blackish brown above and grayish fawn beneath, and his legs are feathered with the latter colour down to the very toes, which are long and grayish. His claws are of moderate length and curved; but the force of his clutch is far inferior to that of the Eagles.

The Bearded Griffin is the largest European bird of prey, and builds its aiery among the loftiest precipices of nearly all the alpine chains of the old Continent. Here it displays the tyranny, but not the courage, of 'the Eagle, attacking such living animals only as are likely to fall an easy prey, and gorging in troops with all the rapacity of Vultures upon the most corrupted carrion.

The individual figured is a fine specimen, but is not yet in perfect plumage.

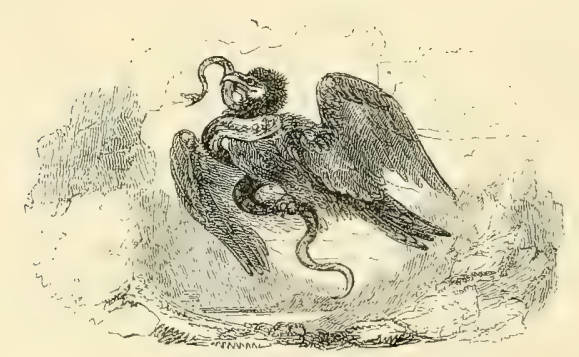




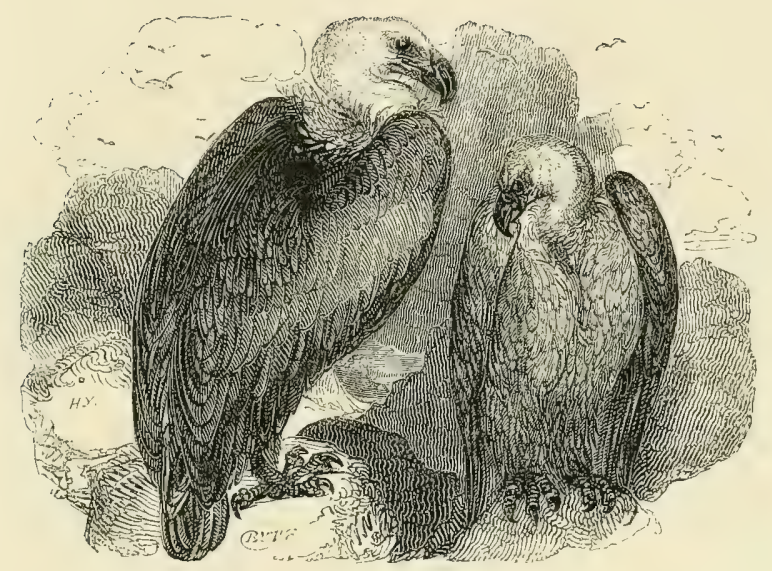

THE GRIFFON VULTURE.

VULTUR FULVUS. LINN.

If the Eagles are considered as bearing a close analogy to the more noble and perfect among the Carnivorous Quadrupeds, such as the Lion and the Tiger, which live in solitary grandeur and attack none but living victims, the Vultures may, with equal propriety, be regarded as the representatives of the Jackal, the Wolf, the Hyæna; and other inferior animals of that Order, which hunt in packs and prey upon carrion. Endowed like these animals with an extreme fineness of scent, they are attracted by the smell of dead, and more especially of putrid, carcases, at an immense and almost incredible distance; and usually assemble in vast numbers to glut 
themselves upon the disgusting banquet on the field of recent battle, or wherever the work of carnage has been carried to any great extent. Under such circumstances, however horrible that propensity may appear which leads them to prey upon the unburied corpses, they unquestionably fulfil a wise provision of nature by removing from the surface of the earth a mass of corruption and putridity which in the warmer climates where they abound would otherwise taint the very atmosphere, and might possibly give rise to diseases still more fatal in their effects than the malignant passions of man himself, from which the destruction sprung. But although such a scene affords the greatest scope for the indulgence of their depraved appetites, and consequently congregates them together in the largest numbers, it is happily of rare occurrence, and their usual subsistence is derived from the bodies of dead animals. To these they are attracted by the smell, and frequently in flocks so numerous as actually to cover and conceal the object of their attack, from which they tear away large gobbets, and swallow them entire and with insatiable avidity, never ceasing while yet a morsel remains. It is only when hard pressed by hunger that they venture to attack a living creature; and their ravages of this kind are always confined to the peaceful and timid denizens of the poultry-yard. They never carry off their victims in their talons, but uniformly devour them upon the spot; and even that portion of their prey which they transport to their young is first swallowed, and afterwards disgorged in the nest.

These peculiarities of habit, by which the Vultures are strikingly contrasted not merely with the Eagles, 
but even with the smallest of the Falcon tribe, are the necessary result of their organisation. Their beak, it is true, is like that of the Eagles strongly curved at the point alone, and they also possess all the technical characters of the Rapacious Order; but their talons are far inferior, both in size and in the degree of their curvature, and they are consequently unable to grasp their prey with sufficient force to transport it through the air. Their diminished power of flight renders them incapable of soaring upwards to search abroad with piercing eye for the objects of their rapacity; and they are therefore left dependent upon the acute sensibility of their nostrils, which amply supplies the deficiency. Of the external characters which they exhibit the most remarkable is derived from the want of plumage on the head and neck, which are covered in the greater number of the species by nothing more than a sort of down or by short and smooth hairs. The object of this provision appears to be to enable them to bury as it were their heads in the carrion on which they feed, without exposing their plumage to be soiled by the filth which it might otherwise contract. Their eyes are placed on a level with their cheeks; their heads are rounded above; they have most frequently a ruff of considerable extent round the lower part of their necks; and their legs are usually bare of feathers and covered with large scales. Their very attitudes offer the most perfect contrast to those of the Eagles; the latter constantly maintaining a bold upright posture, with their wings closely pressed to their sides, and their tails elevated, while the Vultures on the contrary are always seen bending forwards in a crouching position, with their wings depressed and separated 
from their bodies, and their tails trailing upon the ground.

The Griffon Vulture is equal in size to the larger species of Eagle; his head and neck are covered with short white down, and the latter is ornamented at its base with an extensive ruff of long feathers of a clear and brilliant white. The plumage of the body is reddish gray; the quill-feathers of the wings and tail are of a blackish brown; and the beak and claws are nearly black. He is a native of the greater part of Europe and of Asia, and inhabits during the summer the more elevated regions of the two continents, building his nest in the rocks and among inaccessible precipices. In the winter he is said to migrate to warmer and more temperate climes. His habits are precisely those of the rest of the group to which he belongs.

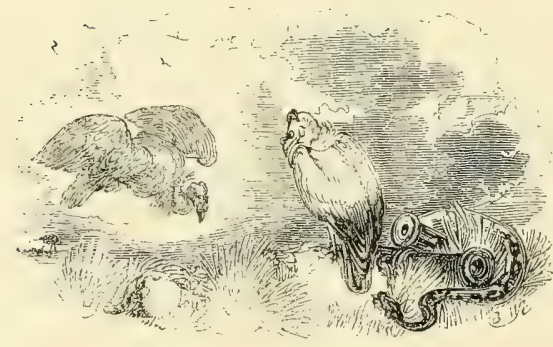




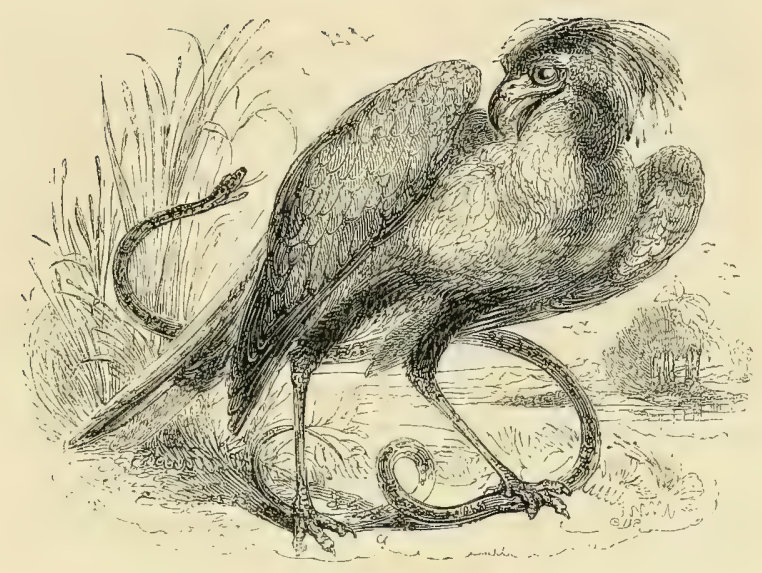

THE SECRETARY BIRD.

GypogeranUs SERPENTARIUS. ILLig.

THE singular conformation of this bird, so different in many respects from that of the Order to which both in its leading characters and in its habits it obviously belongs, rendered it for a long time one of the torments of ornithologists, who puzzled themselves in vain to assign it a definitive place in the system, and could not agree even with regard to the grand division of the class to which it ought to be referred. Thus M. Temminck was at one time inclined to refer it to the Gallinaceous Order; and M. Vieillot, after repeatedly changing his mind upon the subject, at last arranged it among the Waders, with which it has absolutely nothing in common 
except the length of its legs. It appears, however, to be now almost universally admitted that its closest affinity is with the Vultures, with which it agrees in the most essential particulars of its organization, and from which it differs chiefly in certain external characters alone, which unquestionably give to it an aspect exceedingly distinct, but are not of themselves of sufficient importance to authorize its removal to a distant part of the classification. It constitutes in fact one of those mixed and aberrant forms by means of which the arbitrary divisions of natural objects established by man are so frequently assimilated to each other in the most beautiful, and occasionally in the most unexpected, manner.

The principal generic characters of the Secretary consist in the form of his beak, which is shorter than the head, thick, and curved nearly from the very base, where it is covered with a cere; in the long and unequal feathers which take their origin from the back of his head, and are susceptible of elevation and depression; in the naked skin which surrounds his eye, and which is shaded by a series of hairs in the form of an eyebrow; in the great length and slenderness of his tarsi, which form his most striking characteristic in an Order remarkable for a structure exactly the reverse; and in the shortness of his toes, which are terminated by blunted talons of little comparative size or curvature. The only known species measures upwards of three feet in length. Its plumage, when in a perfect state, is for the most part of a bluish gray, with a shade of reddish brown on the wings, the large quill-feathers of which are black. The throat and breast are nearly white, and the rest of the under surface of the body offers a mixture of black, red, 
and white, the plumage of the legs being of a bright black, intermingled with scarcely perceptible brownish rays. The plumes of the crest which ornaments the back of the head, and from the supposed resemblance of which to the pens frequently stuck behind the ears of clerks and other writers the name of Secretary was given to the bird, are destitute of barbs at the base, but spread out as they advance, and are coloured with a mixture of black and gray. Each of the wings is armed with three rounded bony projections, with which, as well as with his feet, the bird attacks and destroys his prey.

In his habits he partly resembles both the Eagle and the Vulture, but differs from them most completely in the nature of his prey and in his mode of attacking it. Like the former he always prefers live flesh to carrion; but the food to which he is most particularly attached consists of snakes and other reptiles, for the destruction of which he is admirably fitted by his organization. The length of his legs not only enables him to pursue these creatures over the sandy deserts which he inhabits with a speed proportioned to their own, but also places his more vulnerable parts in some measure above the risk of their venomous bite; and the imperfect character of his talons, when compared with those of other rapacious birds, is in complete accordance with the fact that his feet are destined rather to inflict powerful blows, than to seize and carry off his prey. When he falls upon a serpent, he first attacks it with the bony prominences of his wings, with one of which he belabours it, while he guards his body by the expansion of the other. $\mathrm{He}$ then seizes it by the tail and mounts with it to a considerable height in the air, from which he drops it to the 
earth, and repeats this process until the reptile is either killed or wearied out; when he breaks open its skull by means of his beak, and tears it in pieces with the assistance of his claws, or, if not too large, swallows it entire.

Like the Eagles these birds live in pairs, and not in flocks; they build their aiery, if so it may be termed, on the loftiest trees, or, where these are wanting, in the most bushy and tufted thickets. They run with extreme swiftness, trusting, when pursued, rather to their legs than to their wings; and as they are generally met with in the open country, it is with difficulty that they can be approached sufficiently near for the sportsman to obtain a shot at them. They are natives of the south of Africa, and appear to be tolerably numerous in the neighbourhood of the Cape; where, it is said, they have been tamed to such a degree as to render them useful inmates of the poultry-yard, in which they not only destroy the snakes and rats which are too apt to intrude upon those precincts, but even contribute to the maintenance of peace among its more authentic inhabitants by interposing in their quarrels and separating the furious combatants who disturb it by their brawls.

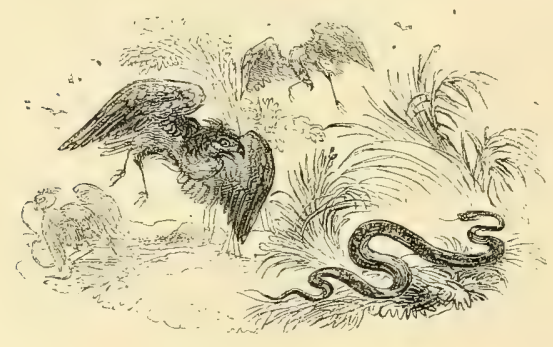




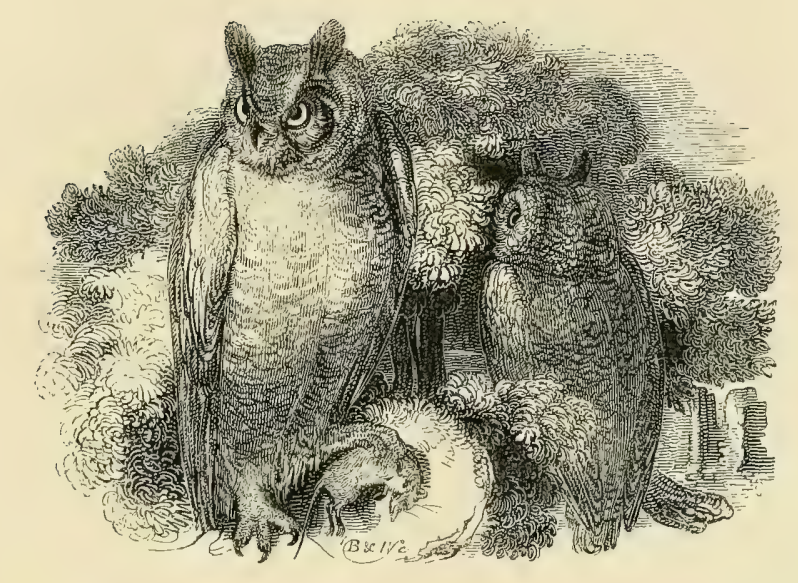

THE VIRGINIAN HORNED-OWL.

StrIX VIRGINIANA. Linn.

ALL the preceding birds belong to that division of the Rapacious Order which pursue their prey in the open face of day, and are consequently termed Diurnal; but those which we have now to notice are on the contrary Nocturnal in their habits, and only venture abroad in the shades of the evening, or under cover of the darkness of the night. They are readily distinguished from the former by their short and compressed bill, curved from its very base; by the anterior position of their eyes, which are of great size and surrounded by a circular dise of stiff hairs and feathers, covering the base of the bill anteriorly and extending posteriorly over the ears, which, as well as the disc, vary considerably in size in 
the different races; by the great extent of dilatation of which their pupils are capable, a provision admirably calculated for enabling them to see by night; by the breadth and apparent bulk of their heads and bodies, both of which are thickly clothed with long and soft feathers; by the plumage of their legs, which in all the European species is continued down to the very toes, and sometimes even along them; by the direction of their toes, which are all naturally turned forwards, the external one being, however, capable of taking an opposite direction; and by the high degree of retractility and sharpness of their claws.

All these birds were comprehended by Linnæus under the generic name of Strix, but later naturalists have subdivided them into several genera, dependent on the size of the ears and of the ocular dises, on the presence or absence of two remarkable tufts of feathers on the head having somewhat the appearance of horns, and on the covering of the legs and feet. The Virginian. Horned Owl is spread over nearly the whole continent of America from north to south. Its plumage is brown above, marked with numerous transverse black stripes, and the feathers of the under surface are of a dirty white, transversely striped with blackish-brown.

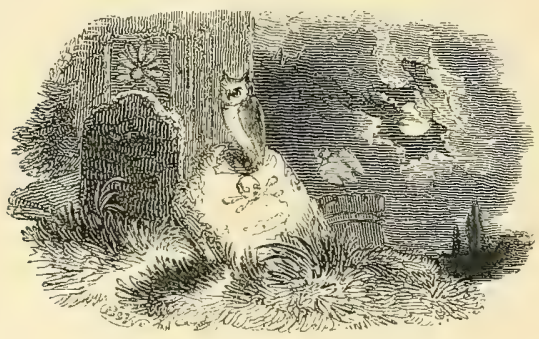




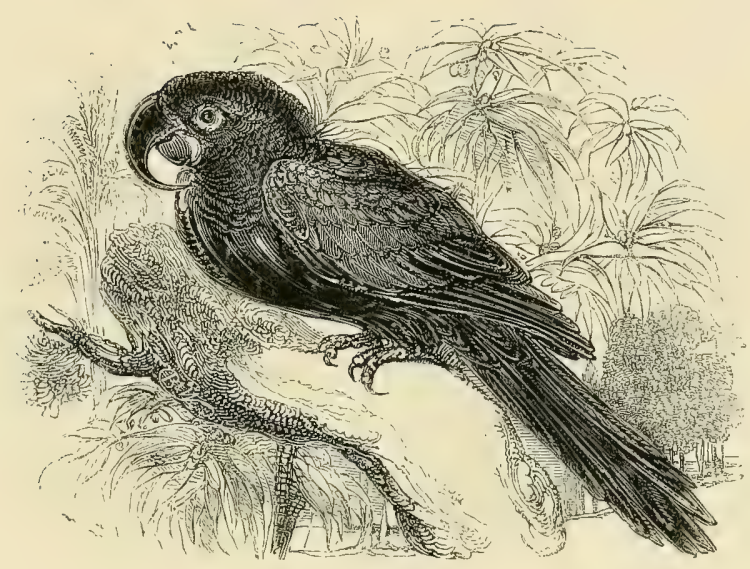

THE DEEP BLUE MACAW.

ANodorhynCUs MaXTMILIANI. SpIX.

The second Order of Birds, which comprehends both the Picæ and Passeres of Linnæus, is essentially distinguished from the rest of the class by the structure of the feet, which are formed for perching. Those of the Scansorial tribe in particular, to which all the species to be here noticed belong, have two of the toes directed forwards, and the remaining two directed backwards, in such a manner as to enable them to grasp the branch of a tree or other similar objects with peculiar firmness, and consequently to climb with more than usual agility. This section comprehends some of the most gorgeously coloured and splendid among birds, as well as those 
which evince the highest degree of intelligence, in the imitation especially of the human voice, for which they have been celebrated from the earliest times.

The beautiful bird, the portrait of which is prefixed to the present article, is one of the rarest of its tribe, and has until very lately been confounded by ornithologists with the Hyacinthine Macaw, a fine but much less splendid species. It is figured by M. Spix in his Brazilian Birds under the name which we have adopted; but is there given without either characters or description. Its claim to generic distinction would seem to depend on the excessive length and powerful curvature of its claws and upper mandible, and on the slight developement of the toothlike process of the latter. Its colour is throughout of a deep and brilliant blue; the beak, legs, and claws, are black; and the cere and a naked circle round each of the eyes are of a bright yellow. Our specimen measures two feet four inches from the top of the head to the extremity of the tail, and the expansion of his wings is four feet. The length of the upper mandible is five inches, and that of the lower, two.

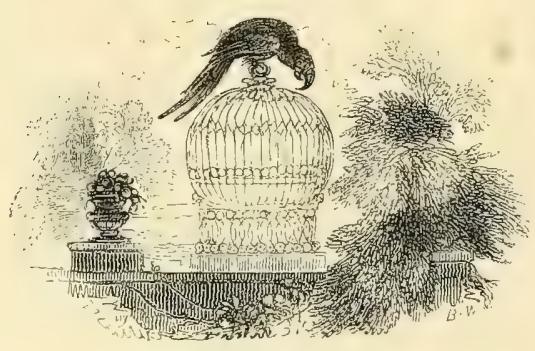




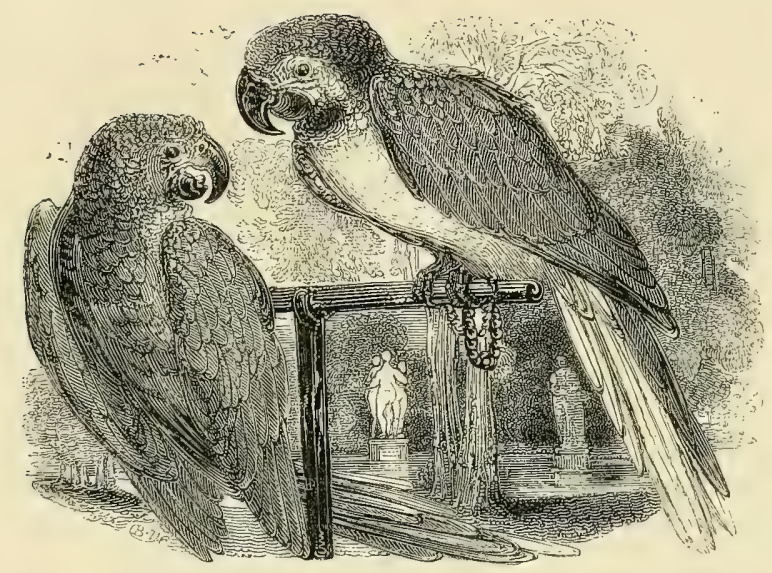

THE BLUE AND YELLOW MACAW.

Macrocercus AtraraUna. Vieili.

THE genus Macrocercus is characterized by the robustness of its beak, which is extremely broad and powerful; by the nakedness of its face, which is sometimes entirely bare, and sometimes partially covered with lines of short and scattered feathers; and by the size and form of its tail, which is longer than the body, regularly graduated, and terminating in an acute apex. The whole of the species are American, and are remarkable for the brilliancy of their colours, which are perhaps more varied and more gaudy than those of any of the other modern divisions of the Linnean genus Psittacus. They are consequently more sought after as objects of luxury and 
elegance, and bear a higher comparative value than the rest of the Parrots. In common with the entire tribe, they inhabit the tropical regions of the earth, and live chiefly upon fruits and seeds. Among the latter they uniformly give the preference to such as are provided with a hard and shelly covering. These they crack with great dexterity, carefully rejecting the outer coat, and swallowing only the internal nut.

The Blue and Yellow Macaw is one of the finest of the group. The whole of its upper surface is covered with plumage of the most beautiful azure; the feathers of the under parts on the contrary are of a brilliant yellow. The naked part of the cheeks, which are white slightly tinged with flesh colour, is ornamented with three lines of minute blackish feathers; and the throat is surrounded by a broad collar of greenish black. The forehead is yellowish green.

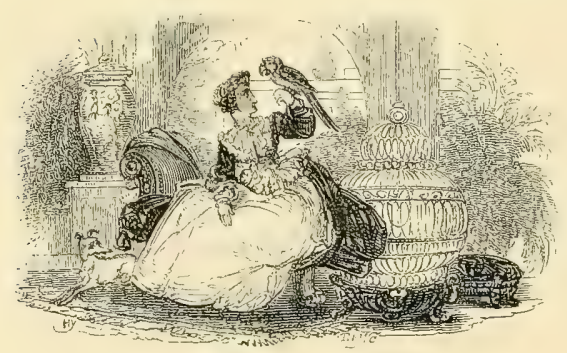




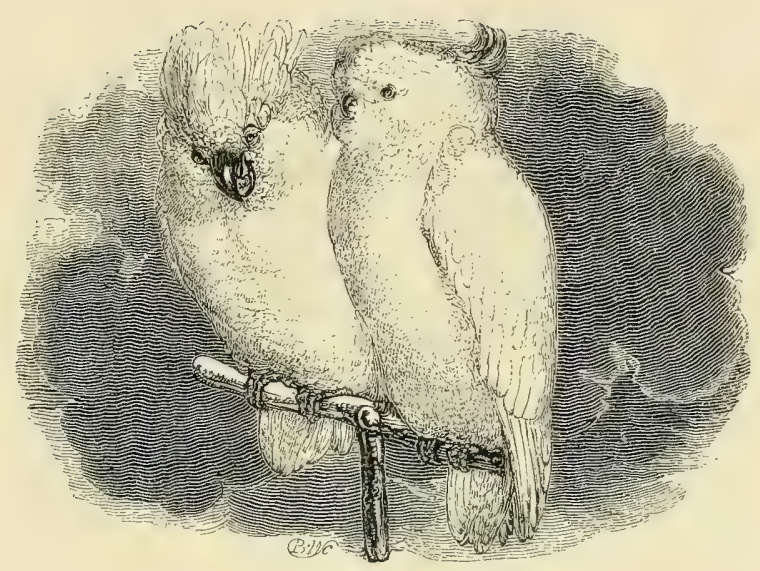

THE YELLOW-CRESTED COCKATOO.

Plyctolophus sulphureus. Vieilt.

The Cockatoos have a strong, broad, and well curved beak; their eyes are surrounded by a naked space; their tail is short, square, and equal at the end; and their head is furnished with a remarkable crest of long and slender feathers, which may be raised or depressed at will, and are frequently of a different colour from the rest of the plumage. This latter character forms the most distinguishing mark of the group, which is partly indigenous to. India and the Indian Islands, and partly to Australia. They are fond of damp and marshy situations, and usually inhabit the neighbourhood of rivers or of smaller streams, in which they'indulge themselves 
with frequent bathing, a practice in which, even in captivity, they seem, in common with many others of the tribe, to take a particular pleasure. Like the rest of the Parrots they live entirely on vegetable substances, and chiefly upon seeds; some of them, however, are said to feed upon roots. Their usual nourishment, in a domesticated state, is the same with that of the other Parrots, consisting generally of nothing more than hemp-seed, from which they detach the outer covering with much adroitness. They have also a great relish for sweetmeats and pastry.

The present species is pure white throughout, with the exception of its crest, the longer feathers of which are bright yellow; and of the under surface of the wings and tail, which are straw-coloured, as are also occasionally the cheeks. The beak is nearly black. It is a native of the Moluccas, and is not unfrequently brought to Europe. It is remarkably intelligent, and becomes attached to those who show it kindness.

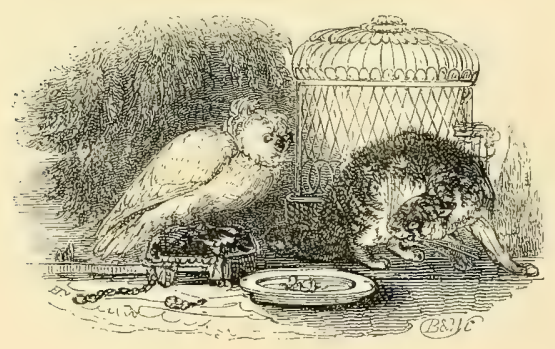




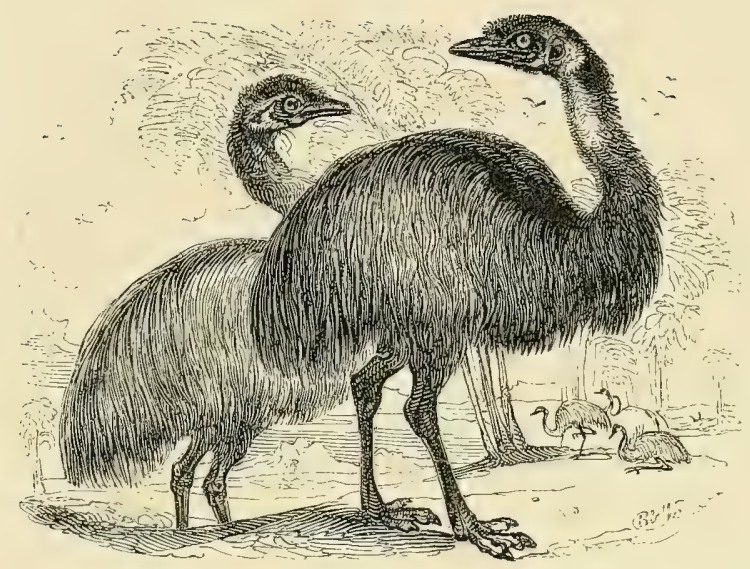

THE EMEU.

Dromiceius Nove Hollandie. Vieilt.

The New Holland Emeu, as well as the Ostrich and the Cassowary, to both of which it is nearly related, is now generally regarded as belonging to the Rasorial Order, the Gallinæ of Linnæus, the feet of which are formed for running and for scratching up the earth in search of the seeds which constitute their usual subsistence. Some of the birds, however, which are referred to it, and particularly those now under consideration, feed upon fruits and roots. The whole of the Order are distinguished by a certain degree of convexity on the upper surface of the bill, the base of which is enveloped by a membrane, in which are situated the nostrils covered by a cartilagi- 
nous scale; by the muscular plumpness of their bodies, and especially of their legs; by the shortness of their wings, and the diminution of strength in their pectoral muscles; and by the thickness and strength of their anterior toes, generally three in number, united at the base alone by a connecting membrane, and roughened beneath. These characters conjoined sufficiently indicate that their proper place of abode is the surface of the earth, on which they are enabled to run with a greater or less degree of speed; and that the air, in which they are incapable of elevating themselves to any considerable height, or of propelling their flight with more than moderate swiftness, and into which some of them cannot even raise themselves at all, is an uncongenial element to which they can seldom resort. They furnish the principal and most useful breeds of our domestic poultry, and stock our farm-yards with their most valuable inhabitants.

The distinctive generic characters of the New Holland Emeu, which forms part of the Ostrich family, and is, with the sole exception of the Ostrich, the largest bird known to exist, consist in the flattening of its bill from above downwards, instead of from side to side; in the absence of the bony process which crests the head of the Cassowary, of the wattles which depend from his neck, and of the long spurlike shafts which arm his wings; and in the equal, or nearly equal, length of all his claws. The Emeus, however, agree with the Cassowaries in the number of their toes, three on each foot, all of them directed forwards and extremely thick and short, the posterior toe, which is common to most of the Order, being in them entirely wanting; in the excessive short- 
ness of their wings, which do not even, as is the case with the Ostriches, assist them in running, much less in flight, of which, in common with the latter, they are absolutely incapable; and in the structure of their feathers, which are for the most part double, each tube being divided near its origin into two shafts, the barbs of which are soft, downy, and distinct from each other, and assume at a distance rather the appearance of a silky covering of hair than that of the common plumage of birds:

The New Holland bird has the head and upper part of the neck thinly covered with slender black feathers; the space around the ears alone being left bare, and exhibiting, as well as the neck and throat, which are but partially concealed by the scattered plumage with which they are provided, the blue tinge of the skin. The general colour of the plumage is grayish brown above, with a more plentiful intermixture of the gray and a consequent lighter tinge beneath. The young are striped longitudinally with brown and gray. Their bill is black, and their legs are remarkably thick and of a dull brown. The great length of the latter and of the neck, and the erect attitude and quiet demeanour of these birds, which sometimes attain as much as seven feet in height, give them altogether a noble and imposing appearance. They were formerly common in the neighbourhood of Botany Bay, subsisting, like the rest of their tribe, upon vegetable substances, chiefly fruits. They are extremely wild, and run with great swiftness when pursued, outstripping it is said the fleetness of the greyhound. Like the Kanguroos, they are sometimes hunted by the colonists as articles of food; and their flesh is stated to have 
much of the flavour of beef. The quantity of provision supplied by one of these birds is by no means inconsiderable.

The animals of the part of New Holland from which these birds are derived appear in general to suffer little from their transportation to the climate of England. The Emeus, like the Kanguroos, have become to a certain extent naturalized in the Royal Park at Windsor, where they breed without difficulty and with no extraordinary precautions. Here they have assigned to them a sufficient space of ground to take ample exercise; and this circumstance contributes not a little to the thriving condition in which they are met with. They are perfectly harmless unless when irritated or pursued, in which case they sometimes strike very severe blows with their beaks, which are extremely hard. The pair in the Tower were obtained from this establishment, where they were bred.

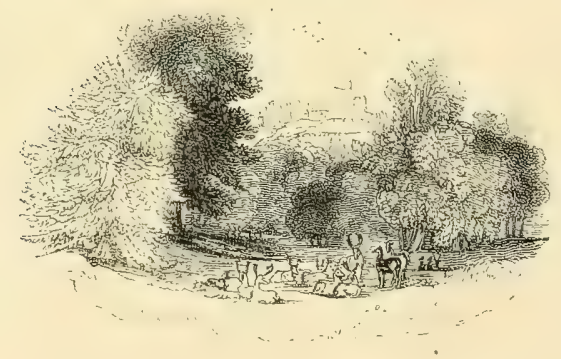




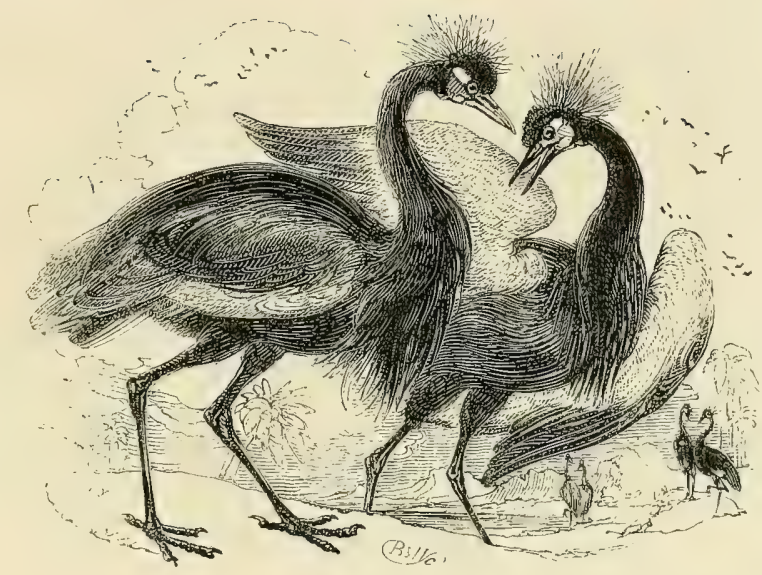

THE CROWNED CRANE.

ANTHRopotdes PAVONINUS. VIEILL.

THE fourth Order of Birds, the Waders, are strikingly characterized by the great length of their legs, the lower part of which is entirely bare of feathers; a peculiarity which is of essential service by enabling them to stand for a long time in the water without injury to their plumage, watching for the fish and reptiles, of which the larger species, and the worms and insects, of which the smaller among them, make their usual prey.

The beautiful birds represented above, which formed part of the Linnean genus Ardea, since subdivided into numerous distinct groups, offer the following generic characters. Their bill is conical, pointed, scarcely longer 
than the head, and grooved along its upper surface; their head is ornamented with a crest of long and slender filamentous feathers, capable of being raised and depressed at pleasure; their wings are large and powerful; their legs are covered with large scales; the outer ' and middle toes are united at the base; and their claws are short and without denticulations.

The Crowned Crane is remarkable for its light and elegant proportions, and for its graceful and varied attitudes. Its forehead is covered by a thick tuft of short velvety feathers of a soft and brilliant black; its naked cheeks and temples are of a delicate rose colour; and the yellow filaments of its crest terminate in blackish pencils. The long and slender feathers which descend upon its neck, and the broader ones which clothe the upper and under surface of its body are black with a slight tinge of lead-colour; the primary wing-feathers are also black, the secondary reddish-brown, and the wing-coverts white. The bill and legs are black. It is a native of Western Africa; is extremely tame, and may be readily domesticated. It frequently attains the height of four feet.

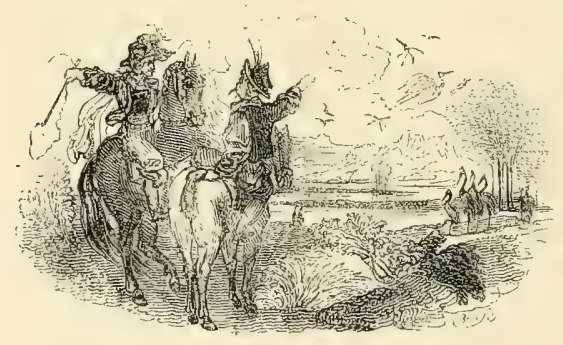




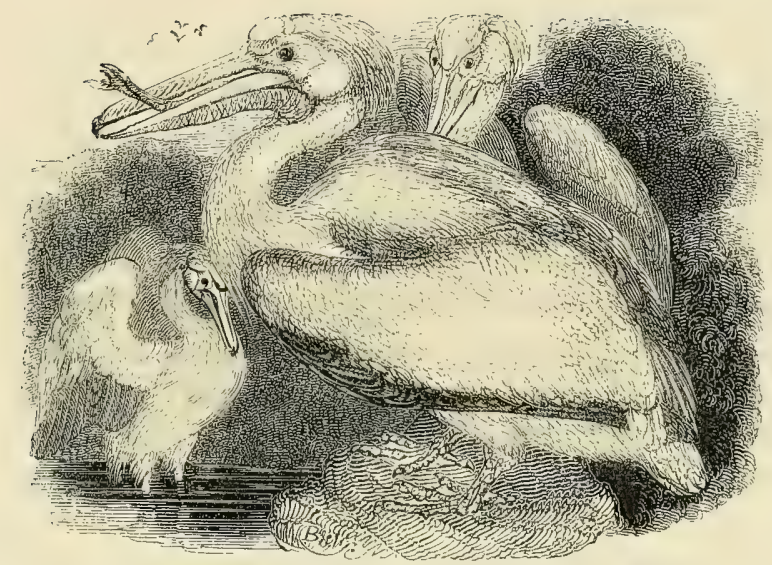

THE PELICAN.

Pelecanus Onocrotalus. Linn.

The Pelican affords an excellent illustration of the fifth and last Order of Birds, the Swimmers; the essential character of which consists in the membranous union of the toes, which renders them what is usually termed web-footed, and enables them to propel themselves upon the surface of the water with greater or less rapidity in proportion to the greater or less comparative extent of the membrane in which their toes are enveloped. They are all consequently inhabitants of marshy situations, of the banks of rivers and lakes, or of the seacoast; and most of them seek their subsistence in their most congenial element, the water, notwithstanding that by far 
the greater number of them are also endowed with very considerable powers of flight.

Linnæus united under the common title of Pelicans, the Cormorants, the Boobies, and several other birds, which differ from the typical species of the genus by many important characters, the chief point of agreement between them consisting in the form and extent of the membrane which unites the toes. The Linnean group has subsequently been raised to the rank of a family, and its component parts form several distinct genera, that which comprehends the true Pelicans, the genus Onocrotalus of Brisson, being characterized as follows. Their bill is of very great length, straight, broad, flattened above, and terminated by a slight hook; the lower mandible consists of two lateral branches, united at the point, and having interposed between them a membranous pouch capable of very great dilatation; their four toes are all enveloped to the very apex in the common membrane; their legs are short, strong, and maintain the body in a state of equilibrium, their lower part being entirely destitute of feathers.

With the exception of the quill-feathers of the wings; which are black, the plumage of the Pelican in the Tower is throughout of an extremely light and delicate flesh-colour, varied only by occasional darker tinges. The head and upper part of the neck are clothed with a short down, except on the temples, which are naked and flesh-coloured; the upper mandible is of a dull yellow in the middle; with a reddish tinge towards the edges, and a blood-red spot on its curved extremity; and the pouch is of a bright straw-colour.

The Pelican is one of the largest water-birds, consider- 
ably exceeding the size of the swan, and frequently measuring from five to six feet between the extremity of the bill and that of the tail, and from ten to twelve between the tips of the expanded wings. Its bill is nearly a foot and a half in length, and from an inch and a half to two inches broad; and its pouch is capable of containing, when stretched to its utmost extent, two or three gallons of water. The quantity of fish which it sometimes accumulates in the same serviceable repository is spoken of as enormous. Notwithstanding their great bulk and apparent clumsiness, the large extent of their wings, and the extreme lightness of their bones, which are so thin as to be almost transparent, enable these birds to rise to a lofty pitch in the air, to hover at a moderate elevation, or to skim rapidly along the surface of the water with as much facility as they dive into its depths in pursuit of their prey. They sometimes assemble in large numbers, and in this case are said by Buffon to act in concert, and to show no little skill in manœuvring with the view of securing a plentiful quarry, forming themselves into a circular line, and gradually narrowing the extent of the space enclosed, until they have driven the fishes into so small a compass as to render them a certain prey; when at a given signal they all at once plunge into the water and seize upon their terrified victims, filling their pouches with the spoil, and flying to the land, there to devour it at their leisure. This fishery is carried on both at sea and in fresh water.

They are found in nearly every part of the globe, but are of rare occurrence in the north of Europe. The beautiful pair figured at the head of this article are said to be from Hungary. The female is now sitting upon 
three eggs, and has built herself a very perfect nest for the purpose. Should these be brought to maturity, as there is every reason to expect, they will probably be the first that were ever hatched in England. She never quits her charge; but is fed by the male, who crams his pouch with double his usual allowance, and then proceeds to shovel her fair share into his partner's throat. It is in this manner also that the young are fed, the old bird pressing his full pouch against his chest, and contriving thus to disgorge a portion of its contents; an action which has no doubt given rise to the fabulous notion of the Pelican's feeding its young with its own blood. In fact, the appearance of the bird when in this attitude, with the bloody spot on the end of its bill closely pressed against the delicate plumage of its breast, may readily account for the prevalence of such an idea in the minds of superficial observers. The first traces of this fable are to be found in the writings of some of the early fathers of the church, and it was eagerly adopted by the heralds of later days, whose unbounded credulity was ever on the watch for the marvellous, in natural history more especially.

Our birds are commonly allowed three dozen of small live plaice each per day.

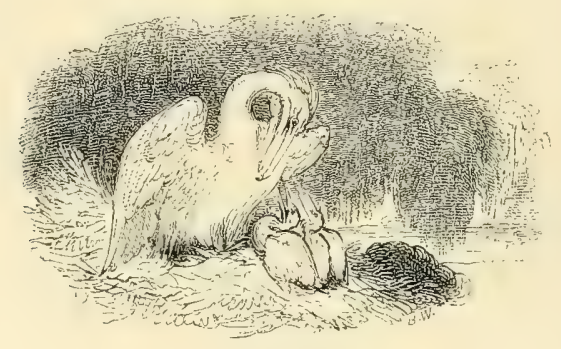




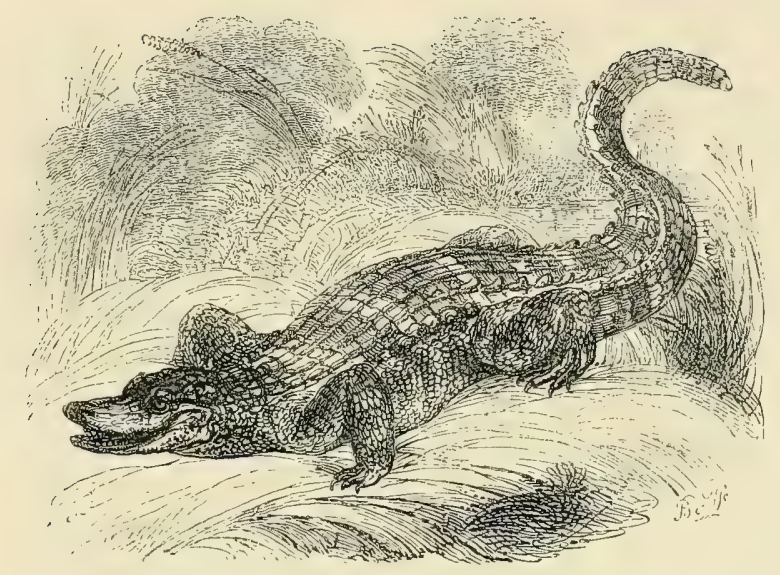

THE ALLIGATOR.

Crocodilus lucius. Cuv.

Tue enormous Reptile from which this genus derives its name belongs to the same subdivision of that class as the agile Lizard and the many-hued Chamæleon, with which it was comprehended by Linnæus under the single generic title of Lacerta. This group has subsequently been elevated to the rank of an order, consisting of numerous genera, among which the Crocodiles are distinguished by the following characters. Their toes are five in number on the anterior feet, and four on the posterior; their sharp and conical teeth are arranged in a single series in each jaw; their tongue is flat, fleshy, and closely attached almost to its very edge; and their bodies are clothed with large, thick, square scales, the 
upper of which are surmounted by a strong keel, those of the tail forming superiorly a dentated crest, double at its origin.

The Alligators constitute a natural subdivision of the genus, in which the snout is broad, blunt, and less produced than in the true Crocodiles; the fourth tooth on each side of the lower jaw enters a hole in the upper when the mouth is closed; and the toes are only halfwebbed. They appear to be exclusively natives of America. The present species is distinguished by its broad and flat snout; with nearly parallel sides, united in front by a curved line; by the peculiar arrangement of its nuchal scales; and by the elevated internal margins of its orbits. Its colour is dark brown above, and somewhat lighter beneath. It is one of the most dreadful scourges of the countries which it inhabits, preying upon all kinds of animals that come within its reach, and sometimes even upon man himself. Our specimen was apparently very young, not measuring more than three feet in length; but during two years that it was kept in the Menagerie it was not observed to have at all increased in size. It was fed once a week upon raw beef.

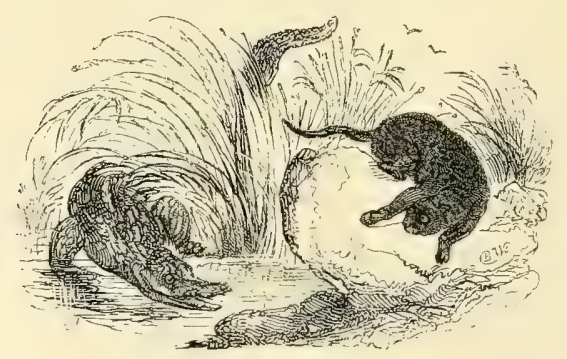




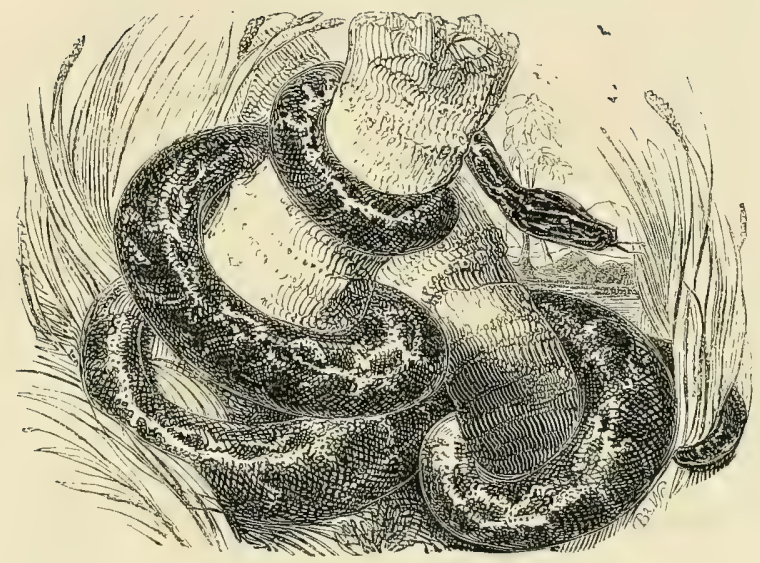

TIIE INDIAN BOA.

Python Tigris. Daud.

The Serpents form a division of the Reptile Class too well known by their elongated scaly bodies, and their total deprivation of external members, to require any minute description of their organization. They are also held by the generality of mankind in so much abhorrence, and regarded for the most part with such strong feelings of unmitigated disgust, that we feel but little inclined to dwell upon their history, how much soever they may on many accounts be considered as deserving of a more extended notice.

They are frequently divided into two great sections; the one, which is by far the most numerous, compre- 
hending all those in which the poison-fangs are wanting, and which are consequently dangerous only in proportion to the extent of their muscular force; and the other consisting of those in which the fangs are present, and the bite of which is accompanied with the pouring out of a venomous secretion. At the head of the first of these divisions rank the Boas, which in the Linnean arrangement comprehended all those snakes, whether venomous or not, whose under surface was covered with narrow transverse plates, and whose tail was destitute of rattle. Later zoologists have, however, confined that appellation to those among the Linnean Boas, which are without poisonous fangs and have claws near the vent, and have regarded as a distinct genus the snakes which in addition to these latter characters have the scales of the under surface of the tail so arranged as to form two distinct rows. To the latter, which inhabit the Old Continent exclusively (while the former are all of them natives of America), they have assigned the name of Python.

The present species, which is commonly exhibited under the popular but erroneous title of the Boa Constrictor, appears to be the Pedda Poda of Dr. Russell's Indian Serpents. It is said by that writer to attain a length of eight or ten feet; but living specimens have been brought to this country of twice that size, and some of those now in the Tower are fifteen or sixteen feet long. The number of transverse plates on the under surface of the body is stated to be two hundred and fifty-two, and that of the pairs of scales beneath the tail sixty-two. The back is elegantly marked with a series of large irregular brown blotches bordered with black; and numerous smaller spots are scattered along the 
sides. The ground colour is yellowish brown, lighter beneath.

The extent of muscular power which these serpents possess in common with the Boas is truly wonderful. To the smaller among them the lesser quadrupeds and even birds fall an easy prey; but the larger, when excited by the stimulus of hunger, are capable of crushing within their spiral folds the largest and most powerful of beasts. The sturdy buffalo and the agile stag become alike the victims of their fatal embrace; and the bulk of these animals presents but little obstacle to their being swallowed entire by the tremendous reptile, which crushes them as it were into a mass, lubricates them with the fetid mucus secreted in its stomach, and then slowly distending its jaws and œsophagus to an extent proportioned to the magnitude of the object to be devoured, and frequently exceeding by many times its own previous size, swallows it by one gradual and long-continued effort.

Of the mode in which this operation is effected, a detailed description is contained in Macleod's Voyage of His Majesty's Ship Alceste; and an excellent account has been subsequently given by $\mathrm{Mr}$. Broderip in the second volume of the Zoological Journal from actual observation of the specimens now in the Tower. The vivid description of the latter almost brings before the reader's eye the lightning dash of the serpent; the single scream of its instantly enfolded victim, whose heaving flanks proclaimed that it still breathed; and its last desperate effort, succeeded by the application of another and a deadly coil. With equal force and fidelity it sketches the continuation of the scene, when the serpent, after slowly disengaging his folds, placed his head oppo- 
site to that of his victim, coiled himself once more around it to compress it into the narrowest possible compass, and then gradually propelled it into his separated jaws and dilated throat; and finally presents a disgusting picture of the snake when his meal was at an end, with his loose and apparently dislocated jaws dropping with the superfluous mucus which had been poured forth.

The individual figured at the head of the present article is a female; a fact which was proved by the remarkable circumstance of her producing in May last, after having been more than two years in the Menagerie, a cluster of eggs, fourteen or fifteen in number, none of which, however, were hatched, although the mother evinced the greatest anxiety for their preservation, coiling herself around them in the form of a cone, of which her head formed the summit, and guarding them from external injury with truly maternal solicitude. They were visible only when she was occasionally roused; in which case she raised her head, which formed as it were the cover of the receptacle in which they were enclosed, but replaced it again as quickly as possible, allowing to the spectator only a momentary glance at her cherished treasures.

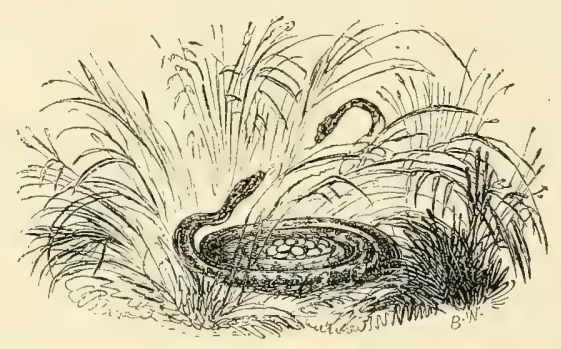




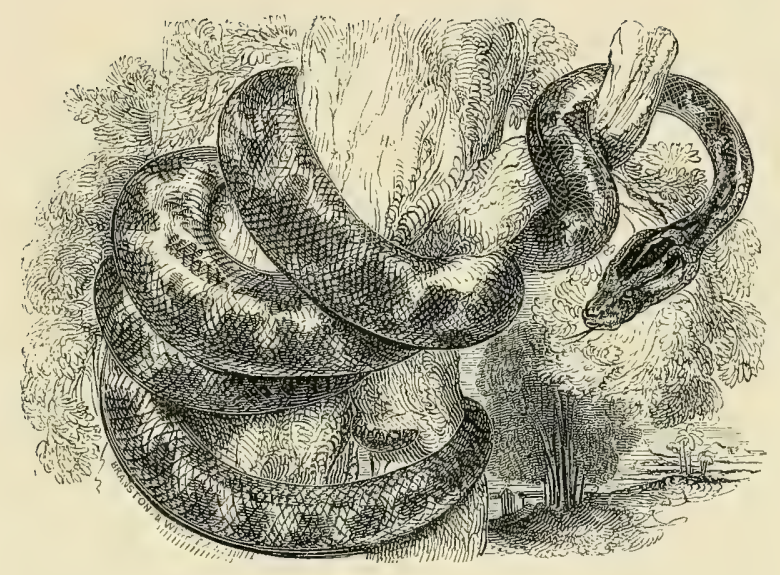

THE: ANACONDA.

PythgN Tigris, Var.

The Anaconda is a name which, like that of the Boa Constrictor, has been popularly applied to all the larger and more powerful snakes. It appears to be of Ceylonese origin, and may therefore belong of right, as well as of usage, to the present Indian species. The serpent which passes under this title at the Tower, and which is figured above, seems to differ in no essential respects from the Boa of the preceding article, the only appreciable distinctions between them consisting in the lighter colour, the greater comparative size of the head, and the acuteness of the tail of that which at present engages our attention.

Happily the appetite of these gigantic snakes bears 
no proportion to their means of gratifying it, as a full meal is uniformly succeeded by a state of torpor, which frequently lasts for a month or six.weeks, or, during the cold season, even for a longer period. 'Those in the Tower, which are kept in a state of artificial warmth, usually feed about every five or six weeks, and a fowl or a rabbit generally suffices for a meal. 'These are held by the keeper within view of the serpent to ascertain whether he is inclined to take his prey or not. About three years ago Mr. Cops, while thus engaged in offering a fowl to one of the Boas, had nearly met with a serious accident; the snake, which was almost blind from the approaching change of its skin, missing the fowl, and seizing upon the keeper's thumb instead, around which and its own head it instantaneously threw two coils, and then, as if surprised at the unexpected resistance, cast an additional fold round his neck, and fixed itself by its tail to one of the posts of its cage in such a manner as nearly to throttle him. His own exertions, however, aided by those of the under keepers, at length disengaged him from his perilous situation; but so determined was the attack of the snake that it could not be compelled to relinquish its hold until two of its teeth had been broken off and left in the thumb.

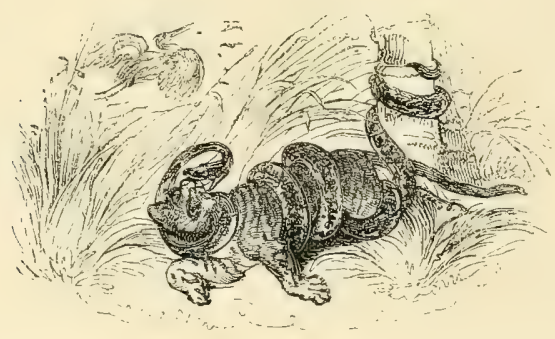




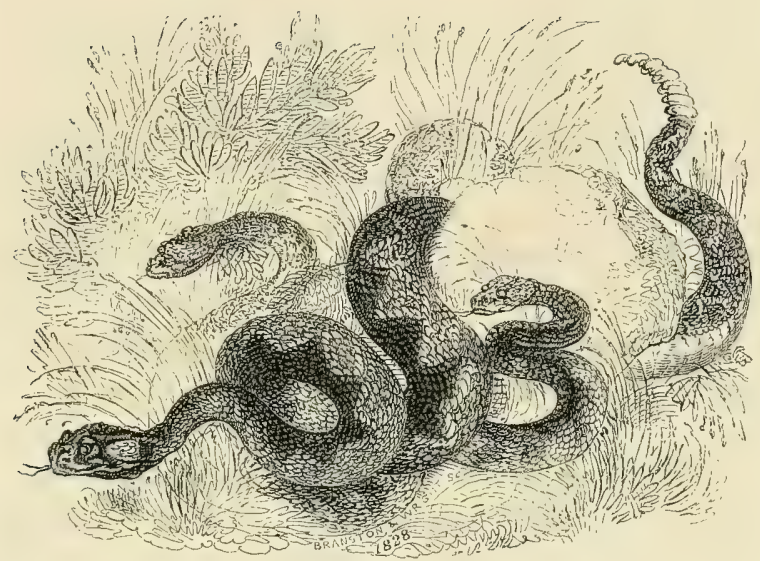

THE RATTLESNAKE.

Crotalus horRIDUS. LINN.

IF the Boas furnish the most terrible examples of the tremendous powers of destruction possessed by a few of that division of the Serpent tribe, whose bite is unattended with the effusion of venom, the Rattlesnakes afford a no less remarkable instance of the dreadful malignity of the poison with which others of the tribe are so abundantly supplied. This poison is secreted by a gland of considerable size situated beneath the eye, the excretory duct of which terminates on each side at the base of a long and tubular fang in the upper jaw, which is concealed while the animal is at rest in a fold of the gum, but is capable of being instantaneously 
erected when he is irritated, and affords at the same time the means of inflicting the wound and of insinuating into it the deadly fluid with which it is charged. In the Rattlesnakes these two fangs are the only visible teeth implanted in the upper jaw; but behind each of them are several rudiments of others by which they are from time to time replaced. Their other distinguishing characters consist in the whole of the transverse plates which cover the under surface of the body and of the tail being simple, and in the singular apparatus by which the latter is terminated, and which is formed of a series, more or less numerous according to the age of the individual, of flattened rings loosely attached one within the other in such a manner as to produce a peculiar rattling sound when the tail is moved with any degree of quickness. The number of rings commonly varies from five to twelve; but in very old specimens it is said to have been found to exceed forty.

All the known species are natives of America, in the vast forests of which they may be said literally to swarm; but happily, like most of the other venomous snakes, they never exert their terrible qualities upon man except in self-defence, and the warning rattle is always heard to give notice of their approach. Their bite is almost uniformly fatal even to the largest animals, and the latter frequently evince such an instinctive dread of them, that, according to M. Bosc, it is almost impossible to compel a horse or a dog to advance towards them. Their food consists principally of the smaller quadrupeds, such as squirrels and rabbits, of other reptiles, and of birds, although they rarely climb trees in pursuit of their prey. It was long believed, and the notion is still popularly 
current, that they possessed the power of fascinating their victims, which were thought to be so completely under the influence of their glance as to precipitate themselves of their own accord into the open throat of their enemy; but the truth appears to be that they actually inspire so great a degree of terror that the animals selected for their attacks are commonly rendered incapable of offering such resistance as might otherwise be in their power, or even of attempting to escape from their pursuit.

Like most reptiles they retire during the winter into holes, in which they remain in a torpid state until the return of spring; and during this period they may be taken or destroyed without danger. Their flesh is eaten by the negroes, who also apply their fat, as well as their rattles, to various medicinal or superstitious uses.

The number at present in the Tower exceeds a hundred, varying from four to six feet in length, and differing very considerably from each other both in colour and markings.

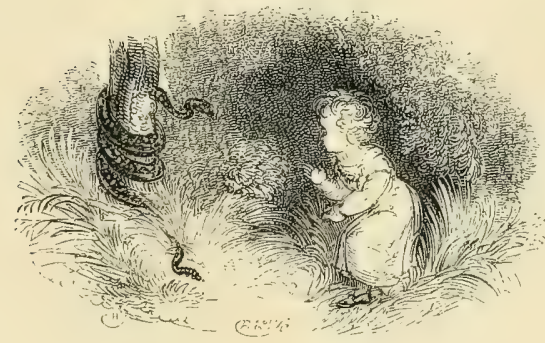


CHISWICK :

PIRINTED BY CHARLES WHITTINGHAY,

COI,LLGE HOUSE. 





SMITHSONIAN INSTITUTION LIBRARIES 